\title{
Der Einfluss von Neuregulin-1 auf Erkrankungen des peripheren Nervensystems
}

\author{
Dissertation \\ zur Erlangung des mathematisch-naturwissenschaftlichen Doktorgrades \\ "Doctor rerum naturalium" \\ der Georg-August-Universität Göttingen \\ im Promotionsprogramm Basisprogramm Biologie \\ der Georg-August University School of Science (GAUSS) \\ vorgelegt von \\ Robert Fledrich \\ aus Erlabrunn \\ Göttingen, 2014
}




\section{Betreuungsausschuss}

Prof. K.-A. Nave, PhD

Prof. Dr. N. Brose

Prof. Dr. M. Göpfert
Abteilung für Neurogenetik, Max Planck Institut für experimentelle Medizin Abteilung für Molekulare Neurobiologie, Max Planck Institut für experimentelle Medizin Abteilung für Zelluläre Neurobiologie Johann von Blumenbach Institut für Zoologie

\section{Mitglieder der Prüfungskommission}

Referent:

Prof. K.-A. Nave, PhD

Abteilung für Neurogenetik, Max Planck Institut für experimentelle Medizin

Korreferent:

Prof. Dr. M. Göpfert

Abteilung für Zelluläre Neurobiologie Johann von Blumenbach Institut für Zoologie

Weitere Mitglieder der Prüfungskommission:

Prof. Dr. M. Rossner

Prof. Dr. M. Simons

Prof. Dr. M. Sereda
Abteilung Molekulare Neurobiologie und Verhaltensbiologie psychiatrischer Erkrankungen Universität München

Abteilung Neurologie Universitätsmedizin Göttingen

Abteilung klinische Neurophysiologie Universitätsmedizin Göttingen 
Meiner Familie 


\section{INHALTSVERZEICHNIS}

1. Einleitung

1.1 Das zentrale und das periphere Nervensystem ....................................................... 14

1.2 Myelinisierung und axonale Unterstützung durch Gliazellen......................................... 15

1.2.1 Neuregulin-1 Signalwirkung im peripheren Nervensystem.................................. 18

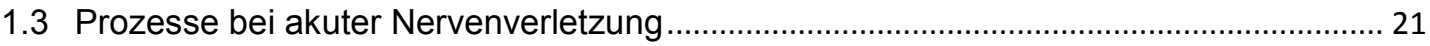

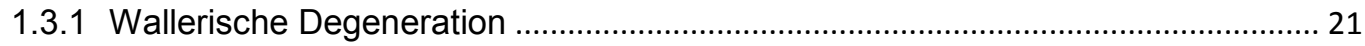

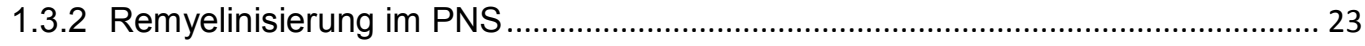

1.4 Chronische Nervenschädigung bei erblichen Neuropathien ...................................... 23

1.4.1 Klassifikation hereditärer Neuropathien - Charcot Marie Tooth Erkrankung ...... 24

1.4.2 Klinische, Elektrophysiologische und histologische Charakteristika .................... 26

1.4.3 Das periphere Myelinprotein 22kDa (PMP22) ................................................. 29

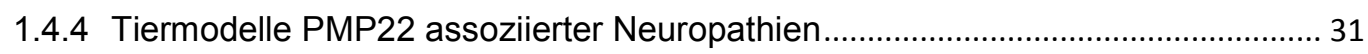

1.4.5 Erkrankungsmechanismen und therapeutische Optionen .................................. 32

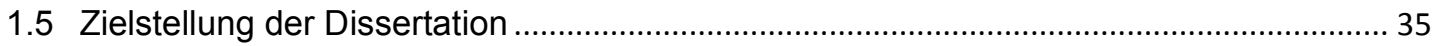

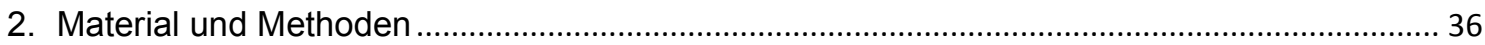

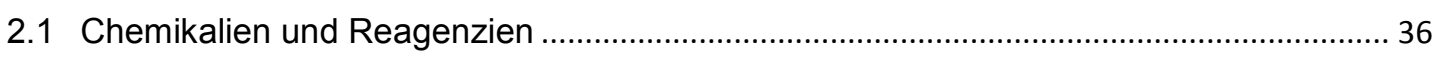

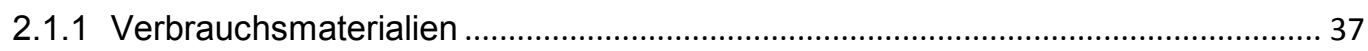

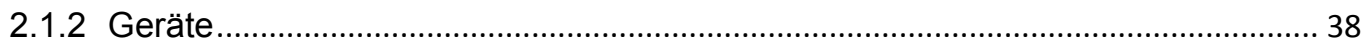

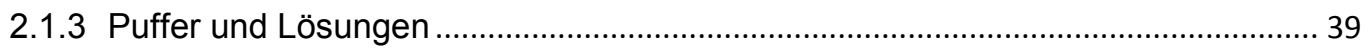

2.1.4 Enzyme und Reaktionskomplettsysteme ........................................................ 42

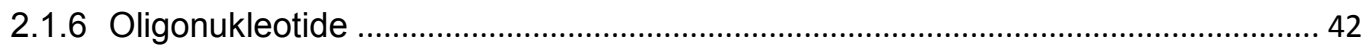

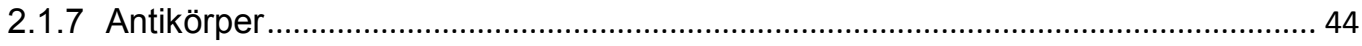

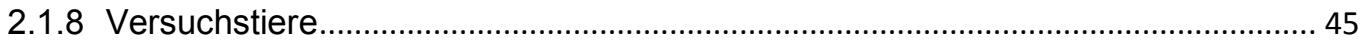

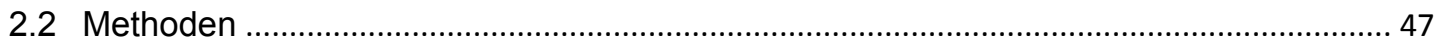

2.2.1 Handhabung und Analyse von Versuchstieren .................................................. 47

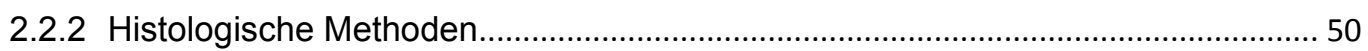

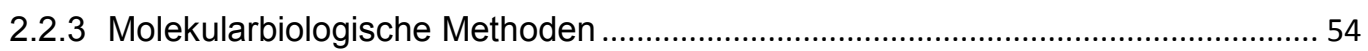

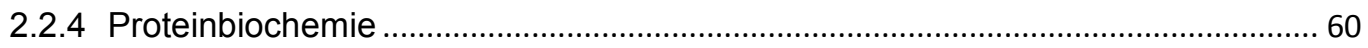

2.2.5 Isolation und Kultivierung von primären Rattenschwanzellen.............................. 61

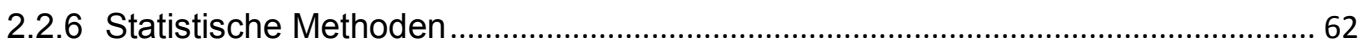




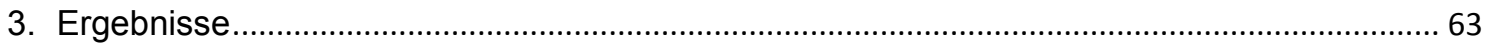

3.1. Frühe postnatale Fehldifferenzierung von Schwannzellen in CMT1A Ratten ............... 63

3.2. Neuregulin-1 Expression in Schwannzellen bei Nervenschädigung ............................. 66

3.2.1 Neuregulin-1 Expression in Schwannzellen von murinen CMT1A Modellen........ 66

3.2.2 Neuregulin-1 Expression in Schwannzellen nach akuter Nervenschädigung ...... 68

3.3. Die funktionelle Relevanz induzierter NRG1 Expression in Schwannzellen bei

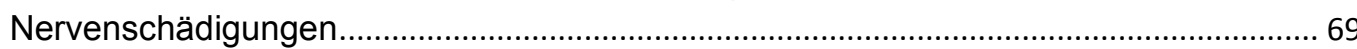

3.4. Neuronale Expression von NRG1 bei akuter und chronischer Nervenschädigung ........ 72

3.5. Der Einfluss von neuronal überexprimiertem NRG1 auf die Pathogenese von

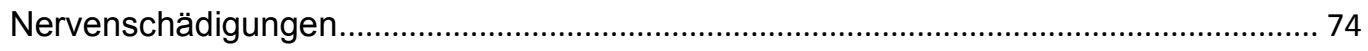

3.5.1. Neuronale Überexpression von NRG1 im Nervenläsionsmodell .......................... 74

3.5.2. Neuronale Überexpression von NRG1 in CMT1A Mäusen .................................. 76

3.6. Therapie von CMT Ratten mit rekombinantem Neuregulin-1 ....................................... 80

3.6.1. Frühe Kurzzeit-Therapie von CMT Ratten mit Neuregulin-1 ................................ 80

3.6.2. Späte Langzeit Therapie von CMT Ratten mit Neuregulin-1 ............................... 85

3.6.3. Therapeutischer Langzeiteffekt einer frühen Kurzzeitbehandlung von CMT Ratten

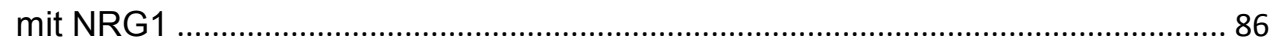

4. Diskussion

4.1. Die Plastizität von Schwannzellen emöglicht regenerative Prozesse nach Nervenschädigungen

4.2. Ausmaß und Zeitpunkt der Aktivität von Signaltransduktionskaskaden regulieren den Differenzierungsstatus von Schwannzellen 90

4.3. Eine frühe Kurzzeittherapie mit rekombinantem NRG1 verhindert die fehlerhafte Differenzierung von Schwannzellen

5. Zusammenfassung.

6. Abbildungsverzeichnis

7. Literaturverzeichnis 98

8. Publikationsverzeichnis 110

Lebenslauf. 112 


\section{ABKÜRZUNGSVERZEICHNIS}

\begin{tabular}{|c|c|}
\hline$\%$ & Prozent \\
\hline${ }^{\circ} \mathrm{C}$ & Grad Celcius \\
\hline$\mu$ & Mikro \\
\hline$\mu g$ & Mikrogramm \\
\hline$\mu l$ & Mikroliter \\
\hline$\mu \mathrm{m}$ & Mikrometer \\
\hline$\mu \mathrm{M}$ & Mikromolar \\
\hline 18SrRNA & $18 \mathrm{~S}$ ribosomal RNA \\
\hline A & Ampere \\
\hline Abb. & Abbildung \\
\hline ACTB & beta actin \\
\hline ADAM17/ TACE & a disintegrin and metalloprotease 17 \\
\hline ADIPOQ & adiponectin \\
\hline AG & Arbeitsgruppe \\
\hline AKT & v-Akt-murine thymoma viral oncogene homolog 1 \\
\hline AP-1 & activator protein 1 \\
\hline APS & Ammoniumperoxidsulfat \\
\hline AraC & Cytosin-beta-d Arabinofuranosid \\
\hline ARF6 & ADP-ribosylation factor 6 \\
\hline AU & arbitrary units \\
\hline BACE & ß-site amyloid precursor protein cleaving enzyme 1 \\
\hline bp & Basenpaare \\
\hline BPE & bovine pituitary extract \\
\hline BRN2 & POU domain, class 3 , transcription factor 2 \\
\hline BSA & Bovines Serumalbumin \\
\hline bzw. & Beziehungsweise \\
\hline
\end{tabular}




$\begin{array}{ll}\mathrm{C}_{6} \mathrm{H}_{5} \mathrm{Na}_{3} \mathrm{O}_{7} & \text { Natriumcitrat } \\ \text { ca. } & \text { circa } \\ \text { CAR3 } & \text { carbonic anhydrase 3 } \\ \text { cDNA } & \text { komplementäre Desoxyribonukleinsäure } \\ \mathrm{CDO} 1 & \text { cysteine dioxygenase 1 } \\ \mathrm{CHN} & \text { kongenital hypomyelinisierende Neuropathie } \\ \mathrm{CIP} & \text { Alkalische Phosphatase } \\ \mathrm{CLDN1} & \text { claudin 1 } \\ \mathrm{CMT} & \text { Charcot-Marie-Tooth Erkrankung } \\ \mathrm{CMTNS} & \text { Charcot-Marie-Tooth Neuropathy Score } \\ \mathrm{CO} & \text { Kohlendioxid } \\ \mathrm{CRD} & \text { Cystein-reiche-Domäne } \\ \mathrm{CREB} & \text { cAMP response element binding } \\ \mathrm{Ct} & \text { threshold cycle (Schwellenwert) } \\ \mathrm{CX} 32 & \text { connexin 32 } \\ \mathrm{CXCL12} & \text { chemokine ligand 12 } \\ \mathrm{CYCPHA} & \text { cyclophilin A }\end{array}$

Da

Dalton

DAB

3-3'-Diaminobenzidin

DAPI

4,6-Diamino-2-phenylindol

$\mathrm{ddH}_{2} \mathrm{O}$

doppelt destilliertes Wasser

$\mathrm{ddH}_{2} \mathrm{O}$

doppelt destilliertes Wasser

DDSA

2-Duodecenyl-succinicacidanhydrid

DDT

Dichlordiphenyltrichlorethan

DDT

D-dopachrome tautomerase

Dhh

desert hedgehog

DMEM

Dulbecco's Modified Eagle's Medium

DMP30

2,4,6-tris-dimethylaminomethyl-Phenol

DNA

Desoxyribonukleinsäure 


\begin{tabular}{|c|c|}
\hline dNTP & Desoxyribonukleotidtriphosphat \\
\hline DPT & dermatopontin \\
\hline Dr. & Doktor \\
\hline DSS & Dejerine-Sottas-Syndrom \\
\hline DTT & 1,4-Dithiotreitol \\
\hline EBF1 & early B-cell factor 1 \\
\hline ECL & enhanced chemiluminescence \\
\hline EDTA & Ethylendiamintetraacetat \\
\hline EGF & epidermal growth factor \\
\hline EGR2 & early growth response 2 \\
\hline EM & Elektronenmikroskop \\
\hline ErbB & erythroblastic leukemia viral oncogene homolog \\
\hline ERK & extracellular signal regulated kinase \\
\hline f.c. & final concentration (Endkonzentration) \\
\hline FCS & Fötales Kälberserum \\
\hline FRET & Fluoreszenz-Resonanz-Energie-Transfer \\
\hline FU & Fluoreszenzeinheiten \\
\hline Fwd & Forward, Forwärtsprimer \\
\hline$g$ & Gravitationskonstante \\
\hline g & Gramm \\
\hline GABA & Y-Aminobuttersäure \\
\hline GARS & glycyl-tRNA synthetase \\
\hline GAS3 & growth arrest gene 3 \\
\hline GDAP1 & ganglioside-induced differentiation-associated protein 1 \\
\hline GDNF & glia cell derived neurotrophic factor \\
\hline GJB1 & gap junction protein beta 1 \\
\hline GPR126 & G-coupled-protein 126 \\
\hline GSTP2 & glutathione S-transferase, pi 2 \\
\hline h & Stunde \\
\hline
\end{tabular}




\begin{tabular}{|c|c|}
\hline $\mathrm{H}_{2} \mathrm{CO}_{3}$ & Kohlensäure \\
\hline $\mathrm{H}_{2} \mathrm{CO}_{4}$ & Perkohlensäure \\
\hline $\mathrm{H}_{2} \mathrm{O}$ & Wasser \\
\hline HBSS & Hanks Balanced Salts Solution \\
\hline $\mathrm{HCl}$ & Salzsäure \\
\hline Hmgcr & 3-hydroxy-3-methylglutaryl-coenzyme-A-reductase \\
\hline HMSN & hereditäre, motorisch-sensible Neuropathie \\
\hline HNPP & die hereditäre Neuropathie mit Neigung zu Druckparesen \\
\hline HRP & Horseradish peroxidase \\
\hline ID3 & inhibitor auf DNA binding 3 \\
\hline $\lg$ & Immunglobulin \\
\hline IGF1 & insuline-like growth factor 1 \\
\hline IGFBP5 & insuline-like growth factor binding protein 5 \\
\hline IL16 & interleukin 16 \\
\hline IL1R1 & interleukin 1 receptor 1 \\
\hline k & kilo \\
\hline $\mathrm{kb}$ & Kilobasen \\
\hline $\mathrm{KCl}$ & Kaliumchlorid \\
\hline kDa & kilo Dalton \\
\hline KFO & Knöchel-Fuß-Orthese \\
\hline $\mathrm{kg}$ & Kilogramm \\
\hline $\mathrm{KHCO}_{3}$ & Kaliumhydrogencarbonat \\
\hline KI67 & antigen identified by monoclonal antibody Ki 67 \\
\hline KIF1ß & kinesin family member $1 \mathrm{~B}$ \\
\hline I & Liter \\
\hline LITAF & lipopolysaccharide induced TNF factor \\
\hline LMNA & lamin $\mathrm{A} / \mathrm{C}$ transcript variant 1 \\
\hline LPL & lipoprotein lipase \\
\hline M & molar \\
\hline
\end{tabular}




\begin{tabular}{|c|c|}
\hline M & Mega \\
\hline $\mathrm{m}$ & milli \\
\hline $\mathrm{m}$ & Meter \\
\hline M. & Musculus \\
\hline M. & Morbus \\
\hline $\mathrm{m} / \mathrm{s}$ & Meter pro Sekunde \\
\hline MAPK & mitogen-activated protein kinase \\
\hline MBP & myelin basic protein \\
\hline $\mathrm{mg}$ & Milligramm \\
\hline $\mathrm{MgCl}_{2}$ & Magnesiumchlorid \\
\hline $\mathrm{MgSO}_{4}$ & Magnesiumsulfat \\
\hline $\min$ & Minute \\
\hline $\mathrm{ml}$ & Milliliter \\
\hline (m)NLG & motorische Nervenleitgeschwindigkeit \\
\hline $\mathrm{mm}$ & Millimeter \\
\hline MNA & Methylnorbornen-2,3-dicarboxyl-anhydrid \\
\hline MOPS & 3-(N-Morpholino)-Propansulfonsäure \\
\hline MPI & Max Planck Institut \\
\hline MPZ(P0) & myelin protein zero \\
\hline mRNA & messenger RNA, Boten-Ribonukleinsäure \\
\hline MTMR & myotubularin related protein 2 \\
\hline MYL2_V2 & myosine light chain v2 \\
\hline$n$ & Anzahl \\
\hline $\mathrm{n}$ & Nano \\
\hline $\mathrm{N}$ & Newton \\
\hline $\mathrm{n}$ & mol \\
\hline N. & Nervus \\
\hline n.s. & nicht signifikant \\
\hline $\mathrm{Na}_{2} \mathrm{HPO}_{4}$ & Dinatriumhydrogenphosphat \\
\hline
\end{tabular}




\begin{tabular}{|c|c|}
\hline $\mathrm{Na}_{2} \mathrm{HPO}_{4}{ }^{*} 2 \mathrm{H}_{2} \mathrm{O}$ & Dinatriumhydrogenphosphat-2-hydrat \\
\hline $\mathrm{NaCl}$ & Natriumchlorid \\
\hline $\mathrm{NaH}_{2} \mathrm{PO}_{4}{ }^{*} 2 \mathrm{H}_{2} \mathrm{O}$ & Natriumdihydrogenphosphat-2-hydrat \\
\hline $\mathrm{NaH}_{2} \mathrm{PO}_{4}{ }^{*} \mathrm{H}_{2} \mathrm{O}$ & Natriumdihydrogenphosphat-hydrat \\
\hline $\mathrm{NaHCO}_{3}$ & Natriumhydrogencarbonat \\
\hline Nal & Natriumiodid \\
\hline $\mathrm{NaOH}$ & Natriumhydroxid \\
\hline NDRG1 & $\mathrm{N}$-myc downstream regulated 1 \\
\hline NEFL & neurofilament light chain \\
\hline NEFM & neurofilament medium \\
\hline NEXN & nexilin \\
\hline NFAT & nuclear factor of activated T-cells \\
\hline NFKB & nuclear factor kappa B \\
\hline $\mathrm{ng}$ & Nanogramm \\
\hline NLG & Nervenleitgeschwindigkeit \\
\hline NNT & nicotinamide nucleotide transhydrogenase \\
\hline NRG1 & Neuregulin-1 \\
\hline $\mathrm{OsO} 4$ & Osmiumtetroxid \\
\hline $\mathrm{p}$ & Signifikanzniveau \\
\hline$P$ & postnataler Tag \\
\hline PO/MPZ & myelin protein zero \\
\hline $\mathrm{P} 2$ & peripheral myelin protein 2 \\
\hline PAX3 & paired box gene 3 \\
\hline PBS & Phosphat gepufferte Salzlösung \\
\hline PCR & Polymerasekettenreaktion \\
\hline PDE2A & phosphodiesterase $2 \mathrm{~A}$ \\
\hline PDE3B & phosphodiesterase 3B \\
\hline PFA & Paraformaldehyd \\
\hline $\mathrm{PI} 3 \mathrm{~K}$ & Phosphatidylinositol-3-Kinase \\
\hline
\end{tabular}




\begin{tabular}{|c|c|}
\hline PLL & Poly-L-Lysin \\
\hline PMP22 & peripheral myelin protein $22 \mathrm{kDa}$ \\
\hline PNS & Peripheres Nervensystem \\
\hline POU3F1 & POU domain, class 3 , transcription factor 1 \\
\hline PPARG & peroxisome proliferator activated receptor gamma \\
\hline PRKAR2B & protein kinase, cAMP dependent regulatory, type II beta \\
\hline PRX & periaxin \\
\hline PVDF & Polyvinylidenfluorid \\
\hline RAB7 & member RAS oncogene family 7 \\
\hline Ras & rat sarcoma superfamily \\
\hline RBP4 & retinol binding protein 4 \\
\hline Rev & Reverse, Rückwärtsprimer \\
\hline RFU & relative Fluoreszenzeinheiten \\
\hline RIBIN & rRNA promoter binding protein \\
\hline RNA & Ribonukleinsäure \\
\hline rpm & rounds per minute \\
\hline rRNA & ribosomale Ribonukleinsäure \\
\hline RT & Raumtemperatur \\
\hline RT & Reverse Transkriptase \\
\hline RT-PCR & Realtime-Polymerasekettenreaktion \\
\hline s & Sekunde \\
\hline S & Svedberg (Sedimentationskoeffizient) \\
\hline s.o. & siehe oben \\
\hline s.u. & siehe unten \\
\hline S100 & S100 calcium binding protein $\mathrm{A} 1$ \\
\hline SBF2 & SET binding factor 2 \\
\hline SC & Schwannzelle \\
\hline Scap & $\begin{array}{l}\text { sterol regulatory element-binding protein cleavage activating } \\
\text { protein }\end{array}$ \\
\hline
\end{tabular}




\begin{tabular}{|c|c|}
\hline SCD1 & stearoyl-coenzyme A desaturase 1 \\
\hline SDS & Natrium-Dodecyl-Sulfat \\
\hline SMAP & Summenmuskelaktionspotential \\
\hline SNAP & Aktionspotential sensorischer Nerven \\
\hline SoX10 & SRY-box containing gene 10 \\
\hline SOX2 & SRY-box containing gene 2 \\
\hline SSG1 & steroid sensitive gene 1 \\
\hline Stdabw. & Standardabweichung \\
\hline Stdf. & Standardfehler \\
\hline $\mathrm{T}$ & Thymin \\
\hline T & Temperatur \\
\hline $\mathrm{t}$ & Zeit \\
\hline Tab & Tabelle \\
\hline TAE & Tris/Acetat Puffer \\
\hline $\operatorname{Tg}$ & Transgen \\
\hline TGFB3 & transforming growth factor, beta 3 \\
\hline THRSP & thyroid hormone responsive protein \\
\hline Thy1 & thymus cell antigen 1 \\
\hline tRNA & transfer RNA \\
\hline$U$ & Units, Enzymeinheit \\
\hline UV & ultraviolett \\
\hline V & Volt \\
\hline V & Volumen \\
\hline VLDL & very low density lipoprotein \\
\hline W & Wochen \\
\hline $\mathrm{Wt}$ & Wildtyp \\
\hline z.B. & zum Beispiel \\
\hline ZNS & Zentrales Nervensystem \\
\hline
\end{tabular}




\section{EINLEITUNG}

\subsection{DAS ZENTRALE UND DAS PERIPHERE NERVENSYSTEM}

Vor mehr als 500 Millionen Jahren tauchte in der Tierwelt ein bemerkenswerter neuer Zelltyp auf; einer, der imstande ist Reize aus der Umwelt aufzunehmen, weiterzuleiten und zu verarbeiten. Diese als Neurone bezeichneten Zellen entwickelten sich im Laufe der Evolution weiter zu hochkomplexen Gewebestrukturen und bilden, zusammen mit Gliazellen, das Nervensystem der heute lebenden tierischen Organismen. Die große Mehrheit multizellulärer Lebewesen besitzt ein Nervensystem oder nervensystemähnliche Strukturen und basale Formen findet man bereits bei Hohltieren (Coelenterata) wie Korallen und Quallen. Hier ist das Nervensystem charakterisiert durch Netzwerke zunächst gleichartiger Zellen, welche diffus im Organismus lokalisiert sind, wobei bereits einfache, spezialisierte Neurone (z.B. Lichtsinnenszellen) vorhanden sein können. Eine Aufgabenverteilung auf verschiedenartige zelluläre Subspezies, wie auch eine Tendenz von der lokalen- hin zur zentralen Informationsverarbeitung (Cephalisierung) sind evidente evolutionäre Prozesse. Bei höheren Organismen, insbesondere bei Vertebraten, wird so ein zentrales- (ZNS) von einem peripheren Nervensystem (PNS) unterschieden, welche sich in Lokalisation, Funktion und Zellzusammensetzung voneinander abgrenzen. Das Nervensystem lässt sich weiterhin in somatische und vegetative Komponenten unterteilen. Das somatische Nervensystem umfasst alle Zellen die der willkürlich gesteuerten Interaktion zwischen Organismus und Umwelt dienen. Das vegetative Nervensystem hingegen reguliert unbewusst und nicht willentlich z.B. die Funktion der inneren Organe.

Das Neuron, als kleinste funktionelle Einheit des Nervensystems, besteht aus einem kernhaltigen Zellkörper (Perikaryon), einem breitbasigen Dendritengeflecht und einem langen, unikalen Axon. Träger der Information sind elektrische Impulse, sogenannte Aktionspotentiale, welche dem Perikaryon über Dendriten zugeleitet (Afferenzen) und über das Axon fortgeleitet (Efferenz) werden können. Dies geschieht durch Spannungsaufbau und -ausgleich an der Membran der Zellfortsätze, realisiert durch passiven und aktiven Austausch von Ionen zwischen intra- und extrazellulärem Medium. Um Informationen zwischen mehreren Neuronen oder zwischen Neuronen und Endorganen (z.B. Muskelzellen) zu übertragen, werden elektrische Impulse in chemische Signale umgewandelt. So induziert z.B. ein elektrisches Potential am distalen Axonende, im synaptischen Endknöpfchen, das Freisetzen von Botenstoffen (Neurotransmitter) in den synaptischen Spalt, welche dann am postsynaptischen Element (z.B. Dendrit oder Muskel) ein neues elektrisches Potential auslösen können. 
Oligodendrozyten, Astrozyten und Mikroglia im ZNS, sowie Schwannzellen im PNS bilden einen weiteren Zelltyp, die sogenannten Glia. Bereits stammesgeschichtlich frühe Lebensformen wie Anneliden und Arthropoden weisen Gliazellen auf, welche bei höheren Vertebraten bis zu 90\% der Gesamtzellmasse des Nervensystems umfassen können. Astrozyten sind stark verzweigte Zellen, die je nach Gehirnregion verschiedene Morphologien und Funktionen haben können. So sind Astrozyten beteiligt an der Entwicklung und Migration von Neuronen, am Schutz der Nervenzellen z.B. vor exzitotoxischen Neurotransmittern, am Energiemetabolismus zwischen Neuronen und ihrer Umgebung, sowie an der Aufrechterhaltung der Blut-HirnSchranke. Mikroglia werden oft als die Makrophagen des Gehirns bezeichnet und stellen die residenten Immunzellen des ZNS dar. Im inaktivierten Zustand prüfen Mikroglia mit weitverzweigten Fortsätzen ihre Umgebung auf potentielle Pathogene. Der Kontakt mit einem Pathogen führt zur Aktivierung der Mikroglia, welche dann in der Lage sind zu phagozytieren und verschiedene proinflammatorische Moleküle zu bilden. Neuere Studien zeigen, dass die Diversität mikroglialer Wirkungsweisen weit größer ist als ursprünglich angenommen und deren Untersuchung ist Gegenstand der derzeitigen Forschung (Cronk und Kipnis, 2013). Oligodendrozyten im ZNS und Schwannzellen im PNS sind vom Zellkörper bis hin zur Synapse eng mit den Axonen von Neuronen assoziiert. Axone oberhalb eines bestimmten Kalibers werden von diesen Gliazellen mit einer elektrisch isolierenden Schicht, dem Myelin, umgeben. Unabhängig von ihrer Funktion als myelinbildende Zellen sind Oligodendrozyten und Schwannzellen auch an der energetischen Versorgung und dem Schutz von Axonen beteiligt, um deren funktionelle Integrität zu gewährleisten.

\subsection{MYELINISIERUNG UND AXONALE UNTERSTÜTZUNG DURCH GLIAZELLEN}

Obwohl auch einzelne Invertebraten myelinähnliche Strukturen aufweisen, ist das von Gliazellen gebildete Myelin kennzeichnend für Vertebraten (Nave, 2010). Viele Invertebraten erreichten eine Optimierung der elektrischen Impulsweiterleitung auf Kosten einer räumlichen Ausdehnung durch radiale Vergrößerung der Axone (z.B. „Riesenaxone“ der Cephalopoda) (Eckert et al., 2002). Durch die Entwicklung des Myelins jedoch konnte die Erregungsweiterleitung bei enormer Platzersparnis um ein Vielfaches gesteigert werden, und sie gilt gemeinhin als essentielle Voraussetzung für die Entwicklung höherer kortikaler Funktionen (Nave, 2010).

Die schnelle Transduktion elektrischer Signale bei myelinisierten Axonen ist die direkte Folge der saltatorischen Erregungsleitung (Eckert et al., 2002). Jede Gliazelle 
ummantelt nur einen gewissen Abschnitt eines Axons mit Myelin (Internodium). Der nicht myelinisierte Bereich zwischen zwei Internodien, der Ranvier-Schnürring (das Nodium), weist eine hohe Dichte spannungsabhängiger lonenkanäle in der axonalen Membran auf (Campbell und Reece, 2009). Wird ein elektrischer Impuls, ein sogenanntes Aktionspotential, z.B. im Zellkörper eines Neurons erzeugt, so findet in der Folge eine Depolarisation nur an den Ranvier-Schnürringen statt, da das gliale Myelin den elektrischen Widerstand des Axons im Bereich der Internodien stark erhöht. Die Aktionspotentiale „springen“ somit von Schnürring zu Schnürring und müssen im Gegensatz zu graduellen Potentialen unmyeliniserter Nervenfasern nicht kontinuierlich fortgetragen werden (Bähr und Frotscher, 2009). Oligodendrozyten im ZNS können mit multiplen Fortsätzen bis zu 50 Internodien ummanteln, während Schwannzellen im PNS jeweils nur ein Internodium myelinisieren (sogenanntes 1:1 Verhältnis, Peters et al., 1991). Das Ausmaß des von der Gliazelle gebildeten Myelins korreliert proportional mit dem Kaliber der Nervenfaser und das wohldefinierte Verhältnis von Axondurchmesser zu Gesamtdurchmesser der Faser (Axon + Myelin) wird als g-ratio bezeichnet (Friede und Bischhausen, 1982).

Morphologisch ist die Myelinscheide als hochspezialisierte Zellmembran zu verstehen, bestehend aus nahezu zytoplasmafreien, kompakten Bereichen, aber auch aus unkompakten, zytoplasmahaltigen Domänen, welche z.B. einen molekularen Transport ermöglichen (Snaidero et al., 2014, Abb. 1). Auf biochemischer Ebene ist Myelin vergleichbar mit gewöhnlichen Zellmembranen, hat jedoch mit $70 \%$ Lipiden (davon $50 \%$ Cholesterin) und nur 30\% Proteinen einen höheren Lipidanteil (Simons und Trotter, 2007). Grundsätzlich ist das von Oligodendrozyten und Schwannzellen gebildete Myelin gleichartig und unterscheidet sich lediglich in der Protein/Lipidzusammensetzung sowie in diskreten morphologischen Domänen (Quarles et al., 2006). Das abundanteste zentralnervöse Myelinprotein ist das Proteolipidprotein (PLP), gefolgt vom Myelinbasischen Protein (MBP), wohingegen das Myelinprotein 0 (PO) das häufigste Myelinprotein im PNS darstellt (Quarles et al., 2006). Der Aufbau der Myelinscheide erfordert eine enorme gliale Lipid- und Proteinbiosyntheseleistung, sowie einen streng kontrollierten zellulären Transport und die fein abgestimmte architektonische Assemblierung einzelner Bestandteile an der Zelloberfläche (Simons und Trotter, 2007). Innerhalb der Vertebraten findet insbesondere bei den Mammalia die Myelinisierung vorwiegend postnatal statt und schreitet bis in die Adoleszenz fort, wobei Dynamik und Ausmaß der Myelinisierung auch noch im Erwachsenenalter einer gewissen Plastizität unterliegen (Nave, 2010). 

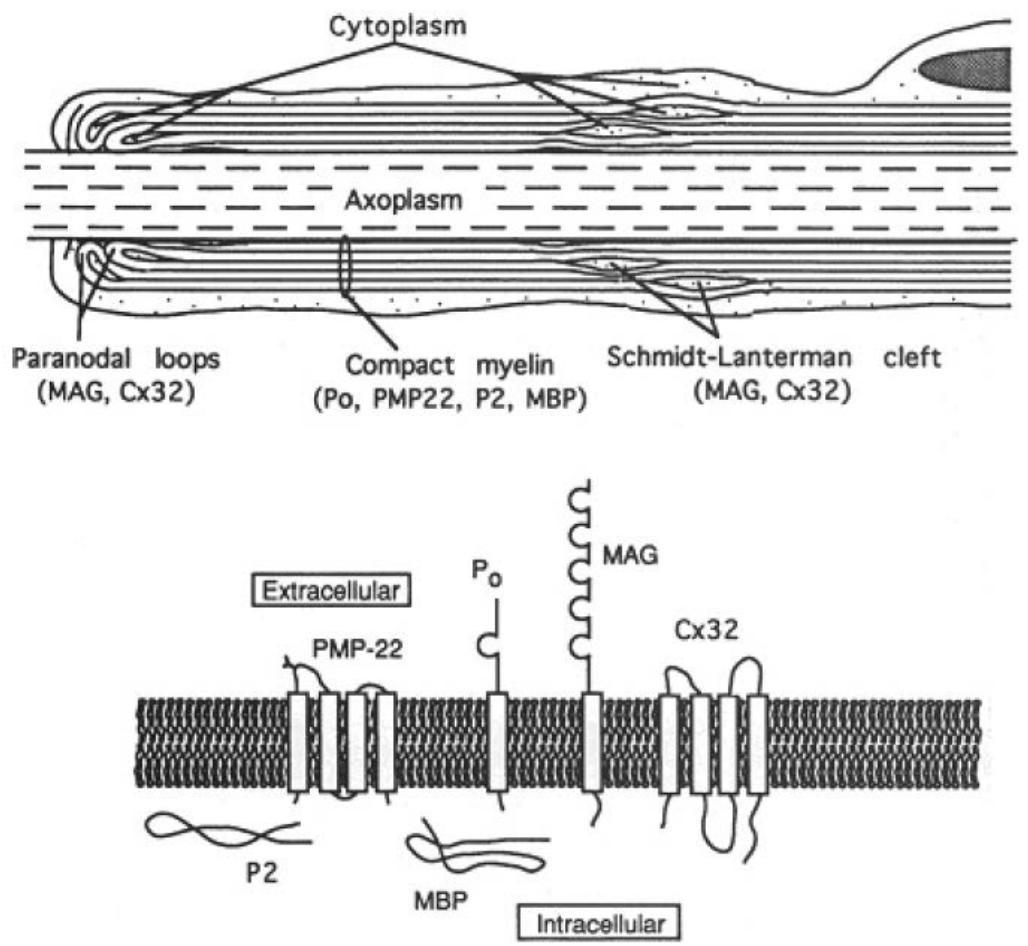

Abbildung 1: Myelinproteine des PNS. Oben: schematischer Longitudinalschnitt durch ein myelinisiertes Axon. Sichtbar sind kompakte Bereiche des Myelins, sowie die unkompakten Domänen der paranodalen Schleifen und Schmidt-Lanterman-Inzisuren jeweils mit den dort charakteristisch lokalisierten Proteinen. Unten: topologische Darstellung der Hauptmyelinproteine des PNS. MAG $=$ myelin associated protein, $\mathrm{Cx} 32=$ connexin $32, \mathrm{P} 0=$ myelin protein zero, $\mathrm{P} 2=$ myelin protein $2, \mathrm{MBP}=$ myelin basic protein (nach Suter et al., 1993).

Die myelinisierenden wie auch die nicht-myelinisierenden Schwannzellen des PNS entstehen aus Neuralleistenzellen, welche während der Embryonalentwicklung zusammen mit den spinalen Nervenfasern in die Peripherie auswandern (Mirsky et al., 2008). Aus migrierenden Neuralleistenzellen entstehen zunächst stark proliferierende Schwannzellvorläuferzellen, welche sich zu unreifen Schwannzellen weiterentwickeln. Unreife Schwannzellen haben immer noch eine ausgeprägte Proliferationsleistung und assoziieren sich in sogenannten Schwannzellfamilien um Bündel noch unmyelinisierter Axone. Reife myelinisierende Schwannzellen entstehen nach dem Aussortieren großkalibriger Axone (Durchmesser $>1 \mu \mathrm{m}$ ) aus den Axonbündeln in einem 1:1 Verhältnis pro Internodium. Mehrere kleinkalibrige Axone bestehen jedoch in sogenannten Remakbündeln fort, welche von einzelnen unmyelinisierenden reifen Schwannzellen ummantelt werden (Jessen und Mirsky, 2005). Während der Entwicklung sind Schwannzellen und deren Vorläufer stets mit auswachsenden Nervenfasern assoziiert und sind zunächst auf axonale Signale angewiesen um zu überleben. Solche axonalen Signale tragen entscheidend zur Schwannzellentwicklung bei, bis hin zur terminalen Differenzierung, der Myelinisierung (Jessen und Mirsky, 2005). Zu unterschiedlichen Differenzierungsstadien exprimieren Schwannzellen 
charakteristische molekulare Signaturen, welche zur Bestimmung der Entwicklungsstufe herangezogen werden können (Abb. 2, Jessen und Mirsky, 2005).

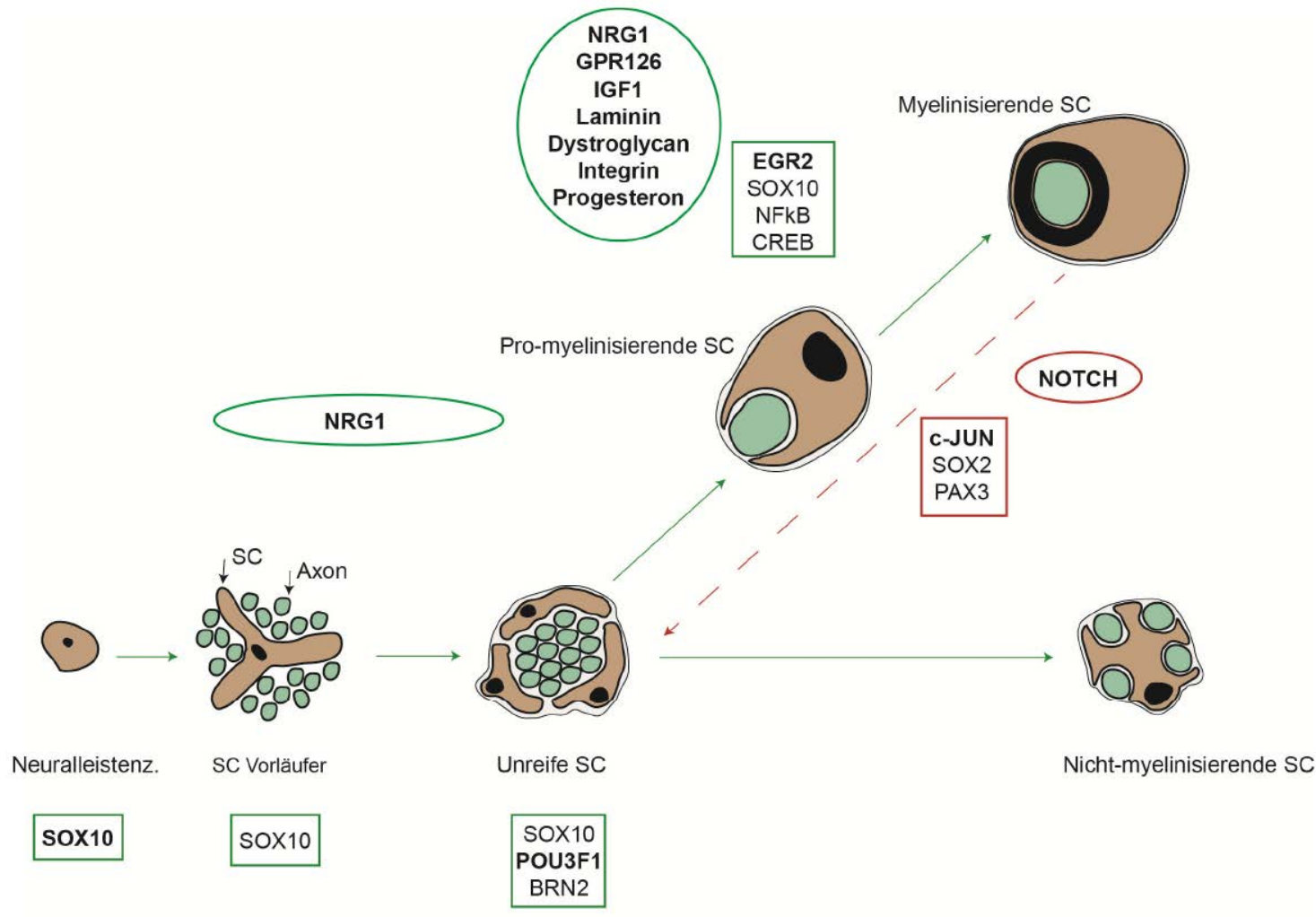

Abbildung 2: Entwicklungsstadien von Schwannzellen im peripheren Nervensystem. Schwannzellen (SC) gehen aus Neuralleistenzellen hervor und sind durch 3 Hauptentwicklungsstadien charakterisiert, SC Vorläufer, unreife SC und reife (myelinisierende oder nicht-myelinisierende) SC. Dargestellt sind in grünen eckigen Kästchen Transkriptionsfaktoren, welche kennzeichnend für das entsprechende Entwicklungsstadium sind. Extrinsische Faktoren, welche für das Überleben oder der Reifung von Schwannzellen essentiell sind, sind grün eingekreist dargestellt. Axonal exprimiertes NRG1 ist für das Überleben der Vorläuferzellen sowie deren Entwicklung zu unreifen Schwannzellen essentiell und determiniert darüber hinaus das Myelinisierungsschicksal sowie die Myelindicke peripherer Nervenfasern. Nach einer Nervenverletzung dedifferenzieren Schwannzellen zurück in proliferierende unreife Schwannzellen. Diese Dedifferenzierung wird maßgeblich vom Transkriptionsfaktore cJUN reguliert. (modifiziert nach Jessen und Mirsky, 2005).

\subsubsection{NEUREGULIN-1 SIGNALWIRKUNG IM PERIPHEREN NERVENSYSTEM}

Neuregulin-1 (NRG1) ist ein Wachstumsfaktor, welcher wichtige Zell-Zell-Interaktionen für die Entwicklung und Funktion von Herz, Lunge und Nervensystem mediiert (Falls, 2003). NRG1 wird durch eines der größten menschlichen Gene kodiert und existiert aufgrund alternativen Spleißens und mehrerer Promotoren in mehr als 16 verschiedenen Isoformen (Falls, 2003). Alle NRG1-Isoformen beherbergen eine epidermal growth factor (EGF)-ähnliche Domäne, welche zwingend erforderlich ist, aber auch alleine ausreicht um Rezeptoren aus der Gruppe der ErbBRezeptortyrosinkinasen zu aktivieren (Falls, 2003). Entsprechend ihrer 
unterschiedlichen N-Termini werden die NRG1-Isoformen aktuell in 6 unterschiedliche Typen eingeteilt (I-VI), wobei die Isoformen I, II und III am besten untersucht sind (Nave und Salzer, 2006). Alle Isoformen werden zunächst als Transmembranproteine synthetisiert, welche dann durch Restriktionsenzyme proteolytisch von der Zellmembran gelöst werden und als soluble Faktoren wirken können (Falls, 2003; Newbern und Birchmeier, 2010). NRG1 Typ I und Typ II weisen eine einzelne Transmembrandomäne auf und sind N-terminal zudem durch eine Immunglobulinreiche Domäne gekennzeichnet (Abb. 3, Falls, 2003). Die NRG1 Typ III Isoform hingegen ist doppelt in der Zellmembran verankert und muss deshalb zweimal proteolytisch prozessiert werden um als solubler Faktor zu agieren (Abb. 3, Fleck et al., 2013). Obwohl auch Gliazellen NRG1 Typ III synthetisieren können, wird NRG1 Typ III im Nervensystem hauptsächlich von Neuronen exprimiert (Nave und Salzer, 2006). Eine fehlende NRG1 Typ III Expression wird nicht toleriert und Mäuse mit ablatiertem NRG1 Typ III sterben kurz nach der Geburt aufgrund von Entwicklungsdefekten der neuromuskulären Endplatte und einer daraus resultierenden fehlerhafter Innervation der Atemmuskulatur (Wolpowitz et al., 2000). NRG1 Typ III defiziente Mäuse weisen darüber hinaus eine reduzierte Anzahl spinaler Motoneurone und sensorischer Nervenzellen sowie einen nahezu vollständigen Verlust von Schwannzellvorläuferzellen auf (Falls, 2003). NRG1 reguliert alle Entwicklungsstadien von Schwannzellen entscheidend, von der Proliferation von Schwannzellvorläufern bis zur terminalen Differenzierung und Myelinisierung der Schwannzelle (Birchmeier und Nave, 2008). Die Menge des axonal präsentierten NRG1 Typ III ist abhängig vom Kaliber der Nervenfaser und signalisiert der Schwannzelle ob und wie stark ein Axon myelinisiert werden soll (Michailov et al., 2004; Taveggia et al., 2005).

Im Gegensatz zu NRG1 Typ III führt die neuronale Überexpression von NRG1 Typ I in Mäusen nicht zu einer Vergrößerung der Myelinscheide Im PNS (Michailov et al., 2004). Auch ist die Expression von NRG1 Typ I nicht erforderlich für das Überleben von Schwannzellvorläuferzellen sowie für deren weitere Entwicklung zu unreifen und reifen Schwannzellen (Sandrock et al., 1997). Jedoch führte eine reduzierte neuronale NRG1 Typ I Expression bei Mäusen zu einer verschlechterten Entwicklung von Acetycholinrezeptoren an der neuromuskulären Endplatte (Sandrock et al., 1997). 


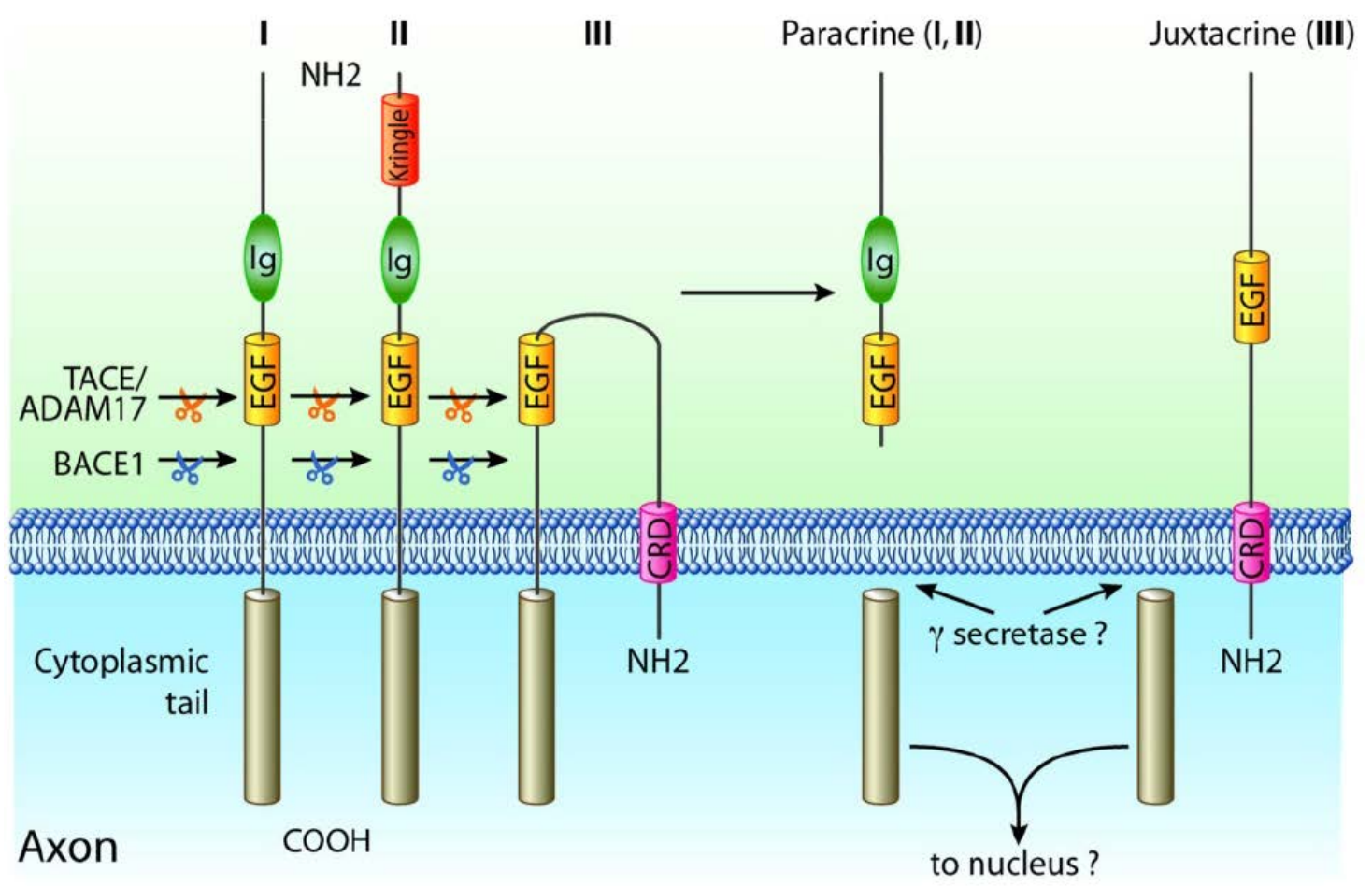

Abbildung 3: Die Struktur der Neuregulin-1 Isoformen Typ I - III. Die Neuregulin-1 Isoformen werden als Transmembranproteine synthetisiert und auf der axonalen Oberfläche präsentiert. Allen Isoformen gemein ist eine EGF (epidermal growth factor) -ähnliche Domäne, welche erforderlich ist und allein ausreicht um ErbB-Rezeptoren auf Schwannzellen zu aktivieren (Falls, 2003). Die N-termini unterscheiden sich bei den unterschiedlichen Isoformen, so haben Typ I und II Immunglobulin-Domänen die der Typ III Isoform fehlt. NRG1 Typ III hingegen beherbergt eine Cystein-reiche Domäne (CRD) welche diese Isoform als zweite Transmembrandomäne charakterisiert (Falls, 2003). Die proteolytische Spaltung durch die Sekretase BACE1 löst nur die extrazellulären Bereiche der Typ I und II Isoformen von der Zellmembran, so dass diese als parakrine Signale wirken können (Taveggia et al., 2010). Eine Prozessierung durch TACE in der EGF-ähnlichen Domäne inhibiert hingegen das NRG1 Signal (Taveggia et al., 2010). Die intrazellulären C-Termini hingegen können durch y-Sekretasen gelöst werden und als retrogrades Signal für das Neuron wirken (aus Stassart et al., 2012).

An der axonalen Oberfläche eingebautes NRG1 kann durch Sekretasen proteolytisch prozessiert werden, was den Aktivierungsstatus von NRG1 verändert (Abb. 3, Stassart et al., 2012). Aus den membranständigen Proteinen können so gelöste Signalmoleküle entstehen, die entweder parakrin oder autokrin wirken (Abb. 3, Newbern und Birchmeier 2010). Die Sekretase BACE1 (ß-site amyloid precursor protein cleaving enzyme 1) löst die Isoformen Typ I und II und aktiviert NRG1 Typ III (Abb. 3, Stassart et al., 2012). Eine proteolytische Spaltung in der signaltransduktorisch essentiellen EGF-ähnlichen Domäne aller Isoformen durch TACE/ADAM-17 (a disintegrin and metalloprotease 17) hingegen inhibiert die Funktion von NRG1 (Taveggia et al., 2010).

Aktives NRG1 aktiviert die auf der Schwannzelloberfläche lokalisierten ErbBRezeptortyrosinkinasen und induziert eine Rezeptor-Homo- oder Heterodimerisierung (Nave und Salzer, 2006). Die im PNS vorwiegende Dimer-Form wird aus ErbB2 und 
ErbB3 gebildet, wobei nur ErbB3 eine Rezeptorfunktion und nur ErbB2 eine Kinasefunktion besitzt (Falls, 2003). Wichtige sekundäre Signalwege sind der PI3K/AKT (phosphatidylinositol-3-kinase/v-Akt murine thymoma viral oncogene homolog 1)-Signalweg sowie die Ras/MAPK/ERK (Ras/mitogen-activated protein kinase/extracellular signal regulated kinase)-Kaskade und der NFAT (nuclear factor of activated $T$ cells)/Calcineurin-Signalweg (Stassart et al., 2012). Über Aktivierung eines oder mehrerer dieser Signaltransduktionskakskaden wird in Gliazellen Proliferation, Migration und Differenzierung gesteuert (Newbern und Birchmeier, 2010). Insbesondere die PI3K/AKT- (Taveggia et al., 2010) und MEK/ERK-Signalwege (Newbern et al., 2011) sind essentiell für die Myelinisierung im gesamten Nervensystem.

\subsection{Prozesse bel AKUter NerVEnVERLETZUng}

Im Gegensatz zum ZNS zeichnet sich das PNS durch eine erstaunliche Regenerationsfähigkeit aus (Bosse, 2012). Regenerative Prozesse im PNS sind die Folge von akuten Nervenverletzungen, z.B. nach Traumen, von Schädigungen durch toxische Substanzen sowie auch von degenerativen Ereignissen bei chronischen Erkrankungen des Nervensystems (Chen et al., 2007; Jessen and Mirsky, 2008). Die Regeneration beschädigter Nerven umfasst de- und remyelinisierende Prozesse, eine vollständige Wiederherstellung der Nervenfunktion wird jedoch selten erreicht (Frostick et al., 1998).

\subsubsection{WALLERISCHE DEGENERATION}

Eine akute Nervenschädigung führt zunächst zu einem als Wallerische Degeneration bezeichneten Vorgang (Stoll und Müller, 1999). Hierbei degenerieren die axonalen Bereiche distal der Schädigung, wobei die proximalen Abschnitte erhalten bleiben (Chen et al., 2007). Binnen weniger Stunden kommt es zu einer Fragmentierung der distalen Axone, gefolgt von einem Kollaps der Myelinscheiden (Bosse, 2012). Während die Myelin-Debris anschließend zum Teil von Schwannzellen selbst, aber auch von einwandernden Makrophagen phagozytiert wird (Stoll und Müller, 1999), wachsen die Axone von der Schädigungsstelle erneut aus und reinnervieren, je nach Distanz nach wenigen Wochen, die Zielorgane (Stoll und Müller, 1999). Schwannzellen bilden hierbei die Basis für eine erfolgreiche Nervenregeneration und zeigen während des Regenerationsvorganges eine erstaunliche Plastizität. Aufgrund der axonalen 
Degeneration nach einer Schädigung verlieren die Schwannzellen zunächst den Kontakt der Nervenfaser, woraufhin diese einen Prozess der De- oder Transdifferenzierung durchlaufen, d.h. sie entwickeln sich von ausdifferenzierten Zellen zurück zu proliferierenden Vorläuferzellen (Jessen und Mirsky, 2005). Während dieser Phase werden auch Gene exprimiert, welche die Infiltration von Makrophagen in das verletzte Gewebe fördern, aber auch für das erneute axonale Auswachsen und das Überleben der Neurone an sich von Bedeutung sind (Jessen und Mirsky, 2008). Das Auswachsen der Axone wird insbesondere dadurch begünstigt, dass sich die dedifferenzierten Schwannzell-Vorläuferzellen zu Leitkanälen, sogenannten BüngnerBändern, anordnen. Diese stellen eine für Axone essentielle, wachstumspermissive Umgebung bereit (Chen et al., 2007). Die Rückentwicklung von reifen Schwannzellen in proliferierende Vorläuferzellen erfordert die Aktivierung bestimmter intrazellulärer Faktoren, die als negative Differenzierungsfaktoren den Prozess der Dedifferenzierung steuern (Abb.2; Jessen und Mirsky, 2008). In den letzten Jahren konnte insbesondere der Transkriptionsfaktor c-Jun (jun proto-oncogene) und die Ras/Raf/MEK/ERK Signaltransduktionskaskade als wichtige Regulatoren der SchwannzellDedifferenzierung identifiziert werden (Arthur-Farraj et al., 2012; Napoli et al., 2012). Mausmutanten, in denen das C-Jun Gen spezifisch in Schwannzellen ablatiert wurde, zeigen nach einer experimentellen Nervenschädigung unter anderem eine gestörte Wallerische Degeneration, einen gehemmten Myelinabbau, eine fehlerhafte Assemblierung der Schwannzellen zu Büngner-Bändern sowie eine deutlich verschlechterte axonale Regeneration (Arthur-Farraj et al., 2012). Mit Hilfe transgener Mäuse, in denen der Ras/Raf/MEK/ERK Signalweg artifiziell in reifen Schwannzellen aktiviert wurde, konnte eine wichtige Funktion dieser Kaskade in der SchwannzellDedifferenzierung nachgewiesen werden (Napoli et al., 2012). So ist die alleinige Aktivierung dieses Signalweges ausreichend, um einen Dedifferenzierungsphänotyp in Schwannzellen zu induzieren. Schwannzellen mit experimentell aktiviertem ERK in vivo zeigen in der Folge Demyelinisierung, Proliferation und eine Sekretion proinflammatorischer Signale, ohne dass eine axonale Schädigung vorliegt (Napoli et al., 2012). Die anschließende Terminierung der Ras/Raf/MEK/ERK Aktivität hatte eine Redifferenzierung und Remyelinisierung der Schwannzellen zur Folge (Napoli et al., 2012). 


\subsubsection{REMYELINISIERUNG IM PNS}

In vieler Hinsicht ähnelt die Redifferenzierung und Remyelinisierung von Schwannzellen nach einer Nervenschädigung der entwicklungsbiologischen Differenzierung und Myelinisierung (Jessen und Mirsky, 2008). Ein wichtiger Unterschied ist jedoch, dass dedifferenzierende Schwannzellen nach Verletzung den axonalen Kontakt und somit axonale Signale entbehren müssen, während sie in der Entwicklung stets mit der Nervenfaser assoziiert sind (Stassart und Fledrich et al., 2013). Entsprechend zeigen redifferenzierende Schwannzellen ein von entwicklungsbiologisch differenzierenden Schwannzellen unterscheidbares Genexpressionsmuster und es ist wahrscheinlich, dass nach einer Verletzung spezifische Faktoren exprimiert werden, die gezielt die Redifferenzierung von Schwannzellen regulieren (Jessen und Mirsky, 2008). Solche spezifischen Redifferenzierungsfaktoren sind bisher jedoch kaum bekannt (Jessen und Mirsky, 2008).

Obwohl Schwannzellen remyelinisierunskompetent sind, erreicht die neu gebildete Myelinscheide nicht die ursprüngliche Dicke und Länge. Somit bleiben die Internodien verkürzt und die Nervenfasern zu dünn myelinisiert, wodurch die Nervenleitgeschwindigkeit und somit die Funktionaliät regenerierter Nerven oft dauerhaft beeinträchtigt bleibt (Bosse et al., 2012).

\subsection{ChRONISCHE NERVENSCHÄDIGUNG BEI ERBLICHEN NEUROPATHIEN}

Das genetisch bedingte Unvermögen der Schwannzellen eine physiologische Myelinstruktur zu bilden bzw. aufrecht zu erhalten charakterisiert eine Gruppe der hereditären, peripheren Neuropathien (Dyck et al., 2005). Unter diesen Neuropathien ist die Gruppe der Charcot-Marie-Tooth-Erkrankung (CMT) oder hereditäre motorischsensible Neuropathie (HMSN) die häufigste. CMT oder HMSN wiederum sind Oberbegriffe für eine in genetischer Ursache und daraus folgenden Symptomen sehr heterogene Zusammenfassung peripherer Neuropathien. Hierbei können unterschiedliche Gendefekte ähnliche Symptome hervorufen oder Mutationen im gleichen Gen unterschiedliche pathologische Prozesse zur Folge haben. Es wurden zahlreiche genetisch modifizierte Tiermodelle hergestellt, um die Pathomechanismen der CMT näher zu untersuchen (Fledrich et al., 2012b). 


\subsubsection{KLASSIFIKATION HEREDITÄRER NEUROPATHIEN - CHARCOT MARIE TOOTH ERKRANKUNG}

Erbliche Krankheiten des peripheren Nervensystems gehören mit einer geschätzten Prävalenz von 1:2500 (Skre, 1974; Emery, 1991; Bort et al., 1995) zu den häufigsten Erbkrankheiten überhaupt. Zuerst wurde von Charcot und Marie eine hereditäre, langsam fortschreitende, distal betonte, symmetrische Muskelatrophie als eigene Krankheitsentität charakterisiert (Charcot und Marie, 1886), wobei Tooth dies unabhängig zeitgleich beschrieb (Tooth, 1886). Die Krankheit erhielt den Eigennamen Charcot, Marie und Tooth (CMT); sie wird klinisch auch als hereditäre motorischsensible Neuropathie (HMSN) bezeichnet. Beide Begriffe werden im Folgenden synonym verwendet. Die HMSN werden nach klinischen Gesichtspunkten in sieben Gruppen eingeteilt (Dyck und Thomas, 2005). Unter CMT1 werden die demyelinisierenden-, also Schwannzell-spezifischen Formen der CMT zusammengefasst, welche durch eine verminderte Nervenleitgeschwindigkeit gekennzeichnet sind. Im Gegensatz dazu wird die axonale oder neuronale CMT2 mit normaler Nervenleitgeschwindigkeit unterschieden. Die CMT3, auch Dejerine-SottasSyndrom genannt, zeigt eine besonders schwere Klinik. Die weiteren Formen CMT4 bis 7 sind sehr selten. Weitere Sonderformen wurden ebenfalls beschrieben (Dyck and Lambert, 1968). Dies sind z.B. die kongenital hypomyelinisierende Neuropathie (CHN) und die hereditäre Neuropathie mit Neigung zu Druckparesen (HNPP).

Diese klinisch orientierte Einteilung erblicher, peripherer Neuropathien wurde in den letzten 20 Jahren durch Erkenntnisse in Molekularbiologie und Genetik zunehmend erweitert. Verschiedene Genloci wurden mit hereditären Neuropathien assoziiert und Gendefekte als Ursache identifiziert (Tab. 1). Dabei wurde deutlich, dass vergleichbare Symptome ganz unterschiedlichen Gendefekten zugrunde liegen können, aber auch, dass Mutationen im gleichen Gen verschiedene Symptome hervorrufen können. Eine adäquate Klassifikation der CMT muss deshalb nach klinischen, als auch nach genetischen Gesichtspunkten erfolgen (Martini, 2000).

Eine regelmäßig aktualisierte Liste der hereditären Neuropathien auf Basis einer genetischen Einteilung ist verfügbar unter: http://www.molgen.ua.ac.be/CMTMutations. 


\begin{tabular}{|c|c|c|c|c|}
\hline Тур & Locus & $\begin{array}{l}\text { genetische } \\
\text { Mutationen }\end{array}$ & klinische Charakteristika & Häufigkeit \\
\hline \multicolumn{5}{|c|}{ CMT1: autosomal oder X-gonosomal dominante demyelinisierende Neuropathie mit $m N L G<38 m / s$} \\
\hline CMT1A/E & $17 p 11.2$ & $\begin{array}{l}\text { PMP22 } \\
\text { Duplikation/ } \\
\text { Punktmutation }\end{array}$ & $\begin{array}{l}\text { Beginn in 2. Lebensdekade. Schwäche, } \\
\text { Muskelatrophie, sensorischer Verlust, Beginn in } \\
\text { Füßen und Verlauf nach proximal }\end{array}$ & häufig \\
\hline HNPP & $17 p 11.2$ & PMP22 Deletion & $\begin{array}{l}\text { Episodische Mononeuropathien mit schmerzlosen } \\
\text { Druckparesen. Milde Demyelinisierung }\end{array}$ & häufig \\
\hline CMT1B & 1q22-q23 & MPZ(P0) & $\begin{array}{l}\text { wie CMT1A, aber früherer Beginn und stärkere } \\
\text { Ausprägung }\end{array}$ & häufig \\
\hline CMT1C & 16p13.1-p12.3 & LITAF & ähnlich wie CMT1A & selten \\
\hline CMT1D & $10 q 21.1-q 22.1$ & KROX20 & wie CMT1A, Ausprägung variiert je nach Mutation & selten \\
\hline CMT1X & Xq13.1 & CX32 & $\begin{array}{l}\text { ähnlich wie CMT1A, aber distale Atrophie stärker } \\
\text { betont. Männer stärker betroffen als Frauen. }\end{array}$ & häufig \\
\hline \multicolumn{5}{|c|}{ СMT3: stark demyelinisierende Neuropathien (autosomal dominant oder rezessiv) mit $m N L G<38 \mathrm{~m} / \mathrm{s}$} \\
\hline DSS & \multicolumn{2}{|c|}{$\begin{array}{l}\text { dominant (PMP22, MPZ, GJB1, } \\
\text { KROX20 und NEFL) } \\
\text { rezessiv (MTMR und PRX) }\end{array}$} & $\begin{array}{l}\text { Verzögerte motorische Entwicklung bereits vor } \\
\text { Alter von } 3 \text { Jahren. Ausgeprägte Schwäche und } \\
\text { Atrophien distaler Muskeln, erheblicher } \\
\text { sensorischer Verlust }\end{array}$ & selten \\
\hline $\mathrm{CHN}$ & \multicolumn{2}{|c|}{$\begin{array}{l}\text { dominant (KROX20, PMP22 und } \\
\text { MPZ) } \\
\text { rezessiv (KROX20) }\end{array}$} & $\begin{array}{l}\text { Ähnliche Klinik wie DSS, aber Hypotonie von } \\
\text { Geburt an. }\end{array}$ & selten \\
\hline
\end{tabular}

CMT4: autosomal rezessive demyelinisierende Neuropathien mit $m N L G<38 \mathrm{~m} / \mathrm{s}$

\begin{tabular}{|c|c|c|c|c|}
\hline CMT4A & $8 q 13-q 21$ & GDAP1 & $\begin{array}{l}\text { schwere Neuropathie, Beginn in erster } \\
\text { Lebensdekade, Verlauf bis zur } \\
\text { Rollstuhlgebundenheit }\end{array}$ & selten \\
\hline CMT4B1 & $11 q 23$ & MTMR2 & fokal gefaltetes Myelin, Beginn in früher Kindheit & selten \\
\hline CMT4B2 & $11 \mathrm{p} 15$ & SBF2 & $\begin{array}{l}\text { fokal gefaltetes Myelin, Beginn in erster bis zweiter } \\
\text { Lebensdekade }\end{array}$ & selten \\
\hline CMT4D & $8 q 24$ & NDRG1 & $\begin{array}{l}\text { Beginn in erster Lebensdekade, starke } \\
\text { Ausprägung, fortschreitender Gerhörverlust }\end{array}$ & selten \\
\hline CMT4F & $19 q 13.1-q 13-3$ & PRX & $\begin{array}{l}\text { Beginn in erster Lebensdekade, schwere } \\
\text { Neuropathie (besonders Sensorik), } \\
\text { Hypomyelinisierung }\end{array}$ & selten \\
\hline CMT4 & 10q21.1-q22.1 & KROX20 & $\begin{array}{l}\text { Beginn in Kindheit, Verlauf bis zur } \\
\text { Rollstuhlgebundenheit }\end{array}$ & selten \\
\hline
\end{tabular}

CMT2: autosomal dominate axonale Neuropathien mit $m N L G>38 \mathrm{~m} / \mathrm{s}$

\begin{tabular}{|c|c|c|c|c|}
\hline СMT2A & 1p35-p36 & KIF1ß & ähnlich wie CMT1A & selten \\
\hline CMT2B & $3 q 13-q 22$ & RAB7 & $\begin{array}{l}\text { Beginn in 2. bis } 3 \text {. Lebensdekade, starker } \\
\text { sensorischer Verlust, distale Geschwüre }\end{array}$ & selten \\
\hline CMT2D & $7 \mathrm{p} 14$ & GARS & $\begin{array}{l}\text { Beginn in 2. bis } 3 \text {. Lebensdekade, vorwiegend in } \\
\text { oberen Extremitäten, hauptsächlich motorische } \\
\text { Defizite }\end{array}$ & selten \\
\hline CMT2E & $8 p 21$ & NEFL & variabler Beginn und Schwere & selten \\
\hline
\end{tabular}

AR-CMT2: autosomal rezessive axonale Neuropathien mit $m N L G>38 \mathrm{~m} / \mathrm{s}$

$\begin{array}{lll}\text { AR- } & \text { 1q21.2-q21.3 LMNA } \\ \text { CMT2A } & \end{array}$

Beginn in 2. Lebensdekade, stark ausgeprägte

Muskelschwäche und distale bis proximale selten Atrophie

Tabelle 1: Klassifikation peripherer hereditärer Neuropathien mit identifizierter genetischer Ursache: Die verschiedenen Typen der CMT sind den entsprechenden Vererbungsmodi (autosomal / gonosomal, dominant / rezessiv) und der pathologischen Form (demyelinisierend: $\mathrm{mNLG}<38 \mathrm{~m} / \mathrm{s}$; axonal: mNLG > $38 \mathrm{~m} / \mathrm{s}$ ) zugeordnet. mNLG: motorische Nervenleitgeschwindigkeit; DSS: Dejerine-SottasSyndrom; CHN: kongenital hypomyelinisierende Neuropathie; PMP22: peripheral myelin protein 22kDa; MPZ(P0): myelin protein zero; LITAF: lipopolysaccharide induced TNF factor; EGR2: early growth response 2; CX32: Connexin 32; GJB1: gap junction protein beta 1 ; NEFL: neurofilament light chain polypeptide; MTMR: myotubularin related protein 2; GDAP1: ganglioside-induced differentiation-associated protein 1; SBF2: SET binding factor 2; NDRG1: N-myc downstream regulated 1; PRX: Periaxin; KIF1ß: kinesin family member 1B; RAB7: member RAS oncogene family 7; GARS: glycyl-tRNA synthetase; LMNA: lamin A/C transcript variant 1 (modifiziert nach Suter und Scherer, 2003). 


\subsubsection{KLINISCHE, ELEKTROPHYSIOLOGISCHE UND HISTOLOGISCHE CHARAKTERISTIKA}

Obwohl zahlreiche Subformen der hereditären motorisch-sensiblen Neuropathien unterschieden werden, beschreiben diese vorwiegend ähnliche Symptome (siehe Tab. 1).

Die CMT-Erkrankung wurde von Tooth zunächst als peroneale Muskelatrophie beschrieben (Tooth, 1886), was eine Degeneration der äußeren Wadenmuskulatur impliziert, welche durch den Nervus peronaeus innerviert wird. Die laterale Wadenmuskulatur ist für Dorsalextension und Pronation des Fußes zuständig, sodass Betroffene die Knie abnorm hoch anheben müssen um nicht mit den Füßen auf dem Boden zu schleifen. Dieses als Steppergang bezeichnete Symptom ist ein charakteristisches Merkmal der fortgeschrittenen CMT. Pathologische Veränderungen der Fußanatomie, wie Hohlfuß (pes cavus), Pferdefuß (pes equinovarus) und Hammerzehen treten häufig auf (Dyck und Thomas, 2005) (Abb. 4A und 4B). In besonders fortgeschrittenen Stadien können ebenfalls die Hände betroffen sein (Abb. 4C und 4D). Durch die progrediente, symmetrische Muskelatrophie von distal nach proximal, insbesondere der unteren Extremitäten, erscheinen diese in Form einer „invertierten Champagnerflasche“ (Birouk et al., 1997; Kuhlenbäumer et al., 2002) (Abb. 1E und 1F). Die Muskeleigenreflexe distaler Anteile der Gliedmaßen können abgeschwächt bis gänzlich erloschen sein (Garcia et al., 1995). Neben motorischen Verlusten sind auch Fälle mit sensorischen Defiziten, vor allem im Bereich der Füße und Hände, beschrieben worden (Dyck and Thomas, 2005).

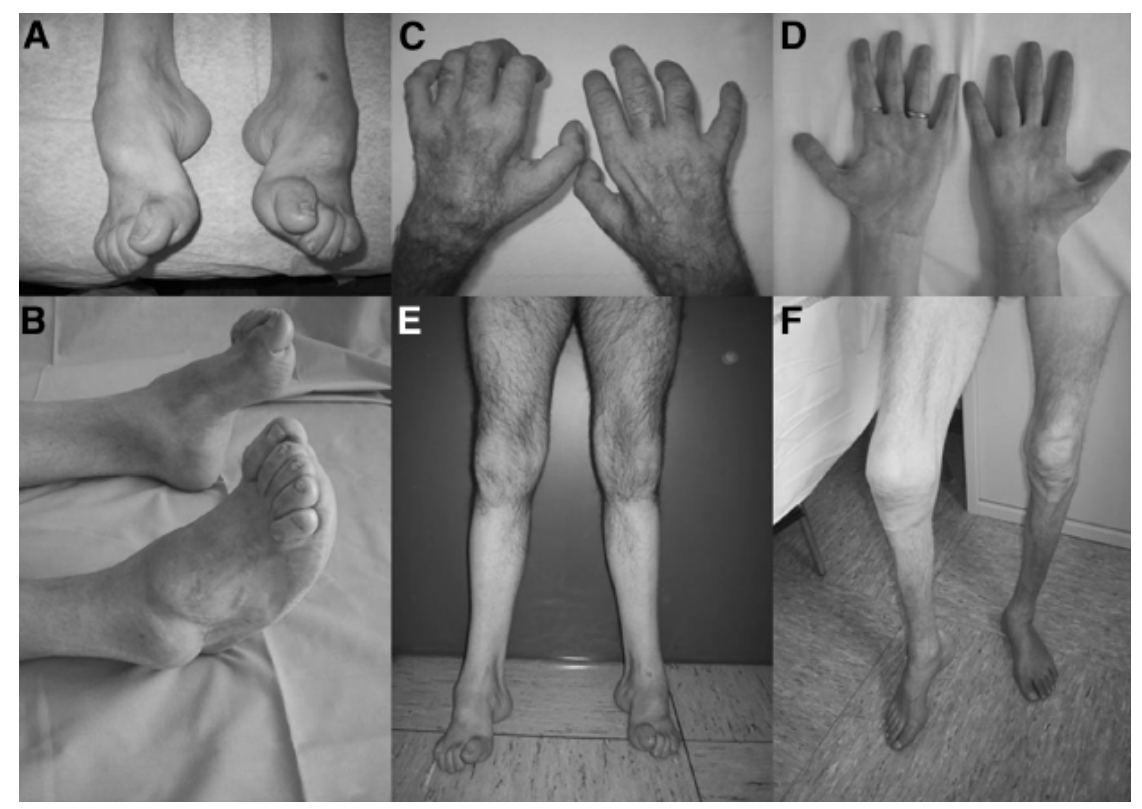

Abbildung 4: Klinische Charakteristika der CMT: $(A, B)$ moderate bis schwere Fußdeformationen mit pes cavus, Hammerzehen und Geschwüren. (C,D) Atrophie der Handmuskulatur. (E,F) Atrophie der unteren Beinmuskulatur (nach Pareyson et al. 2006). 
Das Erkrankungsalter und der Schweregrad der CMT sind sehr variabel, wobei eine frühe Manifestation als ein negativer prognostischer Faktor für den Erkrankungsverlauf beschrieben wurde (Birouk et al., 1997). In den meisten Fällen treten die ersten Symptome in der zweiten Lebensdekade auf (Dyck and Thomas, 2005). Der Grad der Betroffenheit ist ebenfalls sehr variabel und kann von leichtem Kribbelgefühl in Füßen und Händen bis hin zur Rollstuhlgebundenheit reichen (Dyck and Thomas, 2005). Ein Unterschied im Erkrankungsverlauf wurde zwischen Geschwistern (Kaku et al., 1993) und sogar zwischen eineiigen Zwillingen (Garcia et al., 1995) beobachtet. Es wird daher angenommen, dass epigenetische Faktoren als Krankheitsmodulatoren eine bedeutende Rolle spielen. Über genaue Ursachen dieser Variabilität ist jedoch noch wenig bekannt.

Neben den klinischen Symptomen ist oftmals bei Betroffenen eine reduzierte Nervenleitgeschwindigkeit (NLG) messbar, welches als Unterscheidungsmerkmal für verschiedene CMT Typen dient. So wird die Schwannzell-spezifische Form der CMT (CMT1) mit einer reduzierten NLG von der axonalen Form der CMT (CMT2) mit unveränderter NLG abgegrenzt (Harding und Thomas, 1980) (Tab. 1). Da Veränderungen in der NLG bei der CMT1 schon vor den ersten Symptomen detektierbar sind, eignet sie sich bei jungen Patienten für eine frühe Diagnose und Verlaufsbeurteilung (Nicholson, 1991; García et al., 1998; Burns und Ouvrier, 2006; Yiu et al., 2008). Eine Korrelation der NLG-Reduktion mit der Klinik der CMT1 in erwachsenen Patienten konnte jedoch nicht eindeutig belegt werden, sodass die NLG hier nicht für eine Verlaufsbeurteilung der Krankheit herangezogen werden kann (Dyck und Lambert, 1968; Harding und Thomas, 1980; Bouché et al., 1983; Reilly und Shy, 2009). Die Leitgeschwindigkeiten peripherer Nerven sind bei CMT1-Patienten im Mittel um die Hälfte reduziert und bleiben im Laufe des Lebens weitestgehend konstant (Dyck und Lambert 1968). Eine verringerte NLG ist verursacht durch Demyelinisierung, während eine Reduktion der Muskelsummenaktionspotentiale (MSAP) einen, bei der CMT1 sekundären, axonalen Verlust widerspiegelt. Im Gegensatz zur NLG nimmt die Amplitude im Krankheitsverlauf ab (Killian et al., 1996) und korreliert mit der Klinik der CMT1 (Krajewski et al., 2000).

Extensive histologisch-morphometrische Vergleichsstudien biopsierter peripherer Nerven (Nervi suralis) bei gesunden und betroffenen Menschen zeigen im Querschnitt demyelinisierte Fasern, axonalen Verlust sowie verstärkte Einlagerung von Bindegewebe und hyperplastische Neurolemmata (Dyck und Thomas, 2005). Vornehmlich großkalibrige, motorische Axone weisen in Longitudinalschnitten peripherer Nervenbiopsate eine segmentale Demyelinisierung auf (Dyck und Thomas, 
2005). Es sind also lediglich einzelne Schwannzellen betroffen, obwohl alle denselben genetischen Hintergrund aufweisen. Ein weiterer typischer histologischer Befund ist die sogenannte „Zwiebelschalenformation“ („onion bulb formation“), wobei axonale Internodien nicht wie üblicherweise von nur einer Schwannzelle ummantelt, sondern von mehreren Lagen konzentrischer Zellen und ihren Fortsätzen umgeben werden (Abb. 5). Diese Zellen zeigen Merkmale promyelinisierender, undifferenzierter Schwannzellen (Guénard et al., 1996).
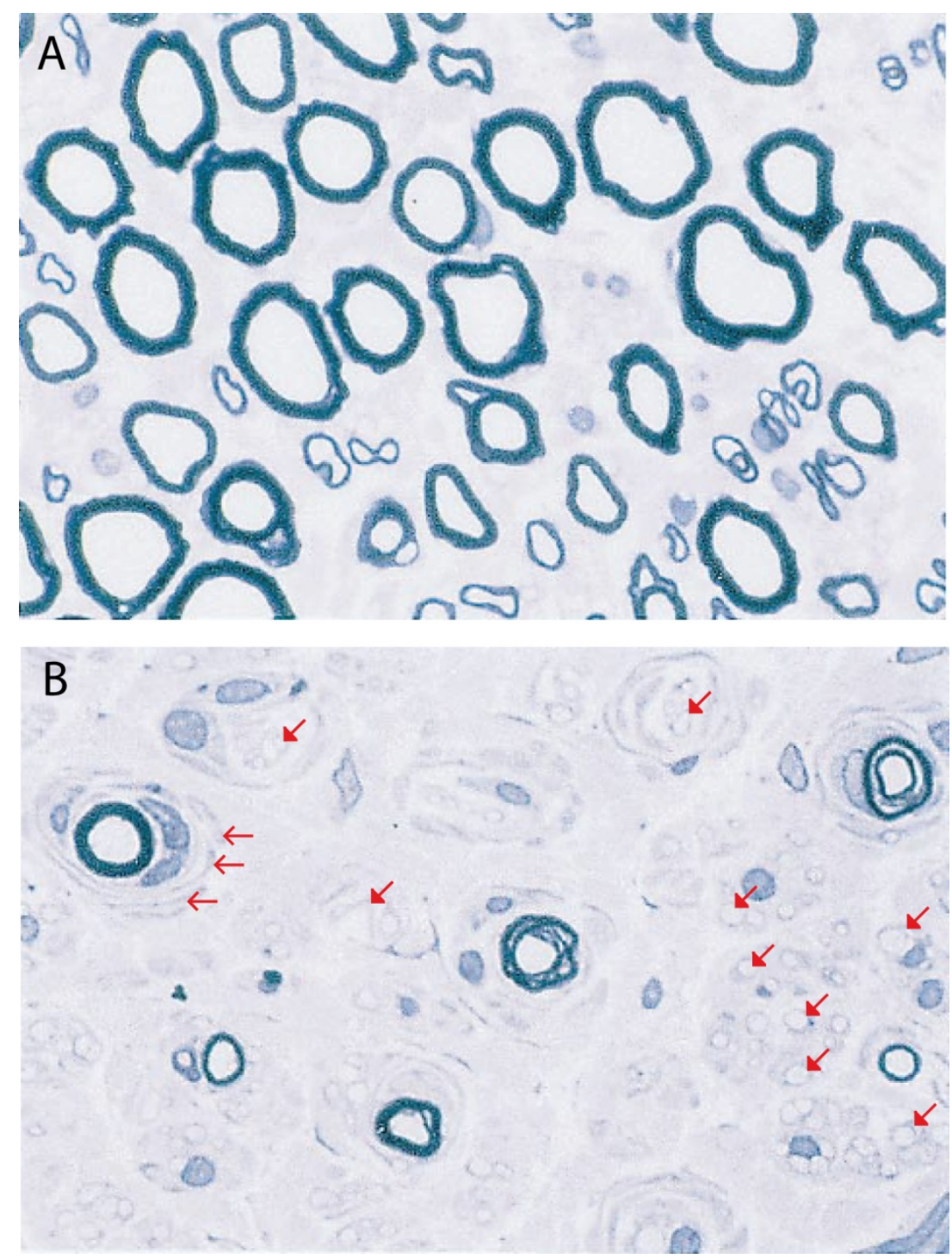

Abbildung 5: Querschnitte durch Nervi suralis: (Thionin-gefärbt): (A) gesunder Proband zeigt normal myelinisierte Axone. (B) CMT1A Patient zeigt erhöhte Einlagerung von Bindegewebe, axonalen Verlust, demyelinisierte Axone (exemplarisch, geschlossene Pfeile), sowie Zwiebelschalenformationen mit mehreren Lagen konzentrischer Schwannzellen (offene Pfeile) (modifiziert nach Nishimura et al., 1996). 


\subsubsection{DAS PERIPHERE MYELINPROTEIN 22KDA (PMP22)}

Die autosomal, dominant vererbte HMSN-Subform CMT1A ist mit einer Prävalenz von 1:5000 die häufigste aller hereditären, peripheren Neuropathien (Nelis et al., 1996). Es konnte gezeigt werden, dass der zugrundeliegende Gendefekt für diese Subform im Großteil aller Fälle auf einer partiellen DNA-Duplikation von 1,5 Millionen Basenpaaren auf dem kurzen Arm des 17. Chromosoms (17p11.2-p12) beruht (Lupski et al., 1991; Raeymaekers et al., 1991). Ursache dieser Duplikation ist in fast allen Fällen ein ungleiches Crossing Over während der Meiose der Spermatogenese (Palau et al., 1993). So ist die genomische Region beiderseits von hochgradig homologen Wiederholungssequenzen flankiert - „CMT1A repeat" genannt - was eine ungleiche Rekombination während der Spermatogenese begünstigt (Pentao et al., 1992; Abb. 6). Der duplizierte Bereich codiert unter anderem das Gen für das periphere Myelinprotein mit einem Molekulargewicht von 22 kDa (PMP22) (Lupski et al., 1991; Raeymaekers et al., 1991; Matsunami et al., 1992; Timmerman et al., 1992). In rund 70\% aller Fälle wird die CMT1A durch die Duplikation auf Chromosom 17 und der damit einhergehenden erhöhten Gendosis für PMP22 verursacht (Wise et al., 1993; lonasescu, 1995; Kurihara et al., 2002; Morocutti et al., 2002). Es wurden auch andere Fälle berichtet, welche auf Mutationen im PMP22-Genlocus beruhen und welche kollektiv als CMT1E bezeichnet werden (Nicholson et al., 1992; Roa et al., 1993; Pareyson und Marchesi, 2009). Der Bereich 17p11.2-p12 ist ein sogenannter Mutations-Hot Spot, welcher günstige Umstände für de novo Mutationen beherbergt (Boerkoel et al., 1999). Solche Punktmutationen können zu Funktionsverlust, aber auch zu Überfunktion des Proteins führen (Houlden und Reilly, 2006). Die Deletion der PMP22-enthaltenden Region 17p11.2-p12, als Gegenbild zur Duplikation während einer ungleichen Rekombination, führt zur hereditären Neuropathie mit Neigung zu Druckläsionen (hereditary neuropathy with liability to pressure palsies: HNPP); einer vergleichsweise milden Verlaufsform (Abb. 6). PMP22 werden 2-5\% des Totalproteingehaltes des PNS-Myelins zugeschrieben (Pareek et al., 1993). Im Myelin wurde das Transkript erstmals bei Nerv-Quetsch-Experimenten detektiert, wobei eine Herunterregulation in distalen Nervenstümpfen zu verzeichnen war (Kitamura et al., 1976; Spreyer et al., 1991; Welcher et al., 1992). Anschließende Charakterisierungstudien zeigten, dass die mRNA für PMP22 in Schwannzellen während der Myelinisierung stark hochreguliert ist (Snipes et al., 1992). Diese Studien korrelierten mit Untersuchungen auf Proteinebene, bei welchen durch Western Blot und Immunhistologie zusätzlich demonstriert werden konnte, dass PMP22-Protein im kompakten und nicht im unkompakten Myelin exprimiert wird (Snipes et al., 1992; Haney et al., 1996). Unabhängig davon wurde ein weiteres PMP22 Transkript, zunächst als Growth-Arrest Gene 3 (GAS3) bezeichnet, in 
wachstumsarretierten Fibroblasten identifiziert (Manfioletti et al., 1990). Beide Transkripte sind Isoformen desselben Genes mit verschiedenen Promotorregionen und abweichenden untranslatierten ersten Exonen (Exon 1A und 1B). Für die CMT1A ist lediglich das Exon 1A enthaltende Transkript von Bedeutung, da dies spezifisch in Schwannzellen exprimiert wird (Suter et al., 1994; van de Wetering et al., 1999). PMP22 mit dem translatierten Exon 1B wird ubiquitär exprimiert.

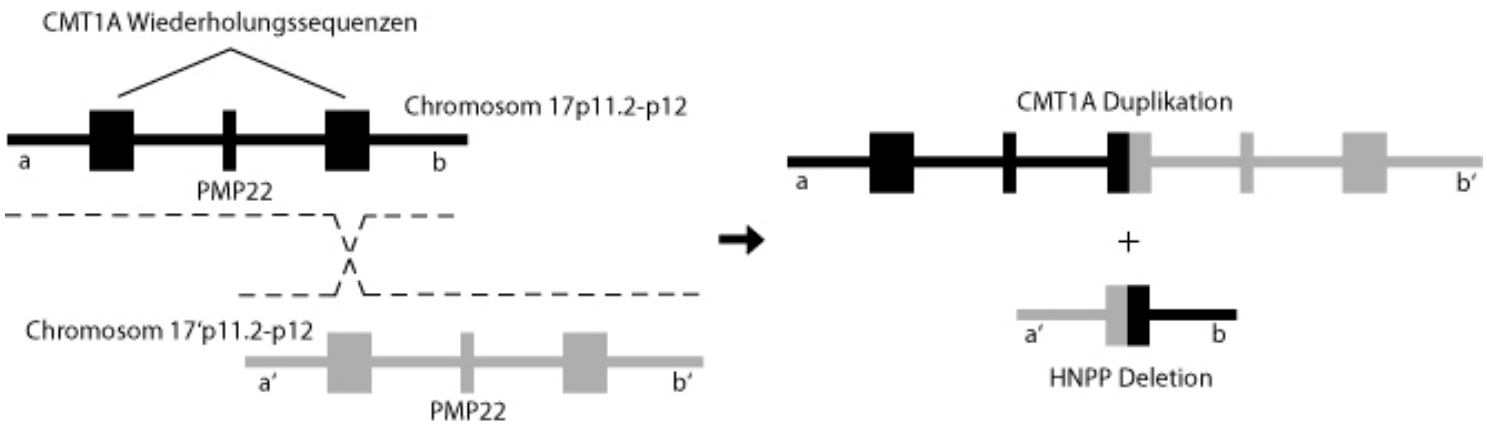

Abbildung 6: Schematische Darstellung des Rekombinations - hot spots auf Chromosom 17: PMP22 ist von hochgradig homologen Wiederholungssequenzen flankiert (CMT1A repeats), welche ein fehlerhaftes Anlagern der Nichtschwesterchromatiden während der Meiose begünstigen. Ein ungleiches Crossing Over generiert die CMT1A-Duplikation und die HNPP-Deletion. Nach Befruchtung enthält die Keimzelle demnach eine oder drei Kopien des PMP22-Gens (modifiziert nach Snipes et al., 1993).

PMP22 ist ein kleines, äußerst hydrophobes, integrales Membranprotein mit vier Transmembranhelices und zwei extrazellulären Schleifen, wovon eine glykosiliert ist. $\mathrm{N}$ - und C-Termini befinden sich im intrazellulären Medium (Abb. 7). PMP22 tendiert dazu mit sich selbst und mit MPZ (Myelin Protein Zero) zu dimerisieren (D'Urso et al., 1999; Tobler et al., 2002). Expressions- und biochemische Studien lassen eine Funktion von PMP22 als strukturelle Komponente im Myelin vermuten (Suter und Scherer, 2003). Darüber hinaus wurde für PMP22 eine funktionelle Beteiligung bei der Regulation von Zelldifferenzierung, Zellmigration und Apoptose von Schwannzellen beschrieben (Fabbretti et al., 1995; Brancolini et al., 1999, 2000; Sancho et al., 2001; Roux et al., 2005). Als früher Bestandteil der sich entwickelnden BlutNervensystemschranke in interzellulären Adhäsionskomplexen konnte PMP22 ebenfalls identifiziert werden (Notterpek et al., 2001; Roux et al., 2004). Eine initiale Rolle bei der Myelinisierung im PNS scheint PMP22 gleichermaßen zuzukommen, da genetisch modifizierte Mäuse ohne PMP22-Gen (knock out) einen verzögerten Beginn der Myelinisierung aufzeigen (Carenini et al., 1999). Als Tiermodell für die HNPP entwickeln diese Mäuse im Alter fokale, hypermyelinisierte Bereiche, sogenannte 
Tomaculae, welche im weiteren Verlauf degenerieren und zu Demyelinisierung führen (Adlkofer et al., 1995; Neuberg et al., 1999).

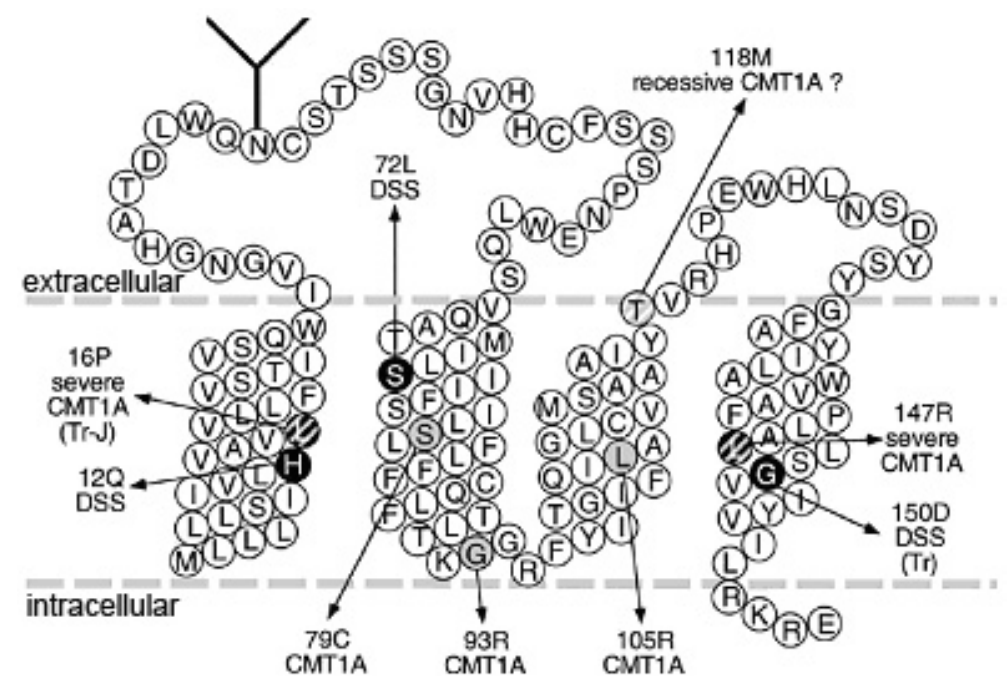

Abbildung 7: Das Periphere Myelin Protein 22kDa (PMP22). Das Protein besteht aus 160, vorwiegend hydrophoben Aminosäuren, welche sich über vier Transmembrandomänen in die Schwannzell-membran integrieren. Zwei Schleifen reichen in das extrazelluläre Medium, wobei die erste glykosiliert ist (Y-Form). C- und N-Termini reichen in den intrazellulären Raum. Die markierten Aminosäuren stellen mit ihren Pfeilbezeichnungen im Fall von Punktmutationen entsprechende CMT-Erkrankungen des Menschen dar (nach Naef und Suter, 1999).

\subsubsection{TIERMODELLE PMP22 ASSOZIIERTER NEUROPATHIEN}

Tiermodelle menschlicher Erkrankungen sind ein nützliches Werkzeug die zugrundeliegenden Pathomechanismen näher zu untersuchen. Für die vielen Subformen der CMT Erkrankung wurden zahlreiche genetisch modifizierte Nagetiermodelle entwickelt (Fledrich et al., 2012b). Im speziellen wurden transgene Mauslinien (Huxley et al., 1996, 1998; Magyar et al., 1996; Robertson et al., 2002) und eine Rattenlinie (Sereda et al., 1996) als Tiermodelle der CMT1A generiert, welche PMP22 überexprimieren. Die Korrelation der Pathologie mit der Gendosis spiegelt sich auch in diesen transgenen Nagetieren wieder. Gerade Tiermodelle mit einer leichten Überexpression von PMP22 zeigen Symptome, welchen denen von CMT1A-Patienten sehr ähnlich sind (Sereda et al. 1996, Huxley et al. 1998). Linien mit einer besonders starken Überexpression zeigen teilweise überhaupt keine Myelinisierung (Amyelinisierung) und sollten deswegen nicht als Tiermodell für die CMT1A verwendet werden (Fledrich et al., 2012b). Die von Sereda et al. (1996) generierte transgene PMP22 überexprimierenden Rattenlinie („CMT-Ratte“) zeigt die für die CMT1A typischen histologischen Charakteristika, wie Demyelinisierung und axonalen Verlust. Eine reduzierte Nervenleitgeschwindigkeit, reduzierte Amplituden der Muskelsummenaktionspotentiale (MSAP) sowie Muskelschwäche und -atrophie sind 
die Folgen (Sereda et. al 1996). Diese Ähnlichkeiten der Symptome mit der Pathologie betroffener Menschen prädisponieren die CMT-Ratte zu einem hervorragenden Tiermodell um die zugrundeliegenden Mechanismen der CMT1A auf zellulärer Ebene näher zu untersuchen.
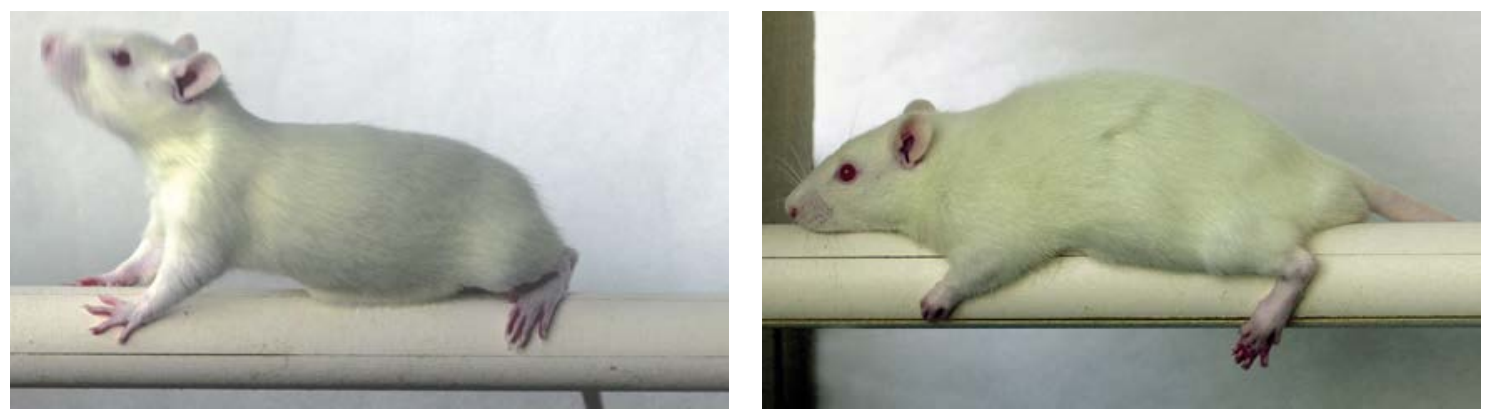

Abbildung 8: Pmp22 transgene Ratten sind ein Tiermodell für die humane CMT1A Erkrankung. Eine adulte Wildtypratte kann problemlos auf einer Stange laufen (links). Eine Pmp22 transgene Ratte (rechts) hingegen zeigt beim Stangentest Laufschwierigkeiten und kann sich nur kurze Zeit auf der Stange halten (modifiziert nach (Sereda et al., 2003)).

\subsubsection{ERKRANKUNGSMECHANISMEN UND THERAPEUTISCHE OPTIONEN}

Die Art und Schwere der Neuropathie bedingt die Anzahl der genomischen PMP22Kopien. Die PMP22-Gendosis korreliert mit deren mRNA-Expression, als auch mit der Schwere der CMT1A, was in Patienten auf mRNA- und Proteinebene gezeigt werden konnte (Hanemann et al., 1994; Yoshikawa et al., 1994; Vallat et al., 1996). Durch diesen Gendosiseffekt wird ein physiologisches Gen allein durch Überexpression zum pathologischen Krankheitsgen. Ein solches Konzept ist auch für ein Myelinprotein im ZNS bekannt. Eine veränderte Gendosis für das Proteolipid-Protein (PLP), welches strukturelle Ähnlichkeiten zu PMP22 aufweist (Popot et al., 1991; Inouye und Kirschner, 1994), führt zum Phänotyp der Pelizaeus-Merzbacher-Erkrankung, einer demyelinisierenden Erkrankung des ZNS (Ellis und Malcolm, 1994). Obwohl die konkreten molekularen Mechanismen der CMT1A noch weitestgehend unbekannt sind, gibt es verschiedene Hypothesen mit welchen versucht wird, die kausalen Zusammenhänge zwischen PMP22-Überexpression, Demyelinisierung und der damit einhergehenden axonalen Degeneration zu erklären (zusammengefasst von Niemann et al., 2006, sowie von Meyer zu Hörste et al., 2006). Als mögliche Ursachen, weshalb eine erhöhte PMP22-Gendosis zur Neuropathie führt, werden derzeit vor allem eine Fehlregulation der Schwannzellproliferation und -differenzierung und/oder der intrazellulären Sortierungsprozesse der Schwannzellen sowie ein gestörter Aufbau des Myelins diskutiert. PMP22 zeigt Dimerisierung und Oligomerisierung mit sich selbst und mit MPZ/P0 (D'Urso et al., 1999; Tobler et al., 2002). MPZ/P0 stellt mit ca. 50\% den 
größten Anteil aller Myelinproteine im PNS dar. Wie von der Aminosäuresequenz abgeleitet und in vitro und in vivo bestätigt, erfüllt dieses Protein vor allem strukturelle Aufgaben, wie die Verbindung benachbarter Myelinlamellen (Giese et al., 1992; Martini et al., 1995; Yin et al., 2000). Es ist deshalb vorstellbar, dass sich im Fall der CMT1A eine erhöhte Abundanz an PMP22 in Schwannzellen (Vallat et al., 1996) auch auf MPZ/PO auswirkt und deshalb eine Veränderung der fein abgestimmten Stöchiometrie beider Interaktionspartner einen negativen Einfluss auf die strukturelle Assemblierung der Myelinscheide hat (Snipes and Suter, 1995; D'Urso et al., 1999).

Verschiedene intrazelluläre Sortierungsprozesse wurden mit PMP22 assoziiert. So konnte bei Überexpression in Schwannzellkulturen gezeigt werden, dass der intrazelluläre Membrantransport gestört ist und PMP22 in Endosomen akkumuliert (Chies et al., 2003). In ähnlichen Experimenten wurde PMP22 in Aggresomen Zusammenschlüsse missgefalteter Proteine, Chaperone und Proteasomen nachgewiesen, welche sich auch nach Inhibition proteasomaler Abbauwege in Schwannzellen bildeten (Notterpek et al., 1999). Es wäre vorstellbar, dass diese Proteinaggregate toxisch oder als mechanisch-chemische Störung des normalen Proteintransports wirken. Des Weiteren konnte im Tiermodell gezeigt werden, dass bei Überexpression von PMP22 vermehrt Lysosomen in peripheren Nerven zu finden sind (Sereda, 1999). Beide Protein-abbauende Wege, über Lysosomen und Proteasomen, werden also durch die PMP22 Überexpression aktiviert.

Eine Behinderung der Differenzierung von Schwannzellen konnte in Mäusen mit hoher Pmp22 Überexpression nachgewiesen werden (Magyar et al., 1996), während Proliferation und Apoptose dieser Zellen gesteigert wird (Sancho et al., 2001). Auch die „Zwiebelschalenformationen“, bei welchen sich pathologischerweise mehrere Schwannzellen konzentrisch mit ihren Fortsätzen um ein Axon lagern (Abb. 5), können als fehlerhafte Differenzierung interpretiert werden, da sie Marker promyelinisierender, undifferenzierter Schwannzellen exprimieren (Guénard et al., 1996).

Die primäre Pathologie der CMT1A äußert sich in der Demyelinisierung peripherer Nerven. Die klinischen Symptome dieser Krankheit werden jedoch durch einen axonalen Verlust und der damit einhergehenden ausbleibenden Muskelinnervation verursacht (s.o.). Es stellt sich die Frage, ob und wenn ja warum eine Demyelinisierung die Axone schädigt. In Nerven von sogenannten „trembler-Mäusen“, welche eine natürlich vorkommende Pmp22-Mutation tragen, wie auch in PMP22überexprimierenden Ratten (s.u.) wurde eine gesteigerte Dichte und eine verminderte Phosphorylierung von axonalen Neurofilamenten und eine Reduktion des axonalen Transports festgestellt (de Waegh et al., 1992; Grandis et al., 2004). In 
Xenotransplantationsversuchen wurde demonstriert, dass Schwannzellen von CMT1APatienten übertragen auf gesunde Axone deren Struktur verändern (Sahenk et al., 1999). In diesen Experimenten wurde eine erhöhte Neurofilamentdichte, sowie eine Degeneration der distalen Axonanteile veranschaulicht. Eine erhöhte Abundanz an axonalen Neurofilamenten, welche zudem in geringerem Maße phosphoryliert sind, kann den axonalen Transport beeinträchtigen (Brownlees et al., 2002; Pérez-Ollé et al., 2005; Sasaki et al., 2006). In diesem Fall wäre es möglich, dass z.B. die Transportbehinderung von Mitochondrien zu einem Energiemangel der Axone distaler Muskelgruppen und folglich zu dessen Degeneration führt. Tatsächlich wurden Punktmutationen zweier Gene, welche am mitochondrialen Transport beteiligt sind, mit der CMT2A assoziert (Zhao et al., 2001; Züchner et al., 2004). Eine solche Hypothese einer verschlechterten Energieversorgung wäre eine Erklärung für die distale Betonung der CMT1A. Bedingt durch die langen Transportwege sind die langen Axone distaler Muskelgruppen besonders anfällig für eine Beeinträchtigung des Transports und degenerieren deshalb zuerst. 


\subsection{ZIELSTELLUNG DER DISSERTATION}

Die Ursachen für die unvollständige Remyelinisierung nach einer Nervenverletzung im PNS sind noch weitestgehend unverstanden. Als mögliche zugrundeliegende Faktoren werden insbesondere eine fehlende Stimulation von Schwannzellen durch proregenerative Signale oder inhibitorische Faktoren diskutiert (Sherman and Brophy, 2005). Die Identifikation solcher Signale könnte helfen neue therapeutische Optionen bei akuten Nervenschädigungen zu entwickeln. Darüber hinaus könnten solche Faktoren auch die Regenerationsfähigkeit bei chronischen Nervenschädigungen, wie bei der immer noch unheilbaren CMT1A Erkrankung, fördern.

Inwiefern sind dedifferenzierte Schwannzellen nach Nervenläsion mit Schwannzellen erkrankter CMT1A Patienten vergleichbar? Aus der Literatur ist bekannt, dass dedifferenzierte Schwannzellen nach einer akuten Nervenverletzung bestimmte Gene exprimieren (z.B. cJUN) deren Proteine auch in Schwannzellen von CMT1A Patienten detektiert werden konnten (Hutton et al., 2011). Durch eigene Genexpressionsprofilanalysen (microarrays) mit Pmp22 transgenen und wildtypischen Ratten konnten in mRNA Extrakten aus Ischiasnervgewebe eine Vielzahl differentiell regulierter Gene identifiziert werden (Fledrich et al., 2012a). Hierbei wurde unter anderem ein erhöhtes mRNA Level von Neuregulin-1 (Nrg1) in Pmp22 überexprimierenden Schwannzellen festgestellt; ein Befund der auch für dedifferenzierte Schwannzellen bei akuter Nervenschädigung zutrifft (Carroll et al., 1997).

Die funktionelle Analyse des eigentlich neuronalen Wachstumsfaktors NRG1 in Gliazellen des PNS bei akuter und chronischer Nervenschädigung sowie eine Untersuchung des therapeutischen Potentials von NRG1 ist Gegenstand der vorliegenden Dissertation. 
2. Material und Methoden

\subsection{Chemikalien und ReAgenZIEN}

Agarose

Ammoniumacetat

Azur-II-Farbstoff

Bromphenolblau

Beta-Mercaptoethanol

Chloroform

DDSA (2-Duodecenyl-succinicacidanhydrid)

DMP30 (2,4,6-tris-dimethylaminomethyl-Phenol)

DTT (1,4-Dithiotreitol)

Essigsäure

EDTA (Ethylendiamintetraacetat)

Ethanol

Ethidiumbromid

„Ficoll (Typ 400)“

Glutardialdehyd

HBSS (Hanks Balanced Salts Solution)

Isopropanol

Kaliumchlorid $(\mathrm{KCl})$

Ketamin (Ketanest $₫$ )

Lidocain, Salbe $2 \%$

Methylenblau

Dinatriumhydrogenphosphat $\left(\mathrm{Na}_{2} \mathrm{HPO}_{4}\right)$

Dinatriumhydrogenphosphat-2-hydrat

$\left(\mathrm{Na}_{2} \mathrm{HPO}_{4} * 2 \mathrm{H}_{2} \mathrm{O}\right)$

Natriumchlorid $(\mathrm{NaCl})$

Natriumdihydrogenphosphat-hydrat

$\left(\mathrm{NaH}_{2} \mathrm{PO}_{4}{ }^{*} \mathrm{H}_{2} \mathrm{O}\right)$

Natriumhydroxid $(\mathrm{NaOH})$

Osmiumtetroxid

Paraformaldehyd

Pellet Paint ${ }^{\mathrm{TM}}$

Propylenoxid

Salzsäure $(\mathrm{HCl})$
Bio-Rad, Hercules, CA, USA

Merck, Darmstadt

Merck, Darmstadt

International Biotechnology Inc.

Merck, Darmstadt

Merck, Darmstadt

Serva, Heidelberg

Serva, Heidelberg

GibcoBRL, Karlsruhe

Merck, Darmstadt

Merck, Darmstadt

Merck, Darmstadt

Sigma-Aldrich, Schnelldorf

Sigma-Aldrich, Schnelldorf

Merck, Darmstadt

GibcoBRL, Karlsruhe

Merck, Darmstad

Merck, Darmstadt

Parke-Davis, Berlin

Merck, Darmstadt

Merck, Darmstadt

Merck, Darmstadt

Merck, Darmstadt

Merck, Darmstadt

Merck, Darmstadt

Merck, Darmstadt

Serva, Heidelberg

Serva, Heidelberg

Merck, Darmstadt

Serva, Heidelberg

Serva, Heidelberg 
Sodium-Dodecyl-Sulfat (SDS)

Taq-Polymerase Puffer

Tris- $\mathrm{HCl}$ Base

Xylencyanol

Xylol

Xylazin (Rompun®)
Sigma-Aldrich, Schnelldorf

Promega, Mannheim

Sigma-Aldrich, Schnelldorf

Merck, Darmstadt

Merck, Darmstadt

Bayer, Leverkusen

\subsubsection{VERBRAUCHSMATERIALIEN}

$\mathrm{CO}_{2}$-Gas

Einmalhandschuhe

Eppendorfgefäße

Falconröhrchen, Größe: 15ml, $50 \mathrm{ml}$

histologisches Einschlussmittel „Eukitt“

Injektionskanülen

Kosmetiktücher

Nahtmaterial

Objektträger

PCR-Mikrotiterplatten

PCR-Plattenfolie „Air Pore Sheet”

Pipettenspitzen

Präparationsbesteck

Rattenstandarddiät „Ssniff R/M-H V1535“

Spritzen „Normlnjekt“, Größe : 1ml

Stickstoff, flüssig

Transferpipetten

Trockeneis

Weichholzgranulateinstreu „Bedding S8/15“
Messer-Griesheim, Krefeld

Hartmann, Heidenheim

Eppendorf, Hamburg

Becton \& Dickinson

Le Pont De Claix, Frankreich

Kindler, Freiburg

Becton \& Dickinson

Le Pont De Claix, Frankreich

Wepa professional, Arnsberg

Braun, Tuttlingen

Menzel-Gläser, Braunschweig

ABgene, Surrey, UK

ABgene, Surrey, UK

Molecular Bioproducts,

San Diego, CA, USA

Fine Science Tools, Heidelberg

Ssniff Spezialdiäten, Soest

Henke Saas Wolf, Tuttlingen

Messer-Griesheim, Krefeld

Bio-Rad, Hercules, CA, USA

Messer-Griesheim, Krefeld

Ssniff Spezialdiäten, Soest 


\subsubsection{GERÄTE}

7500 Real-Time PCR System

Agarose Gelekammer mit Kämmen

Agarosegeldokumentation „ImageMaster VDS“

Agilent Bioanalyzer 2100

Diamantmesser „Semithin Diamond Knife 45 “

Feinwaage, digital

Fräse für Epon-Präparate

Gefrierschrank $-20^{\circ} \mathrm{C}$

Gefrierschrank $-80^{\circ} \mathrm{C}$

Nürtingen

Gelladestation für Agilent Bioanalyzer

Gewebe-Einbettautomat "Lynx el”

Gewebehomogenisierer „Ultraturrax T8“

Glaswaren

Griffstärkemesser (incl. Newtonmeter)

Lightcycler 480

Magnetrührer

Mikroskop „Leica DM RXA2“

PCR-Thermocycler „T3“

PCR-Versiegler „Combi Thermosealer“

Peristaltikpumpe

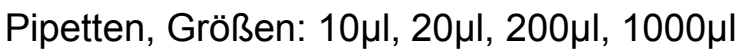

Reinstwasseranlage „SeralPur Pro 90 CN“

Rotationsmikrotom „Leica RM 2155“

Spannungsgeräte Elektrophorese

Spektralphotometer

Thermomixer
Applied Biosystems

Hauswerkstatt MPI exp. Med

Amersham Pharmacia Biotech,

Freiburg

Agilent Technologies, Böblingen

Diatome U.S.,

Fort Washington, PA, USA

Heraeus Instruments,

Langenselbold

Reichert, Wien, Österreich

Liebherr, Ochsenhausen

New Brunswick Scentific,

Agilent Technologies, Böblingen

Vision BioSystems Inc,

Norwell, MA USA

IKA Labortechnik, Staufen

Schott, Mainz

Hauswerkstatt MPI exp. Med.

Roche

Omnilab, Bremen

Leica Microsystems, Wetzlar

Biometra, Göttingen

Advanced Biotechnologies,

Surrey, UK

Heraeus Instruments,

Langenselbold

Gilson, Villiers-le-Bel, Frankreich

Seral, Ransbach

Leica Microsystems, Wetzlar

Amersham Pharmacia Biotech,

Freiburg

Amersham Pharmacia Biotech,

Freiburg

Eppendorf, Hamburg 
Tierkäfige Ratten

Trocknungszentrifuge „Speed Vac“

UV-Illuminator

Videomikroskopie-Kamera

Probenmischgerät „Vortexer“

Zentrifuge „Laboratory Centrifuge 4K15“

Zentrifuge „Heraeus Biofuge 13“
Tecniplast, Buguggiate, Italien

Eppendorf, Hamburg

Amersham Pharmacia Biotech,

Freiburg

Hamamatsu, Herrsching

Bender \& Hobein, München

Sigma Laborzentrifugen,

Osterode am Harz

Heraeus Instruments,

Langenselbold

\subsubsection{PUFFER UND LÖSUNGEN}

\section{DNA-Probenpuffer}

$\begin{array}{ll}\text { Bromphenolblau } & 0,25 \% \\ \text { Xylenxyanol } & 0,25 \% \\ \text { „Ficoll (Typ 400)“ } & 15 \% \text { in } \mathrm{H}_{2} \mathrm{O}\end{array}$

PBS (phosphat-gepufferte Salzlösung (10X Stammlösung, 1000 ml)

$\begin{array}{lc}\mathrm{NaCl} & 100 \mathrm{~g} \\ \mathrm{KCl} & 2,5 \mathrm{~g} \\ \mathrm{Na}_{2} \mathrm{HPO}_{4}{ }^{*} 2 \mathrm{H}_{2} \mathrm{O} & 7,2 \mathrm{~g} \\ \mathrm{KH}_{2} \mathrm{PO}_{4} & 2,5 \mathrm{~g} \\ \text { auf } 900 \mathrm{ml} \text { mit } \mathrm{H}_{2} \mathrm{O} \text { auffüllen; } \mathrm{pH} 7,2 \text { mit } 10 \mathrm{~N} \mathrm{NaOH} \text { einstellen; auf } 1000 \mathrm{ml} \text { mit } \\ \mathrm{H}_{2} \mathrm{O} \text { auffüllen; autoklavieren; zur Verwendung die Stammlösung 1:10 } \\ \text { verdünnen (1x PBS) }\end{array}$

TAE-Puffer (50x, 1000ml)

Tris- $\mathrm{HCl}$ Base

Essigsäure $100 \%$

$\operatorname{EDTA}(0,5 \mathrm{M} \mathrm{pH} 8)$

auf $1000 \mathrm{ml}$ mit $\mathrm{H}_{2} \mathrm{O}$ auffüllen
$242 \mathrm{~g}$

$57,1 \mathrm{ml}$

$100 \mathrm{ml}$ 
Fixanz für Licht- und Elektronenmikroskopie nach Karlsson und Schultz , pH 7,5 (1965, Elektronenmikroskopie)

$\begin{array}{ll}\text { Natriumdihydrogenphosphat } \times \mathrm{H}_{2} \mathrm{O} & 0,36 \mathrm{~g} \\ \text { Dinatriumhydrogenphosphat } \times 2 \mathrm{H}_{2} \mathrm{O} & 3,1 \mathrm{~g} \\ \mathrm{NaCl} & 1 \mathrm{~g} \\ \text { Glutardialdehydlösung } & 20 \mathrm{ml} \\ \text { Paraformaldehyd (PFA) } & 8 \mathrm{~g}\end{array}$

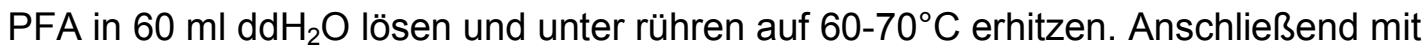
$\mathrm{ddH}_{2} \mathrm{O}$ auf $80 \mathrm{ml}$ auffüllen. Tröpfchenweise $1 \mathrm{M} \mathrm{NaOH}$ zugeben bis Lösung klar wird.

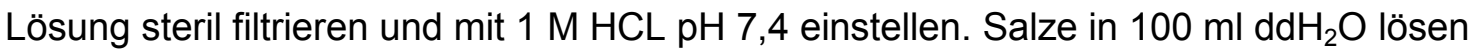
und zu PFA geben. Glutardialdehydlösung zugeben.

Kunstharzmischung Epon (Luft 1961)

Epon Lösung $A$ :

Glycidether

DDSA

eine Stunde mit Magnetrührer rühren

Epon Lösung B:

Glycidether

MNA

eine Stunde mit Magnetrührer rühren

Gebrauchslösung Epon:

Epon Lösungen A + B im Verhältnis 1 : 1 mischen; 1,8\% DMP30 zugeben

Methylen-Azur-II-Färbelösung (Richardson et al. 1960)

Methylenblau-Lösung: 1\% Methylenblau in 1\% wässriger Boraxlösung

Azur-II-Lösung: $1 \%$ Azur II in $\mathrm{H}_{2} \mathrm{O}$

beide Lösungen in einem Verhältnis von 1:1 mischen.

\section{Narkoselösung}

$\begin{array}{ll}\text { Ketamin }(10 \%) & 0,75 \mathrm{ml} \\ \text { Xylazin }(2 \%) & 0,2 \mathrm{ml} \\ \mathrm{NaCl}(0,9 \%) & 9,05 \mathrm{ml}\end{array}$


Laufpuffer für Polyacrylamidgele (20x):

$\begin{array}{ll}\text { MOPS } & 1 \mathrm{M} \\ \text { Tris Base } & 1 \mathrm{M} \\ \text { SDS } & 69,3 \mathrm{mM} \\ \text { EDTA } & 20,5 \mathrm{mM}\end{array}$

Lysepuffer für Proteinlysaten aus Ischiasnerven:

$\begin{array}{ll}\text { Sucrose } & 320 \mathrm{mM} \\ \text { Tris } & 10 \mathrm{mM} \\ \mathrm{NaHCO} 3 & 1 \mathrm{mM} \\ \mathrm{MgCl}_{2} & 1 \mathrm{mM}\end{array}$

Proteinase-Hemmer (Complete, Roche) und Phosphatase-Hemmer (PhosSTOP, Roche), je 1 Tablette für 10 ml Lösung.

Protein-Probenpuffer (2x):

Glyzerin

SDS

Bromphenolblau

Tris-Base
$20 \%$

$4,6 \%$

$0,4 \%$

$125 \mathrm{mM}$

auf $50 \mathrm{ml}$ mit ddH2O auffüllen $\mathrm{pH}$ 6,8

zu $20 \mu$ l Probenpuffer vor Probenzugabe $1 \mu$ l ß-Mercaptoethanol (5\%) zugeben

SDS-Sammelgelpuffer $(250 \mathrm{ml})$ :

Tris-Base

SDS $(20 \%)$
$15,15 \mathrm{~g}(0,5 \mathrm{M})$

$5 \mathrm{ml}(0,4 \%)$

auf $250 \mathrm{ml}$ mit ddH2O auffüllen, $\mathrm{pH}$ 6,8 mit $\mathrm{HCl}$ einstellen

SDS-Trenngelpuffer $(250 \mathrm{ml})$ :
Tris-Base
$45,42 \mathrm{~g}(1,5 \mathrm{M})$
SDS $(20 \%)$
$5 \mathrm{ml}(0,4 \%)$

auf $250 \mathrm{ml}$ mit ddH2O auffüllen, $\mathrm{pH} 8,8$ mit $\mathrm{HCl}$ einstellen

\section{Waschpuffer:}

PBS 
Western Blot-Puffer (1000 ml):

$\begin{array}{ll}\text { Methanol } & 20 \% \mathrm{v} / \mathrm{v} \mathrm{pH} \mathrm{9,2} \\ \text { Tris-Base } & 48 \mathrm{mM} \\ \text { Glyzin } & 39 \mathrm{mM} \\ \text { SDS } & 0,1 \%\end{array}$

auf $1000 \mathrm{ml}$ mit ddH2O auffüllen

\subsubsection{ENZYME UND REAKTIONSKOMPLETTSYSTEME}

\subsubsection{Enzyme}

Proteinase $\mathrm{K}$

Taq-DNA-Polymerase ( $5 \mathrm{U} / \mu \mathrm{l})$

\subsubsection{Reaktionskomplettsysteme}

„DNeasy 96“ Kit für DNA-Isolation

„RNA 6000 Nano“ Assay

"RNeasy Mini Kit” für RNA Isolation

„Superscript III RT“-Kit

„Power Sybr ${ }^{\circledR}$ Green PCR Master Mix”

„TRIzol“ Reagent

\subsubsection{NUKLEINSÄUREN}

Desoxyribonukleosid-Triphosphate (dNTPs)

DNA-Größenmarker „Lambda/HindIII“

DNA-Größenmarker „PhiX174/Haelll“

randomisierte Nonamerprimer
Boehringer, Mannheim

Boehringer, Mannheim

Qiagen, Hilden

Agilent Technologies, Böblingen

Quiagen, Hilden

Invitrogen, Carlsbad, USA

Applied Biosystems, UK

GibcoBRL, Karlsruhe

Boehringer, Mannheim

Promega, Mannheim

Promega, Mannheim

F. Benseler, MPI für exp. Med.

\subsubsection{OLIGONUKLEOTIDE}

Primeroligonukleotide wurden mit Ausnahme der Genotypisierungsprimer (bereits vorhanden) mit Hilfe der Internet-basierten, von der Firma Roche Applied Science zur Verfügung gestellten Software „Universal ProbeLibrary Assay Design Center“ entworfen, anhand der Software "Oligo Analyzer" (Teemu Kuulasmaa, 2009) gegengeprüft und von F. Benseler (Abt. 501 des MPI für exp. Medizin, Göttingen) synthetisiert. 
Primer zur Genotypisierung transgener Ratten:

$\begin{array}{lll}\text { Pmp22 tg (Rattus) } & \text { s } & \text { 5'-CCAGAAAGCCAGGGAACTC -3' } \\ & \text { as } & \text { 5'-GACAAACCCCAGACAGTTG -3' } \\ \text { Pmp22 tg (Mus) } & \text { s } & \text { 5'-TCAGGATATCTATCTGATTCTC -3' } \\ & \text { as } & \text { 5'-AAGCTCATGGAGCACAAAACC -3' } \\ \text { Pmp22 }{ }^{+-} \text {(Mus) } & \text { s } & \text { 5'-GCATCGAGCGAGCACGTAC -3' } \\ & \text { as } & \text { 5'-ACGGGTAGCCAACGCTATGTC -3' } \\ \text { Nrg1(I) tg (Mus) } & \text { s } & \text { 5'-CTGGTAGAGCTCCTCCGCTTC -3' } \\ & \text { as } & \text { 5'-TGGCAAAGGACCTTAGGCAGTGT -3' } \\ \text { Nrg1(III) tg (Mus) } & \text { s } & \text { 5'-CGATAAGTTTAGGAGCAGTTTGCAG -3' } \\ & \text { as } & \text { 5'-TGGCAAAGGACCTTAGGCAGTGT -3' }\end{array}$

Primer für qPCR:

\begin{tabular}{|c|c|c|}
\hline \multirow[t]{2}{*}{$\operatorname{Nrg1}(I)$ (Mus) } & $s$ & 5'-GGGAAGGGCAAGAAGAAGG -3' \\
\hline & as & 5'-TTTCACACCGAAGCACGAGC -3' \\
\hline \multirow[t]{2}{*}{$\operatorname{Nrg1(II)~(Mus)~}$} & s & 5'-CCTCGTTTCCTCCGCTG -3' \\
\hline & as & 5'-GACTCCTGGCTTTTCATCTCTT -3' \\
\hline \multirow[t]{2}{*}{$\operatorname{Nrg1(III)~(Mus)~}$} & s & 5'- ACTCAGCCACAAACAACAGAAAC-3' \\
\hline & as & 5'- GAAGCACTCGCCTCCATT-3' \\
\hline \multirow[t]{2}{*}{ Nrg1 (Rattus) } & $\mathrm{s}$ & 5'- ATGCCAGAGAAACCCCTGA-3' \\
\hline & as & 5'- GGTGGTCATGGCTGATACATAC-3' \\
\hline \multirow[t]{2}{*}{ RplpO (Rattus) } & s & 5'-GATGCCCAGGGAAGACAG -3' \\
\hline & as & 5'-CACAATGAAGCATTTTGGGTAG -3' \\
\hline \multirow[t]{2}{*}{ RplpO (Mus) } & $s$ & 5'-GATGCCCAGGGAAGACAG -3' \\
\hline & as & 5'-ACAATGAAGCATTTTGGATAATCA -3' \\
\hline \multirow[t]{2}{*}{ Ppia (Rattus) } & $\mathrm{s}$ & 5'-AGCACTGGGGAGAAAGGATT -3' \\
\hline & as & 5'-AGCCACTCAGTCTTGGCAGT -3' \\
\hline \multirow[t]{2}{*}{ Ppia (Mus) } & s & 5'-CACAAACGGTTCCCAGTTTT -3' \\
\hline & as & 5'-TTCCCAAAGACCACATGCTT -3' \\
\hline \multirow[t]{2}{*}{ Hmgcr (Rattus) } & s & 5'-CAACCTTCTACCTCAGCAAGC -3' \\
\hline & as & 5'-CACAGTGCCACACACAATTCG -3' \\
\hline \multirow[t]{2}{*}{ Hmgcr (Mus) } & s & 5'-CAACCTTCTACCTCAGCAAGC -3' \\
\hline & as & 5'-CACAGTGCCACATACAATTCG -3' \\
\hline \multirow[t]{2}{*}{ Prx (Rattus) } & $\mathrm{s}$ & 5'-GAGCCTCAGTTTGCAGGAAG -3' \\
\hline & as & 5'-TTGTAGGGCTCGGCACAT -3' \\
\hline
\end{tabular}




\begin{tabular}{|c|c|c|}
\hline \multirow[t]{2}{*}{$\operatorname{Prx}($ Mus) } & s & 5'-GCCCCCAGGTGACTCTCT -3' \\
\hline & as & 5'-CTCCACGATAATCTCCACCAA -3' \\
\hline \multirow[t]{2}{*}{ Mpz (Rattus) } & $\mathrm{s}$ & 5'-GTCCAGTGAATGGGTCTCAGATG -3' \\
\hline & as & 5'-CTTGGCATAGTGGAAGATTGAAA -3' \\
\hline \multirow[t]{2}{*}{ Mpz (Mus) } & $\mathrm{s}$ & 5'-GTCCAGTGAATGGGTCTCAGATG -3' \\
\hline & as & 5'-CTTGGCATAGTGGAAAATCGAAA -3' \\
\hline \multirow[t]{2}{*}{ Egr2 (Rattus) } & s & 5'-CTACCCGGTGGAAGACCTC -3' \\
\hline & as & 5'-TCAATGTTGATCATGCCATCTC -3' \\
\hline \multirow[t]{2}{*}{ Egr2 (Mus) } & s & 5'-CAGTTCAACСССТСТCСАAA -3' \\
\hline & as & 5'-ACCGGGTAGAGGCTGTCA -3' \\
\hline \multirow[t]{2}{*}{ Pou3f1 (Mus/Rattus) } & s & 5'-GCGTGTCTGGTTCTGCAAC -3' \\
\hline & as & 5'-AGGCGCATAAACGTCGTC -3' \\
\hline \multirow[t]{2}{*}{ p75NTR (Rattus) } & $\mathrm{s}$ & 5'-GGTTGCCATCACCCTTGA -3' \\
\hline & as & 5'-GACAGCGGCATCTCTGTG -3' \\
\hline \multirow[t]{2}{*}{ p75NTR (Mus) } & $\mathrm{s}$ & 5'-CGGTGTGCGAGGACACTGAGC -3' \\
\hline & as & 5'-TGGGTGCTGGGTGTTGTGACG -3' \\
\hline \multirow[t]{2}{*}{ Notch1 (Rattus) } & $\mathrm{s}$ & 5'-GTCATCCTCGCAATGCTTC -3' \\
\hline & as & 5'-GAGGCTCCACCGTCTCAC -3' \\
\hline \multirow[t]{2}{*}{ c-Jun (Mus/Rattus) } & $\mathrm{s}$ & 5'-CCTTCTACGACGATGCCCTC -3' \\
\hline & as & 5'-GGTTCAAGGTCATGCTCTGTTT -3' \\
\hline \multirow[t]{2}{*}{ Sox2 (Mus/Rattus) } & $\mathrm{s}$ & 5'-TCCAAAAACTAATCACAACAATCG -3' \\
\hline & as & 5'-GAAGTGCAATTGGGATGAAAA -3' \\
\hline
\end{tabular}

\subsubsection{ANTIKÖRPER}

Primärantikörper:

Anti-MPZ (polyklonal Kaninchen, 1:250)

J. Archelos, Würzburg

Anti-NRG1 (polyklonal Kaninchen, 1:250)

Santa Cruz SC-348, Heidelberg

Anti-cJUN (monoklonal Maus, 1:500)

$\mathrm{BD}$, Pharmingen

Anti-SOX2 (monoclonal Maus, 1:500)

Calbiochem

Anti-pErbB2 (polyclonal Kaninchen, 1:500)

Santa Cruz

Anti-ErbB2 (polyclonal Kaninchen, 1:500)

Santa Cruz

Anti-pERK1/2 (polyklonal Kaninchen, 1:1000)

Cell Signaling

Anti-ERK1/2 (polyklonal Kaninchen, 1:1000)

Cell Signaling

Anti-pAKT(polyklonal Kaninchen, 1:1000)

Cell Signaling

Anti-AKT (polyklonal Kaninchen, 1:1000)

Cell Signaling

Anti-Tubulin (monoklonal Maus, 1:5000)

Sigma-Aldrich, Schnelldorf

Anti-GAPDH (monoklonal Maus, 1:5000)

Sigma-Aldrich, Schnelldorf 
Sekundärantikörper:

Cy2-gekoppelt-anti-Kaninchen (Ziege, 1:1000) Jackson Immu. Res., Newmarket, UK Cy2-gekoppelt-anti-Maus (Ziege, 1:1000) Jackson Immu. Res., Newmarket, UK Cy3-gekoppelt-anti-Kaninchen (Ziege, 1:1000) Jackson Immu. Res., Newmarket, UK Cy3-gekoppelt-anti-Maus (Ziege, 1:1000) Jackson Immu. Res., Newmarket, UK HRP-anti-Kaninchen (Ziege, 1:1000) Jackson Immu. Res., Newmarket, UK

HRP-anti-Maus (Ziege, 1:1000) Jackson Immu. Res., Newmarket, UK

\subsubsection{VERSUCHSTIERE}

Wildtyp-Ratten vom Stamm Sprague-Dawley.

PMP22-transgene Ratten („CMT-Ratten“) nach Sereda et al. (1996).

Für Experimente mit Mäusen wurden Tiere mit dem Hintergrund C57/B6 verwendet. Im Detail wurden folgende genetisch modifizierte Mäuse verwendet:

- Pmp22 transgene Mäuse aus der C61 Linie (Huxley et al., 1998)

- C57BI6-Tg(Thy1-Nrg1*I)1Kan+/- (=Nrg1(I), Michailov et al., 2004)

- C57BI6-Tg(Thy1-Nrg1*III)1Kan+/- (=Nrg1(III), Michailov et al., 2004)

- C57BI6-Tg(Dhh-cre)1Mejr (=Dhh ${ }^{\text {Cre }}$, Jaegle et al., 2003)

- C57Bl6 - $\left(\mathrm{Nrg1}^{\mathrm{tm} 2 \mathrm{Cbm}}\right)\left(=\mathrm{Nrg1} 1^{\mathrm{flffl}}\right.$, Li et al., 2002)

Genetische Nullmutanten für Nrg1 in Schwannzellen wurden $D h h^{\text {Cre }}$ Mäuse mit $N r g 1^{f / f t l}$ Mutanten verpaart.

\subsubsection{COMPUTERSOFTWARE}

7500 Fast System SDS Software

Excel 2010

geNorm 3.5

GraphPad PRISM

Illustrator 13.0.2

Image J $1.40 \mathrm{~g}$

Oligo Analyzer 1.1.2

Openlab 2.1

Photoshop 10.0.1

qBase 1.3.5
Applied Biosystems, UK

Microsoft Europe, Berlin

Center for Medical Genetics,

Ghent, Belgien

(Vandesompele et al., 2002)

Graphpad Software, Inc.

Adobe Systems Software

Saggart, Irland

$\mathrm{NIH}$, USA

Teemu Kuulasmaa, Kuopio, Finnland Improvision, Heidelberg

Adobe Systems Software

Saggart, Irland

Center for Medical Genetics, Belgium

Ghent, Belgien (Hellemans et al., 2007) 
Statistica 10.0

Universal Probe Library Assay Design Center

Word 2010
StatSoft Europe, Hamburg

Roche Applied Science, Mannheim

Microsoft Europe, Berlin 


\subsection{METHODEN}

\subsubsection{HANDHABUNG UND ANALYSE VON VERSUCHSTIEREN}

\subsubsection{Zucht von Versuchstieren}

Im Zuge der Arbeit wurden ausschließliche männliche Ratten der Linie SpragueDawley und C57/B6-Mäuse beiderlei Geschlechts aus der Zucht des MPI für experimentelle Medizin verwendet. Mäuse und Ratten wurden mittels Polymerasekettenreaktion (PCR) auf genomische DNA aus Gewebebiopsien (s.u.) genotypisiert.

\subsubsection{Tierhaltung}

Die Tierhaltung erfolgte unter standardisierten Bedingungen im Tierhaus des MPI für experimentelle Medizin entsprechend den Empfehlungen der deutschen Gesellschaft für Versuchstierkunde.

\subsubsection{Identifikation der Tiere}

Zur Genotypisierung der Tiere wurde eine Schwanzbiopsie entnommen. Dies erfolgte im Alter von 18 Tagen unter leichter $\mathrm{CO}_{2}$-Narkose gleichzeitig mit der Markierung der Tiere mittels Ohrstanzung. Es wurde ein $3 \mathrm{~mm}$ langes Stück der Schwanzspitze entfernt und bis zur weiteren Verwendung (s.u.) in einem Eppendorffgefäß auf $-20^{\circ} \mathrm{C}$ gelagert. In einem Zuchtprotokoll wurden für jeden Wurf die Anzahl der Nachkommen, das Geburtsdatum, das Geschlecht der Einzeltiere, die Identifikationsnummern der Elterntiere und eventuelle Auffälligkeiten notiert.

Zur Verwaltung der Zucht wurde das Tierdatenbankprogramm PyRAT (Scionics Computer Innovation $\mathrm{GmbH}$ ) verwendet.

\subsubsection{Narkotisierung und Tötung von Versuchstieren}

Für die Durchführung der Nervenkompression-Operation erhielten Mäuse eine Injektionsnarkose durch intraperitoneale Injektion einer Kombination aus $5 \mathrm{mg} / \mathrm{kg}$ Körpergewicht Ketamin (Ketanest ${ }^{\circledR}$ ) und 2 mg/kg Körpergewicht Xylazin (Rompun ${ }^{\circledR}$ ). Für kleinere Eingriffe wie Schwanzbiopsien erhielten die Mäuse/Ratten eine Inhalationsnarkose mit $\mathrm{CO}_{2}$ durch kurzes Einbringen in ein mit $\mathrm{CO}_{2}$ gefülltes Glasgefäß. Für eine histologische Probengewinnung, die eine Perfusion erforderte, wurden die Tiere durch Einleiten von $\mathrm{CO}_{2}$ in einen gasundurchlässigen Käfig getötet. 


\subsubsection{Nervenkompressionsmodel}

Eine experimentelle Nervenläsion wurde bei Mäusen im Alter von 3 Monaten durchgeführt.

Nach Applikation einer Injektionsnarkose (s.o.) wurde die Hautfläche im Bereich des rechten proximal-lateralen Oberschenkels rasiert und desinfiziert. Mit einem Skalpell wurde anschließend in Verlaufsrichtung des $N$. ischiadicus eine $0,8 \mathrm{~cm}$ lange Inzisur gesetzt. Das subkutane Fettgewebe wurde anschließend stumpf präpariert und der $N$. ischiadicus durch stumpfe Spreizung des $M$. gluteus und $M$. semimembranosus freigelegt. Mit einem nicht-resorbierbaren Faden wurde das Endoneurium als Orinentierungshilfe mit einem Knoten versehen. Direkt proximal zur Markierung wurde nun der $N$. ischiadicus mit einer Arterienklemme (Breite $3 \mathrm{~mm}$ ) für 40 s komprimiert. Die Haut wurde nach der Operation mit 2-3 Einzelknopfnähten verschlossen, desinfiziert und mit lokalanästhetischer Lidocainsalbe behandelt. Die operierten Tiere wurden bis zum Erwachen halbstündlich und anschließend zweimal täglich auf Auffälligkeiten kontrolliert.

\subsubsection{Elektrophysiologie}

Elektrophysiologische Messungen werden unter Vollnarkose (siehe oben) an den Hinterbein- und Schwanznerven vorgenommen. Zur Hinterbeinnervanalyse wird der $N$. ischiadicus und der N. tibialis posterior auf der Höhe des Foramen ischiadicum (proximal) und im Bereich des Knies (distal) durch subkutan applizierte Nadelelektroden entlang der Nerven mit Dauer von 0,1ms stimuliert. Gemessen wird die zeitliche Verzögerung zwischen dem Auslösen eines Aktionspotentials und der motorischen Antwort am Muskel. Nach proximaler und distaler Stimulation lässt sich die Nervenleitgeschwindigkeit (NLG) aus dem Abstand beider Stimulationsorte berechnen sowie die Muskelsummenaktionspotentiale (MSAP) als Amplitudenausschlag zwischen maximalem und minimalem Spitzenwert ermitteln. Weiterhin werden die MSAPs sowie die NLG wird an Schwanznerven der Ratten durchgeführt. Zur Messung wird der Schwanz der Ratten in ein Ölbad $\left(37^{\circ} \mathrm{C}\right)$ zur Aufrechterhaltung einer konstanten Körpertemperatur am Schwanz (Messort) gelegt. Die Auslösung der CMAP's von Schwanzmuskeln erfolgt durch einzelne elektrische Stimuli mit Dauer von 0,1ms an den Schwanznerven. Aufgezeichnet werden diese über subkutane Nadelelektroden, welche an das Messinstrument angeschlossen sind. Als Amplitude ist der Ausschlag zwischen maximalem und minimalem Spitzenwert definiert. Die Nervenleitgeschwindigkeiten werden aus den Latenzdifferenzen errechnet. Dazu wird an zwei verschiedenen Lokalisationen mit einem Abstand von $2 \mathrm{~cm}$ proximal am Schwanz sukzessiv gereizt 


\subsubsection{Präparation des Nervus ischiadicus}

Um Transkriptionsanalysen von Schwannzellen durchzuführen wurde der Nervus ischiadicus biopsiert. Hierzu wurden die Mäuse/Ratten durch $\mathrm{CO}_{2}$ getötet und eine Inzision medial am linken Oberschenkel, proximal zur Hüfte gesetzt. Anschließend wurde der Bereich zwischen Musculus gluteus maximus und Musculus semimembranosus stumpf mittels Schere gespreizt um einen Zugang zum Nervus ischiadicus freizulegen. Dieser wurde anschließend mit einer Pinzette gefasst und mit je einem Schnitt distal und proximal biopsiert. Für Transkriptionsanalysen läsionierte Nerven von Mäusen wurden die distalen und proximalen Abschnitte des gequetschten Ischiasnerven, sowie der intakte kontralaterale Nerv zu unterschiedlichen Zeitpunkten nach Nervenläsion präpariert. Proteinbiochemische und histologische Analysen wurden ausschließlich mit distalen Präparaten (u.U. auch kontralateraler Nerv als Kontrolle) durchgeführt.

Der biopsierte Ischiasnerv wurde in ein Eppendorfgefäß überführt und in diesem in flüssigen Stickstoff gegeben. Eine dauerhafte Lagerung der Biopsate wurde bis zur weiteren Verarbeitung auf $-80^{\circ} \mathrm{C}$ durchgeführt.

\subsubsection{Präparation der Spinalganglien und des Rückenmarks}

Nach Tötung mittels $\mathrm{CO}_{2}$ wurden die Mäuse ventral eröffnet und die intestinalen Organe im kompletten Peritoneum bis zum Diaphragma entfernt. Anschließend wurde möglichst effizient das Muskelgewebe beidseits der Wirbelsäule entfernt. Die Wirbelsäule wurde nun mit einer Knochenzange im Bereich des Diaphragmas durchtrennt. Die lumbalen und sakralen Bereiche des Rückenmarks wurden anschließend freigelegt durch vorsichtige doppelte Schnittführung am rechten und linken Rand der Wirbelsäule von cranial nach caudal.

Für eine immunhistochemische Analyse des Rückenmarks wurde dieses im Bereich L3-L4 präpariert.

Für die Präpariation der Spinalganglien wurde zunächst das Rückenmark entfernt. Die Spinalganglien waren nun zugänglich und konnten in den Bereichen L1-L5 präpariert werden.

\subsubsection{Beurteilung der Versuchstiere durch den Griffstärketest}

Um den Phänotyp der Versuchstiere im Hinblick der Betroffenheit peripherer Muskelgruppen zu bestimmen wurde der Griffstärketest an den Vorderextremitäten durchgeführt. Hierzu wurden die Tiere am Schwanz gegriffen, sodass deren Fluchtverhalten sie dazu bewegte sich nach vorn zu bewegen und sich an einer 
angebotenen Stange festzuhalten. Diese Stange war im apparativen Aufbau an einen Newtonmeter befestigt. Bei einem Zug am Schwanz konnte somit das Fluchtverhalten der Tiere ausgenutzt werden um deren Griffstärke zu bestimmen. Es wurden pro Tier fünf Messungen durchgeführt und anschließend der Mittelwert berechnet.

\subsubsection{Ganganalyse und Ischiasnerv-Funktionsindex}

Ganganalysen wurden 2, 4 und 8 Wochen nach experimenteller Nervenläsion durchgeführt. Hierzu wurden die Hinterfüße der Mäuse mit schwarzer ungiftiger Wasserfarbe bemalt. Die Mäuse wurden anschließend frei durch einen mit Papier ausgelegten Korridor laufen gelassen. Fünf gut erkennbare Fußabrücke pro Seite wurden für die Auswertung ausgewählt wobei darauf zu achten war, dass alle Mäuse mit möglichst gleicher Geschwindigkeit laufen. Die Parameter Fußabdrucklänge und Zehenspreizung wurden dann für jeden Fußabdruck vermessen und pro Seite und Tier gemittelt. Die erhobenen Werte der gesunden und läsionierten Seite wurden dann zur Berechnung des Ischiasnervfunktionsindex (sciatic nerve functional index, SFI) herangezogen (Inserra et al., 1998).

\subsubsection{Histologische Methoden}

\subsubsection{Ganzkörperfixation durch Perfusion}

Sämtliche, in die Studie eingeflossenen Tiere wurden nach Tötung durch $\mathrm{CO}_{2}$ perfundiert. Hierzu wurde das Herz der Mäuse/Ratten frei präpariert und eine 23G „Venofix“-Kanüle in den linken Ventrikel eingeführt. Die Vena cava inferior wurde proximal zum Herzen durchtrennt. Über die Kanüle, verbunden mit einer Peristaltikpumpe (Heraeus SR70, Flussrate 2-5 ml/min), wurde der Kreislauf des Tieres zunächst mit $50 \mathrm{ml}$ HBSS perfundiert, gefolgt von $50 \mathrm{ml}$ Fixans nach Karnovsky und Schulz (Karlsson and Schulz, 1965). Eine dauerhafte Lagerung erfolgte in $150 \mathrm{ml}$ Fixans. Die zu untersuchenden Gewebe wurden entnommen.

\subsubsection{Kunstharzeinbettung und Anfertigung von Ultra- und Semidünnschnitte}

Die fixierten Gewebe wurden zur Herstellung von Semidünnschnitten nach der Methode von Luft (Luft, 1961) in das Kunstharz Epon eingebettet. Hierzu wurden die Nerven aus den perfundierten Tieren präpariert (s.o.) und nach mindestens 24 stündiger Immersionsfixierung in Eppendorffgefäßen in immer gleicher Ausrichtung in vorgefertigte Körbchen des Einbettautomaten „Lynx el“ gelegt und dann mit Epon 
infiltriert. Dabei wurden die Proben nach folgendem Schema in den entsprechenden Lösungen geschwenkt.

\section{Reagenz}

1. Puffer

2. $2 \% \mathrm{OsO}_{4}$

3. A. dest.

4. A. dest.

5. A. dest.

6. $30 \%$ Ethanol

7. $50 \%$ Ethanol

8. $70 \%$ Ethanol

9. $90 \%$ Ethanol

10. $100 \%$ Ethanol

11. $100 \%$ Ethanol

12. $100 \%$ Ethanol

13. $100 \%$ Ethanol

14. Propylenoxid

15. Propylenoxid

16. Propylenoxid

17.Propylenoxid/Epon 2:1

18. Propylenoxid/Epon 1:1

19. Propylenoxid/Epon 1:2

20. Epon rein
Dauer

$15 \mathrm{~min}$

$4 \mathrm{~h}$

$20 \mathrm{~min}$

$20 \mathrm{~min}$

$20 \mathrm{~min}$

$30 \mathrm{~min}$

$30 \mathrm{~min}$

$30 \mathrm{~min}$

$30 \mathrm{~min}$

$15 \mathrm{~min}$

$15 \mathrm{~min}$

15 min

$15 \mathrm{~min}$

15 min

15 min

15 min

$2 \mathrm{~h}$

$2 \mathrm{~h}$

$4 \mathrm{~h}$

$4 \mathrm{~h}$

\section{Temperatur}

$4^{\circ} \mathrm{C}$

$4^{\circ} \mathrm{C}$

RT

RT

RT

RT

RT

RT

RT

RT

RT

RT

RT

RT

RT

RT

RT

RT

RT

RT

Nach der Infiltration wurden die Nerven in Epon eingebettet. Dazu wurden sie in Ausgießformen mit reinem Epon gegeben welches durch Erhitzen auf $60^{\circ} \mathrm{C}$ für 24 Stunden polymerisierte, so dass feste Epon-Kunstharzblöcke entstanden. Die Eponblöcke wurden mit einer Fräse an der Spitze zu Pyramidenform angeschliffen. Von diesen Eponblöcken wurden an einem Rotationsmikrotom mit einem Diamantmesser 0,5 $\mu \mathrm{m}$ dicke Schnitte angefertigt. Diese Semidünnschnitte wurden auf Objektträger transferiert und eine Stunde lang auf $60^{\circ} \mathrm{C}$ getrocknet.

Die Ultradünnschnitte (50-70 nm) wurden auf Formvar-befilmte Kupfergritter gezogen und getrocknet. Anschließend wurden die Schnitte für ca. 30 min auf einem Tropfen $2 \%$ Uranylacetatlösung kontrastiert und mit danach mit $\mathrm{H}_{2} \mathrm{O}$ gespült. Die zweite Kontrastierung erfolgte über 6 min mit Bleicitrat nach Reynolds (Reynolds, 1963). 


\subsubsection{Färbung der Semidünnschnitte}

Die Semidünnschnitte wurden gefärbt mit der Methylen-Azur-II-Färbung (Richardson et al., 1960). Die Methylenblau-Lösung und Azur-II-Lösung wurden im Verhältnis 1:1 gemischt und filtriert. Die fertige Lösung wurde auf die Objektträger gegeben und nach einminütiger Inkubation auf $60^{\circ} \mathrm{C}$ mit destilliertem Wasser abgespült. Die gefärbten Schnitte wurden 10 Minuten bei $60^{\circ} \mathrm{C}$ getrocknet und anschließend mit Eukitt-Kleber eingedeckt.

\subsubsection{Histologische Analyse der Nervi ischiadicus}

Von den gefärbten Semidünn-Querschnitten wurden mikroskopische Bilder angefertigt. Die Aufnahmen wurden an einem Lichtmikroskop (Leica DM RXA2) mit einer Videomikroskopie-Kamera und dem Programm Openlab 2.1 angefertigt. Die weitere Verarbeitung erfolgte mit den Programmen ImageJ 1.40g. Die Gesamtanzahl aller Axone der Ischiasnerven wurde gezählt. Hierzu wurden Querschnitte der Nerven auf immer gleicher Höhe fotografiert. Nach Verblindung des Untersuchers wurden alle solchen Axone gezählt, die der Größe nach physiologischerweise eine Myelinisierung erwarten ließen, also alle Axone mit einem Durchmesser von $1 \mu \mathrm{m}$ und mehr. Für die Distribution der Axondurchmesser wurden je mindestens 300 Axone randomisiert ausgewählt und der Umfang mit der Software ImageJ vermessen.

Die elektronenmikroskopischen Analysen umfassten die Bestimmung der Myelindicke (mittels g-ratio) zu verschiedenen Alterszeitpunkten Für die g-ratio-Analyse wurden mit einer Vergrößerung von 3000x randomisiert ca. 20 elektronenmikroskopische Bilder digitalisiert aufgenommen. Im Anschluss wurde mit der Software ImageJ der Umfang des Axons) und der äußere Umfang der Myelinscheide bei mindestens 100 Nervenfasern pro Tier vermessen. Der Quotient aus Axon- und Myelinscheidendurchmesser wurde anschließend berechnet um das g-ratio zu erhalten.

\subsubsection{Parafinneinbettung}

Die N. ischiadici und Rückemmärker für die immunhistochemischen Untersuchungen wurden in 4\% PFA für mind. $24 \mathrm{~h}$ nachfixiert. Anschließend wurde das Gewebe mit Hilfe eines Gewebeinfiltrationsautomaten (MICROM HMP 110) paraffiniert (Schema siehe unten).

Danach wurden die Gewebeproben an einer Ausgießstation mit Paraffin in entsprechende Formen ausgegossen. Nach Aushärtung des Paraffins wurden Paraffinschnitte mit einer Dicke von $5 \mu \mathrm{m}$ angefertigt. Die Schnitte wurden auf 
beschichtete Objektträger (Histobond) aufgezogen und danach bei $37^{\circ} \mathrm{C}$ über Nacht getrocknet.

$\begin{array}{ll}\text { Reagenz } & \text { Dauer } \\ 50 \% \text { Ethanol } & 1 \mathrm{~h} \\ 70 \% \text { Ethanol } & 2 \mathrm{~h} \\ 70 \% \text { Ethanol } & 2 \mathrm{~h} \\ 96 \% \text { Ethanol } & 1 \mathrm{~h} \\ 96 \% \text { Ethanol } & 1 \mathrm{~h} \\ 100 \% \text { Ethanol } & 1 \mathrm{~h} \\ 100 \% \text { Ethanol } & 1 \mathrm{~h} \\ \text { Isopropanol } & 1 \mathrm{~h} \\ \text { Xylol } & 2 \mathrm{~h} \\ \text { Xylol } & 2 \mathrm{~h} \\ \text { Paraffin } & 2 \mathrm{~h} \\ \text { Paraffin } & 2 \mathrm{~h}\end{array}$

\subsubsection{Immunfluoreszenzfärbung der Paraffinschnitte}

Die getrockneten Paraffinschnitte wurden zunächst entparaffiniert, indem sie für $10 \mathrm{~min}$ bei $60^{\circ} \mathrm{C}$ und anschließend in einer absteigenden Alkoholreihe inkubiert wurden. Die Schnitte wurden im Anschluss für $10 \mathrm{~min}$ in Zitratpuffer inkubiert und für weitere $10 \mathrm{~min}$ im selben Puffer bei 650 Watt per Mikrowelle gekocht. Nach Abkühlung wurden die Objektträger in Tris-Puffer mit 2\% Milchpulver gewaschen. Die Schnitte wurden anschließend für 10 min mit Ziegenserum (1:5 verdünnt, $100 \mu \mathrm{l}$ pro Schnitt) inkubiert, um die Hintergrundfärbung zu minimieren. Danach wurde die Primärantikörper in $\mathrm{PBS} / \mathrm{BSA}$ verdünnt aufgetragen und über Nacht bei $4^{\circ} \mathrm{C}$ inkubiert. Die Schnitte wurden am nächsten Tag mehrmals mit Tris-Puffer gewaschen. Nach dem Waschen folgte dann die Inkubation mit den fluoreszenzmarkierten Sekundärantikörpern für $1 \mathrm{~h}$ bei Raumtemperatur. Nach 3-maligem Waschen mit dem Trispuffer wurde anschließend die DAPI-Lösung $(0,5 \mu \mathrm{g} / \mu \mathrm{l})$ für die Kernfärbung aufgetragen. Die Schnitte wurden danach erneut mit dem Tris-Puffer gespült und mit Immu-Mount eingedeckt. Die Analyse der immunhistochemischen Färbungen erfolgte mit einem FluoreszenzDurchlichtmikroskop ( $N$. ischiadici) oder mit einem Konfokalmikroskop (Rückenmark und $N$. ischiadici). 


\subsubsection{MOLEKULARBIOLOGISCHE METHODEN}

\subsubsection{Isolation von DNA}

Zur Unterscheidung der gezüchteten Ratten durch Genotypisierung in Wildtyp- und transgene Tiere, wurde genomische DNA aus Schwanzbiopsien der Tiere gewonnen. Anhand des „DNeasy 96 Kits“ wurde nach dem Protokoll des Herstellers DNA aus den Geweben isoliert. Die bei $-20^{\circ} \mathrm{C}$ gelagerten Biopsien wurden aufgetaut und in eine Mischung aus Puffer ATL $(180 \mu \mathrm{l})$ und Proteinase K $(20 \mu \mathrm{l})$ gegeben. Nach intensivem Mischen und einer kurzen Zentrifugation bei 3000 rpm in einer „Laboratory Zentrifuge $4 \mathrm{~K} 15^{\prime \prime}$ erfolgte durch Inkubation über Nacht bei $55^{\circ} \mathrm{C}$ die Lyse des Gewebes durch die Proteinase K. Am nächsten Tag wurden $400 \mu \mathrm{l}$ Puffer AL/E zu den lysierten Proben gegeben. Nach Mischen und kurzer Zentrifugation bei 3000 rpm wurde der Überstand (maximal $900 \mu \mathrm{l}$ ) auf die Silicamembran der DNeasy Säulchen pipettiert. Die DNeasy Platte wurde mit einem „Air Pore Tape Sheet“ verschlossen und $10 \mathrm{~min}$ bei $6000 \mathrm{rpm}$ zentrifugiert. Es folgten $500 \mu \mathrm{l}$ Puffer AW1 und eine weitere Zentrifugation für $5 \mathrm{~min}$ bei $6000 \mathrm{rpm}$. Nach Zugabe von $500 \mu \mathrm{l}$ Puffer AW2 wurde wieder 5 min bei $6000 \mathrm{rpm}$ zentrifugiert und die DNeasy Platte $15 \mathrm{~min}$ bei $70^{\circ} \mathrm{C}$ inkubiert. Zur Elution der DNA, die nun an die Silicamembran der Säulchen gebunden war, wurden $200 \mu$ l vorgewärmter Puffer AE auf die Säulchen gegeben, $5 \mathrm{~min}$ bei $60^{\circ} \mathrm{C}$ inkubiert und $2 \mathrm{~min}$ bei $6000 \mathrm{rpm}$ zentrifugiert. Der gleiche Vorgang wurde mit weiteren $100 \mu$ Puffer AE wiederholt. Die so eluierte genomische DNA wurde bei $4^{\circ} \mathrm{C}$ gelagert.

\subsubsection{Isolation von RNA}

Für die Genexpressionsmessung wurde Gesamt-RNA aus Ischiasnerven bzw. aus Spinalganglien. Hierfür wurden folgendes Protokoll des Kits (RNeasy Mini Kit, Qiagen), verwendet.

Für Ischiasnerven und Spinalganglien wurde das vom Kit-Hersteller empfohlene Protokoll für fettige Gewebe verwendet. Hierzu wurden die bei $-80^{\circ} \mathrm{C}$ gelagerten Proben direkt in $6 \mathrm{ml}$ Rundboden-Falconröhrchen mit $1 \mathrm{ml}$ TRIzol Lysereagenz überführt und mit Hilfe des Gewebehomogenisierers „Ultraturrax“ zerkleinert. Zwischen den Homogenisierungen wurde das Gerät jeweils dreimal mit destilliertem Wasser gereinigt. Für eine Dissoziation der Nucleoproteinkomplexe wurden die Homogenisate anschließend fünf Minuten bei Raumtemperatur inkubiert. Anschließend wurden je 200 $\mu \mathrm{l}$ Chloroform hinzugegeben, mittels Vortex gemixt und erneut zwei bis drei Minuten inkubiert. Es folgte eine 15-minütige Zentrifugation bei $12000 \mathrm{~g}$ bei $4^{\circ} \mathrm{C}$ mittels Tischzentrifuge. Die entstandene obere klare Phase wurde vorsichtig in ein neues Eppendorffgefäß überführt und mit einer Volumeneinheit $70 \%$ igem Ethanol versetzt 
und durch Pipettieren gemischt. $700 \mu \mathrm{l}$ des Gemisches wurden anschließend auf eine „RNeasy Mini Spin“-Säule mit Silikatmembran gegeben. Diese beladene Säule wurde des Weiteren bei $8000 \mathrm{~g}$ bei Raumtemperatur 15 Sekunden zentrifugiert. Der Durchfluss wurde verworfen und der letzte Schritt mit dem Rest des Ethanol-RNAGemisches wiederholt. Es folgten zwei Waschschritte mit dem Waschpuffer RW1, von welchem jeweils $700 \mu \mathrm{l}$ auf die Säule zur 15-sekündigen Durchflusszentrifugation bei $8000 \mathrm{~g}$ gegeben wurden. Ein dritter Waschschritt erfolgte mit $500 \mu \mathrm{l}$ RPE-Puffer in Ethanol bei dreiminütiger Zentrifugation bei $8000 \mathrm{~g}$ um sicherzustellen, dass sämtliches Ethanol von der Säule entfernt wurde. Die Säule wurde anschließend in ein neues Eppendorffgefäß überführt. Eine Elution der RNA von der Säule erfolgte mit zwei Zentrifugationsschritten bei $8000 \mathrm{~g}$ mit jeweils $50 \mu \mathrm{l}$ RNase-freiem Wasser. Eine Lagerung der aufgereinigten RNA erfolgte wiederum bei $-80^{\circ} \mathrm{C}$.

\subsubsection{Analyse von Qualität und Quantität der RNA}

Neben der Konzentration ist die Integrität einer RNA für deren weitere Verwendung von großer Bedeutung. Hierzu wurde die gewonnene RNA im Agilent Bioanalyzer mit dem RNA 6000 Nano Assay untersucht. Das System basiert auf einer kapillären Elektrophorese auf einem Chip, daher werden nur sehr geringe Mengen Proben-RNA benötigt. Durch den Vergleich des Laufmusters der RNA mit dem einer Standard-RNA lässt sich eine eventuelle Degradation oder eine Kontamination der RNA ausschließen. Vermessen wird maßgeblich die ribosomale RNA (rRNA), da diese mit über 90\% den Großteil des RNA-Gehaltes repräsentiert. Die Eletrophorese eines genügend aufgereinigten RNA-Extraktes liefert somit zwei intensive, scharfe Banden, repräsentativ für die beiden Hauptbestandteile der rRNA mit den Sedimentatioskoeffiezienten $18 \mathrm{~S}$ und $28 \mathrm{~S}$.

Beim Lauf durch das kapilläre Gel bindet die RNA einen fluoreszenten Farbstoff. Aus dem Vergleich der fluoreszenten Signalintensität der Proben-RNA mit der einer Referenz-RNA-Lösung (RNA-Leiter) bekannter Konzentration lässt sich die Konzentration der Proben-RNA bestimmen. Entsprechend dem Protokoll des Herstellers wurde das Gel-Farbstoffgemisch für den Chip vorbereitet, indem $400 \mu \mathrm{l}$ RNA Gelmatrix durch ein Zentrifugenfilterröhrchen mit $2500 \mathrm{rpm}$ in einer Tischzentrifuge zentrifugiert wurden. Nach Zugabe von $130 \mu$ l RNA Farbstoff diente diese Gel-Farbstoff-Mischung als Grundlage für das kapilläre Gel. In einer Gelladestation (Agilent Technologies) wurden $9 \mu$ der Mischung eine Minute lang in die Kapillaren eines RNA-Chips gepresst und bildeten das Gel für die weitere Analyse. Nach Zugabe eines Nano Markers, der als Ausrichtungsreferenz des kapillären Gels diente, wurde die RNA-Leiter als RNA-Mengen- und Größenreferenz zugegeben. Die 
Integrale der fluoreszenten Signale beider Hauptbestandteile der rRNA mit den Sedimentatioskoeffiezienten $18 S$ und $28 S$ wurden zur Bestimmung der Qualität herangezogen. Ein Verhältnis von $28 \mathrm{~S} / 18 \mathrm{~S}=2,1$ galt als qualitatives Optimum. Bei einer Degradierung wäre eine Dispersion der beiden scharfen rRNA-Zacken festzustellen gewesen, während Kontaminationen der Proben Signale mit hoher Retentionszeit geliefert hätten. Nur entsprechend dem Laufmuster nicht degradierte und nicht kontaminierte RNA-Proben wurden in den weiteren Versuchen verwendet.

\subsubsection{Polymerasekettenreaktion (PCR) mit genomischer DNA}

Durch eine PCR ist es möglich, geringe DNA-Mengen in vitro zu amplifizieren (Mullis et al., 1986). Das Prinzip dieser Reaktion basiert auf der hitzestabilen DNA-Polymerase aus dem Bakterium Thermus aquaticus (Taq-Polymerase), die bei ihrem Temperaturoptimum von $72^{\circ} \mathrm{C}$ ausgehend von sequenzspezifisch bindenden Oligonukleotiden (Primern) einen DNA-Strang komplementär zum denaturierten Matrizenstrang synthetisiert. Durch zyklisch ablaufende Reaktionsschritte von DNADenaturierung bei $95^{\circ} \mathrm{C}$, Binden der Primer bei $56^{\circ} \mathrm{C}$ (Annealing) und Synthese der neuen DNA bei $72^{\circ} \mathrm{C}$ (Elongation) lassen sich spezifische DNA-Bereiche exponentiell vervielfachen. Die Standard-PCR wurde zur Amplifikation eines DNA-Abschnitts verwendet, der spezifisch z.B. für das transgene PMP22-Gen der Maus. Dadurch war eine Unterscheidung der Ratten in transgene und Wildtyp-Tiere möglich (Sereda et al. 1996). Für die Reaktionen wurde ein Reaktionskit (Promega) verwendet in einem Reaktionsvolumen von $50 \mu \mathrm{l}$ pro DNA-Probe. Der Reaktionsansatz bestand aus:

$1 \mu \mathrm{l}$ Matritzen-DNA

5 ul 10x PCR-Puffer Promega

$5 \mu \mathrm{l}$ dNTPs (je Nukleotid f.c. $200 \mu \mathrm{M}$ )

$1 \mu \mathrm{l}$ Sense-Primer (f.c. $300 \mathrm{nM}$ )

$1 \mu \mathrm{l}$ Antisense-Primer (f.c. $300 \mathrm{nM}$ )

0,3 $\mu \mathrm{l}$ Taq DNA-Polymerase (f.c.1,6 U / $50 \mu \mathrm{l}$ ) 
Die DNA-Amplifikation erfolgte nach folgendem Protokoll:

$3 \min -95^{\circ} \mathrm{C}$

$30 \mathrm{~s}-56^{\circ} \mathrm{C}$

$90 \mathrm{~s}-72^{\circ} \mathrm{C}$ 35 Zyklen

$60 \mathrm{~s}-95^{\circ} \mathrm{C}$

$60 \mathrm{~s}-55^{\circ} \mathrm{C}$

$10 \min -72^{\circ} \mathrm{C}$

\subsubsection{Gelelektrophorese der PCR-Produkte}

Die Elektrophorese in einem Agarosegel ermöglicht es, DNA-Fragmente entsprechend ihrer Größe aufzutrennen und sichtbar zu machen. Die Auftrennung erfolgte auf 0,74\%igen Agarosegelen. Die Agarose wurde in 1x TAE Puffer zum Lösen aufgekocht und nach Zusatz von Ethidiumbromid (f.c. $1 \mu \mathrm{g} / \mathrm{ml}$ ) in eine Gelkammer gegossen. Verschiedene Gelkämme, die in die Agarose ragten, formten beim Erstarren der Agarose Taschen im Gel. Das Gel wurde in einer Laufkammer platziert und mit 1x TAE Laufpuffer überdeckt. Die DNA-Proben wurden mit 1/10 Volumen Probenpuffer versetzt und in die Geltaschen eingefüllt. Es wurde eine Spannung zwischen 30-180 V (5$10 \mathrm{~V} / \mathrm{cm}$ ) angelegt, abhängig von der erwarteten Größe der DNA-Fragmente und Agarosekonzentration des Gels. Durch die Interkalation von Ethidiumbromid in die DNA konnte diese nach der Elektrophorese auf einem UV-Illuminator sichtbar gemacht und fotografiert werden. Als Größenmarker dienten je nach Größe des untersuchten Fragments entweder $1 \mu \mathrm{g}$ mit Hind III verdaute DNA des Bakteriophagen $\lambda(0,5-23 \mathrm{~kb})$ (Promega) oder $1 \mu \mathrm{g}$ mit Hae III verdaute DNA des Phagen $\varphi$ X174 (70-1350 bp) (Promega).

\subsubsection{6 cDNA-Synthese durch Reverse Transkription von RNA}

Komplementäre DNA wurde mit dem „Superscript-III-RT“ Kit (Invitrogen) synthetisiert. Hierzu wurden 500 ng RNA als Transkript verwendet. Da die Expression von Genen analysiert werden sollte, wurden als Primer solche mit einem Poly-T-Schwanz (dTPrimer, 0,6 $\mu \mathrm{M}$ ) verwendet, um spezifisch mRNA (welche einen Poly-A-Schwanz hat) in cDNA umzuschreiben. Um die Effizienz der Reversen Transkription zu erhöhen wurden dem Reaktionsansatz zusätzlich randomisierte Nonamer-Primer (N9-Primer, $120 \mu \mathrm{M}$ ) zugesetzt; dies bewirkt, dass nicht nur in eine Richtung (sense), sondern auch in die Gegenrichtung (antisense) umgeschrieben wurde.

Je $1 \mu \mathrm{d}$ dT- und N9-Primer wurden dem 500 ng RNA- Transkript zugesetzt. Eine zweiminütige Inkubation bei $70^{\circ} \mathrm{C}$ bewirkte eine Anlagerung (Annealing) der Primer an das Transkript. Anschließend wurden die Proben auf Eis zwischengelagert. Ein 
vorbereiteter Reaktionsmix aus $12 \mu \mathrm{l}$ fünffach konzentrierten „1 $1^{\text {st }}$ Strand“-Puffer, $6 \mu \mathrm{l}$ Dichlordiphenyltrichlorethan (DDT, $100 \mathrm{mM}$ ), $3 \mu \mathrm{l}$ gemischten Nukleotiden (10 mM) und $1 \mu \mathrm{l}$ „Superscript-III"-Polymerase mit einer Wechselzahl von $200 \mathrm{U} / \mu \mathrm{l}$ wurde jeweils einer Probe zugesetzt. Anschließend wurden die Proben $10 \mathrm{~min}$ bei $25^{\circ} \mathrm{C}, 45 \mathrm{~min}$ bei $45^{\circ} \mathrm{C}$ und $45 \mathrm{~min}$ bei $55^{\circ} \mathrm{C}$ inkubiert um die Elongation der angelagerten Primer zu ermöglichen und die reverse Transkription zu beenden.

\subsubsection{Semiquantitative Real-Time-PCR mit Sybr ${ }^{\circledR}$-Green}

Die semiquantitative RT-PCR beruht auf dem Prinzip einer herömmlichen PCR (s.o.), bei welcher in jedem Zyklus das gewünschte Transkript verdoppelt wird. Zusätzlich jedoch kann diese Amplifikation bei der RT-PCR in Echtzeit (Real Time) verfolgt werden. Für die Realisierung gibt es verschiedene Ansätze. Eine sehr exakte Methode ist die Verwendung von sog. TaqMan-Sonden, kurze Oligonukleotide, welche sich spezifisch an das gesuchte Gen-Transkript anlagern und über einen FRETMechanismus (Fluoreszenz-Resonanz-Energie-Transfer) proportional zur Menge des Transkripts Lichtsignale liefern. Die Synthese solcher Sonden ist relativ kostspielig und eignet sich deshalb nicht für großräumige Transkriptomanalysen.

Eine weitere, wesentlich günstigere aber dennoch valide Methode ist die RT-PCR mittels Sybr ${ }^{\circledR}$-Green. Hierbei lagert sich der Farbstoff Sybr ${ }^{\circledR}$-Green spezifisch an doppelsträngige Nukleinsäuren an und sendet nach Bindung ein fluoreszentes Signal aus, welches proportional mit der Menge doppelsträngiger Nukleinsäuren korreliert. Am Ende einer Elongationsphase der PCR, noch vor dem nächsten Dissoziationsschritt, kann somit die Menge an amplifiziertem Transkript bestimmt werden.

Da Sybr ${ }^{\circledR}$-Green jedoch sämtliche doppelsträngige Nukleinsäuren, so auch evtl. genomische DNA-Kontamination und Primer-Dimere, bindet, sind beim Methodendesign im Vergleich zur TaqMan-RT-PCR zusätzliche Anforderungen zu erfüllen. Die Primer müssen so konstruiert sein, dass sie ausschließlich die cDNA, welche mit dem entsprechenden Locus im Genom sequenzidentisch ist, amplifiziert. Dies wird im Allgemeinen dadurch erreicht, dass die Primer so gewählt werden, dass sie ein Intron flankieren, sodass die Zeit eines PCR-Zyklus' nicht ausreicht um genomische DNA zu vervielfältigen. Desweiteren dürfen die Primer keine Dimere oder Schleifen bilden. Ein Test der mithilfe des internetbasierten „Universal Probe Library Assay Design Center" kreierten Primer mit der Software Oligo Analyzer 1.1.2 (Teemu Kuulasmaa), sowie RT-PCR-Kontrolläufe ohne Transkript zeigten, dass diese Anforderung erfüllt werden konnte. 
Durch kontinuierliche Messung der Fluoreszenzintensität während der PCR, lässt sich diejenige PCR-Zyklenzahl bestimmen, bei der das Fluoreszenzsignal die zehnfache Standardabweichung der Grundaktivität überschreitet. Diese Zyklenzahl wird als CtWert (threshold-cycle) definiert und ist umso kleiner, je größer die eingesetzte Menge an DNA-Zielsequenz war.

Die verwendete RT-PCR-Methode mit Sybr ${ }^{\circledR}$-Green heißt „semiquantitativ“, weil der Ct-Wert des zu quantifizierenden Gens auf Ct-Werte so genannter "Haushaltsgene“ (houskeeping genes) normalisiert wird. Diese „Haushaltsgene“ oder Standards werden neben den zu quantifizierenden Genen amplifiziert. Dessen Expressionniveaus werden als konstant in allen untersuchten Proben vorausgesetzt und dienen als Maß für die Menge der eingesetzten DNA. Aus der Differenz zwischen dem Ct-Wert der Zielsequenz und dem Ct-Wert des Standard-Gens wird der so genannte $\Delta$ Ct-Wert berechnet.

$$
\Delta \mathrm{Ct}-\text { Wert } \mathrm{Ziel} / \text { Kalibrator }=\mathrm{Ct}_{\text {Zielsequenz }}-\mathrm{Ct}_{\text {Housekeeping }}
$$

Eine der in der PCR amplifizierten Proben dient als relative Referenz (Kalibrator). Deren Expression wird als „1“ definiert. Nach der Formel

$$
\Delta \Delta \mathrm{Ct}=\Delta \mathrm{Ct}_{\text {Ziel }}-\Delta \mathrm{Ct}_{\text {Kalibrator }}
$$

errechnet sich der $\Delta \Delta$ Ct-Wert. Dieser gibt die Ct-Wertdifferenz relativ zu einer gewählten Probe an, ergibt also den Unterschied zwischen $\Delta \mathrm{Ct}$ der gesuchten Probe $\left(\Delta \mathrm{Ct}_{\text {Ziel }}\right)$ und dem $\Delta \mathrm{Ct}$ einer als relative Referenz gewählten Probe $\left(\Delta \mathrm{Ct}_{\text {Kalibrator }}\right)$. Aus diesem $\Delta \Delta$ Ct-Wert kann die Expression des Zielgens berechnet werden nach der Formel:

$$
\text { mRNA-Konzentration }=2^{-\Delta \Delta C t} \text {. }
$$

Für die Analyse und die Normalisierung der Ct-Rohdaten wurde die Software „qBase 1.3.5“ (Hellemans et al. 2007) verwendet.

Für eine akkurate Normalisierung sind „Haushaltsgene“ notwendig, von welchen vorrausgesetzt wird, dass sie zwischen den zu untersuchenden Proben nicht reguliert sind. Eine Normalisierung auf den Mittelwert der Expression mehrerer verwendeter „Haushaltsgene“ resultiert in valideren Ergebnissen. Für die Identifikation der besten Kombination an Standards wurde die Software "geNorm 3.5“ (Vandesompele, 2002) verwendet, welche aus einem Set putativer Standards diejenigen mit der geringsten Expressionsvariabilität zwischen den einzelnen Proben anhand der Ct-Rohdaten berechnet. 
Für die semiquantitative RT-PCR mit Sybr ${ }^{\circledR}$-Green wurde der vom Hersteller (Applied Biosystems) empfohlene Reaktionsansatz sowie das Standard Amplifikationsprotokoll verwendet:

Reaktionsansatz:

cDNA

5'-Primer (10pmol/ $\mu \mathrm{l})$

3'-Primer (10pmol/ $\mu \mathrm{l})$

SYBR ${ }^{\circledR}$-Green Master Mix

$\mathrm{H}_{2} \mathrm{O}$
Amplifikationsprotokoll:

$2 \mu \mathrm{l} \quad 10 \mathrm{~min}$ bei $95^{\circ} \mathrm{C}$

$1 \mu \mathrm{l}$

$1 \mu \mathrm{l}$

$5 \mu \mathrm{l}$

$1 \mu \mathrm{l}$
$15 \mathrm{sec}$ bei $95^{\circ} \mathrm{C}$

$20 \mathrm{sec}$ bei $60^{\circ} \mathrm{C}$

$40 \mathrm{sec}$ bei $72^{\circ} \mathrm{C}$

\subsubsection{PROTEINBIOCHEMIE}

\subsubsection{Isolation von Proteinen aus Gewebe}

Die auf $-80^{\circ} \mathrm{C}$ gelagerten Proben wurden in Lysepuffer welcher Phosphatase- und Proteaseinhibitoren enthielt mit Hilfe des Gewebehomogenisators PRECELLYS lysiert und bis zur weiteren Verwendung auf Nasseis gelagert. Nach der Homogenisierung wurden durch 10 -minütige Zentrifugation bei $5000 \mathrm{~g}$ auf $4^{\circ} \mathrm{C}$ verbliebene Zelltrümmer herunter zentrifugiert. Der Überstand wurden in ein neues Eppendorfgefäß überführt und kurzfristig auf Nasseis (bei unmittelbar anschließender Konzentrationsbestimmung) oder dauerhaft auf $-80^{\circ} \mathrm{C}$ gelagert.

\subsubsection{Konzentrationsbestimmung von Proteinextrakten}

Die Proteinkonzentration der lysierten Homogenate wurde mittels Lowryassay (Biorad) durchgeführt. Bei diesem kolorimetrischen Verfahren reagieren Proteine im alkalischwässrigen Mileu zunächst irreversibel mit Kupfersulfat und anschießend mit einem farbigen Folinreagenz. Die Intensität der Färbung korreliert proportional mit dem Proteingehalt, sodass die Proteinkonzentration im Abgleich mit einer Eichgeraden photometrisch gemessen und berechnet werden kann

\subsubsection{SDS-Polyacrylamid-Gelelektrophorese (SDS-PAGE)}

Natriumdodecylsulfat (SDS) ist ein stark anionisches Detergenz welches Proteine denaturiert (deren Tertiärstruktur aufbricht) und deren Eigenladung homogen überdeckt. Die Proteine können so in einem Gel (molekulares Sieb) durch ein elektrischen Feld ausschließlich nach ihrem Molekulargewicht aufgetrennt werden. Für die Gelelektrophorese nach Laemmli (Laemmli, 1970) wurden selbst gegossene 
Polyacrylamidgele mit einem Sammelgel und einem Trenngel (mit 10\% SDS) verwendet. Die Elektrophorese wurde bei 200 V und 0,12 A pro Gel durchgeführt.

Die SDS-PAGE wurde zum Zweck der Kühlung und Protektion phosphorylierter Proteine in einer Eiswanne durchgeführt.

\subsubsection{Western blot und immunologische Detektion der Proteine}

Beim Western-Blot werden die aufgetrennten Proteine aus der Polyacrylamidmatrix über das senkrecht zum Gel angelegte elektrische Feld gelöst und auf eine Polyvinylidendifluorid (PVDF) Membran transferiert. Dabei bleibt die Bandenstruktur des SDS-Gels erhalten. Die Membran wurde zunächst in Methanol aktiviert. Anschließend wurden die Proteine über einen Zeitraum von einer Stunde in der Blotkammer bei $30 \mathrm{~V}$ und 0,17 A von dem Gel auf die Membran transferiert. Wie auch bei der SDS-PAGE (s.o.) wurde der Western blot zum Zweck der Kühlung und Protektion phosphorylierter Proteine in einer Eiswanne durchgeführt.

Bevor die Membran für eine Immundetektion genutzt werden kann, müssen die unspezifischen Proteinbindungsstellen der Membran abgesättigt werden. Hierzu wurde die Membran eine Stunde bei $4^{\circ} \mathrm{C}$ in einem Puffer aus PBS mit Tween 20 (PBS-T) und $5 \%$ Bovines Serum Albumin (BSA) verwendet. Anschließend wurde die Membran mit dem Primärantikörper über Nacht auf $4^{\circ} \mathrm{C}$ inkubiert. Nach 3-maligem Waschen mit dem entsprechenden Waschpuffer wurde der Meerrettich-Peroxidase (HRP)-gekoppelte Sekundärantikörper für eine Stunde bei Raumtemperatur inkubiert. Zuletzt wurde die Membran erneut gründlich gewaschen.

Die Detektion der Proteine erfolgte mit einer Chemilumineszenzdetektionslösung der Firma Amersham. Diese enthält das Substrat ECL, welches luminesziert nachdem es durch das Enzym HRP umgesetzt worden ist. Nach Applikation der Detektionslösung wurden die Membranen in einer Dunkelkammer digital belichtet.

\subsubsection{ISOLATION UND KULTIVIERUNG VON PRIMÄREN RATTENSCHWANZELLEN}

Primäre Schwannzellen wurden aus Ischiasnerven von je 4 neugeborenen Ratten (4 Tage alt) gewonnen (Brockes et al., 1979). Die Ischiasnerven wurden in einen Lysepuffer (100 $\mu \mathrm{l}$ Kollagenase, $200 \mu \mathrm{l}$ 2,5 \% Trypsin und $1700 \mu \mathrm{l}$ DMEM) überführt und für $45 \mathrm{~min}$ bei $37^{\circ} \mathrm{C}$ angedaut. Der Lysevorgang wurde durch Zugabe von $4 \mathrm{ml}$ DMEM mit $10 \%$ FCS gestoppt und die Probe für $5 \mathrm{~min}$ bei $800 \mathrm{rpm}$ zentrifugiert. Das entstandene Pellet wurde in $8 \mathrm{ml}$ Ruhemedium resuspendiert und auf eine mit Poly-LLysin beschichtete Zellkulturschale (10 cm Durchmesser) ausplattiert. Die Kultivierung 
der Zellen erfolgte bei $37^{\circ} \mathrm{C}$ und $5 \% \mathrm{CO}_{2}$. Nach $24 \mathrm{~h}$ wurde zu dem Ruhemedium für 3 Tage 0,01 $\mathrm{mM}$ das Antimitotikum AraC hinzugegeben, um schnell proliferierende Zellen wie Fibroblasten zu eliminieren und die Reinheit der Schwannzellkultur zu erhöhen. Nach 3 Tagen wurde das Selektrionsmedium durch Wachstumsmedium ausgetauscht, sodass die Schwannzellkultur expandiert wurde. Dieses Medium enthält neben rekombinantem humanem Neuregulin-1 beta (EGF-ähnliche Domäne) der Firma Reprokine auch $4 \mu \mathrm{M}$ Forskolin (cAMP-Analogon, SIGMA) und lässt Schwannzellen proliferieren. Vor einem Experiment wurden die Schwannzellen wieder auf Ruhemedium transferiert und so für 3 Tage belassen.

\subsubsection{STATISTISCHE METHODEN}

Alle in den Analysen erhobenen Daten wurden mit Excel 2010 weiterbearbeitet. Die statistische Auswertung erfolgte auch mit Statistica 10.0 und Graph Pad Prism. Alle Daten wurden auf Normalverteilung mit dem Kolmogorov-Smirnov-Test geprüft Für normalverteilte Daten mit gleichen Varianzen wurde der zweiseitige students T-Test verwendet. Der nichtparametrische Mann-Whitney U-Test wurde für nichnormalverteilte Daten und Daten deren Stichprobenumfang zu klein für einen Normalverteilungstest waren verwendet. Daten in abhängigkeit zu einer veränderlichen Variablen (z.B. abhängigkeit der Zielgröße von der Behandlungsdosis) wurden mit die Einweg-Varianzanalyse (ANOVA) auf Signifikanz getestet und die Einzelgruppen im Vergleich zur Kontrollgruppe dem Dunnetts Post-Test unterzogen.

Beim Vergleich der Axongrößenverteilung wurde auf den Kolmogorov-Smirnov Test zurückgegriffen. Statistische Unterschiede wurden als signifikant gewertet wenn $\mathrm{P}<$ $0,05\left({ }^{*} \mathrm{P}<0.05,{ }^{* *} \mathrm{P}<0.01,{ }^{* * *} \mathrm{P}<0.001\right)$. Alle Daten sind, wenn nicht anders erwähnt, als Mittelwert +/- Standardabweichung dargestellt. 


\section{ERGEBNISSE}

3.1. Frühe postnatale Fehldifferenzierung VON SchwanNZellen IN CMT1A RATTEN

Patienten mit CMT1A zeigen bereits in früher Kindheit Symptome wie Gangschwierigkeiten, Fußdeformitäten sowie Sensibilitätsstörungen (Berciano et al., 2000; Burns und Ouvrier, 2006; Yiu et al., 2008). Diese klinischen Beobachtungen gaben Anstoß für eine Charakterisierung der frühen postnatalen Pathogenese von CMT1A Ratten.

In Wildtypratten findet die Myelinisierung im PNS früh postnatal statt und ist nach 21 Tagen weitestgehend abgeschlossen. Als Zeitpunkte für morphologische Analysen in CMT Ratten wurden die postnatal Tage (P) 6, 8, 28, 84 und 180 gewählt. Bei P6 zeigen Schwannzellen von CMT Ratten im Ischiasnerv eine Hypermyelinisierung aller Axonkaliber $(>1 \mu \mathrm{m})$, während die Myelindicke im Alter von 180 Tagen bimodal verteilt ist, mit kleinen hypermyelinisierten und großen hypomyelinisierten Axonen (Abb. 9A, C). Die lichtmikroskopische Quantifizierung myelinisierter Axone pro Ischiasnerv ergab bei CMT Ratten bereits im Alter von 6 Tagen eine geringere Anzahl von Nervenfasern. Während des ganzen Lebens bleibt die Anzahl myelinisierter Axone fortwährend unter Wildtyp-Niveau und der größte Unterschied ist bei P18 mit 1000 Axonen Differenz pro Ischiasnerv zu sehen (Abb. 9A-B). Eine Expressionsanalyse von Differenzierungsmarkern in Ischiasnerv-mRNA-Extrakten aus CMT- und Wildtyp Ratten zeigte, dass das mRNA Level des für die Myelinisierung essentiellen Transkriptionsfaktors Egr2 (Krox20) bei CMT Ratten weitestgehend unverändert ist (Abb. 9D). Im Gegensatz dazu werden die transkriptionellen Differenzierungsmarker Hmgcr (HMG-CoA reductase, limitierendes Enzym der Cholesterinbiosynthese), Prx und Mpz (Periaxin und Myelin protein zero, Myelinproteine) ab den postnatal Tagen 6 bis 18 in Ischiasnerven von CMT Ratten geringer exprimiert (Abb. 9D). Die mRNA des Krankheitsgens Pmp22 ist überraschenderweise zu den Myelinisierungszeitpunkten P18 und P28 in CMT Ratten geringer exprimiert, während eine Überexpression die sehr frühen (P1: 2,2-fach; P6: 1,2-fach) und späten Zeitpunkte ( 1,6-fach) charakterisiert (Abb. 9D). Im Kontrast zu den zu gering exprimierten Differenzierungsmarkern werden Marker unreifer Schwannzellen (oder Dedifferenzierungsmarker) wie Pou3f1 (Oct6), Notch1, p75 ${ }^{\text {NTR }}$, cJun und Sox2 in Ischiasnerven von CMT Ratten ab den Tagen P6/P18 verstärkt exprimiert und bleiben über das ganze Leben hinweg hochreguliert (Abb. 9E). 
Um näher zu untersuchen, welche intrazellulären Prozesse in Pmp22 überexprimierenden Schwannzellen zur Aneignung des Dedifferenzierungsphänotyps beitragen wurde eine proteinbiochemische Analyse der Aktivitäten der für die Myelinisierung essentiellen Signaltransduktionskaskaden PI3K/AKT und MEK/ERK durchgeführt. Western blot Analysen mit Ischiasnerv-Proteinextrakten zeigen, dass in CMT Ratten die Menge an phosphoryliertem AKT über konstitutivem AKT von P1 an geringer ist als in Wildtyp-Nerven (Abb. 9F). Diese ab P1 über das ganze Leben hin gehemmte Aktivität des PI3K/AKT Signalweges ist ab P6 gefolgt von einer erhöhten Aktivität des MEK/ERK Signalweges (gemessen als phosphoryliertes ERK1/2 über konstitutivem ERK1/2 (Abb. 9F).

CMT Ratten zeigen bereits im Alter von P6 morphologische Pathologien (Hypermyelinisierung) und die Anzahl myelinisierter Axone erreicht niemals das Wildtyp-Niveau. Während der frühen postnatalen Entwicklung akquirieren Schwannzellen von CMT Ratten einen persistenten Dedifferenzierungsphänotyp, mit einer reduzierten mRNA Expression von Differenzierungsmarkern und einer Induktion von Dedifferenzierungs-assoziierten Transkripten. Dieser Dedifferenzierungs-Phänotyp korreliert mit einem unausgewogenen Verhältnis der Aktivitäten der PI3K/AKT und MEK/ERK Signalwege. 
A

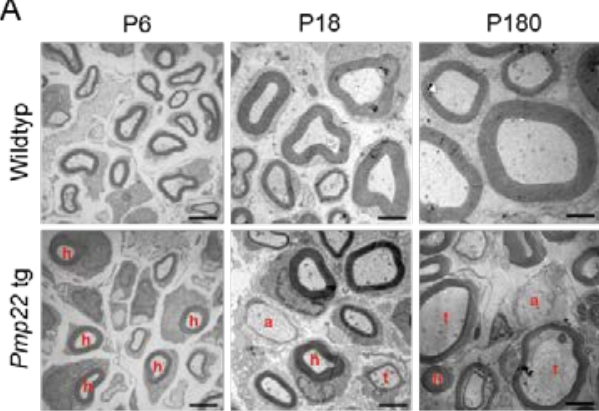

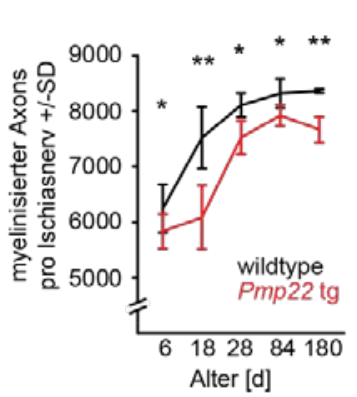

C

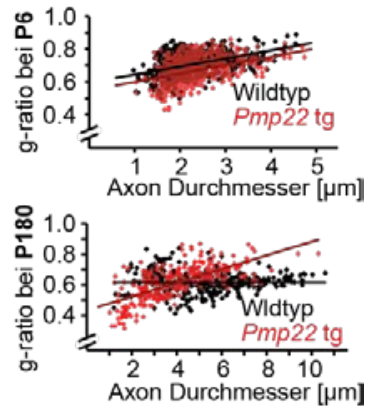

D
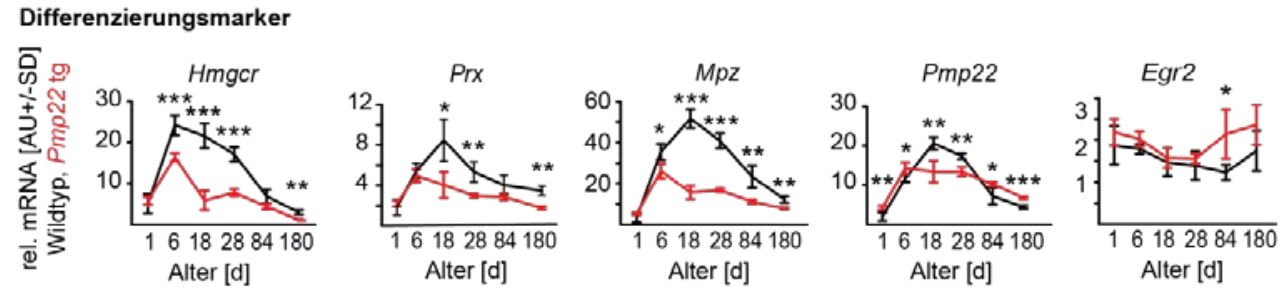

E

Dedifferenzierungsmarker
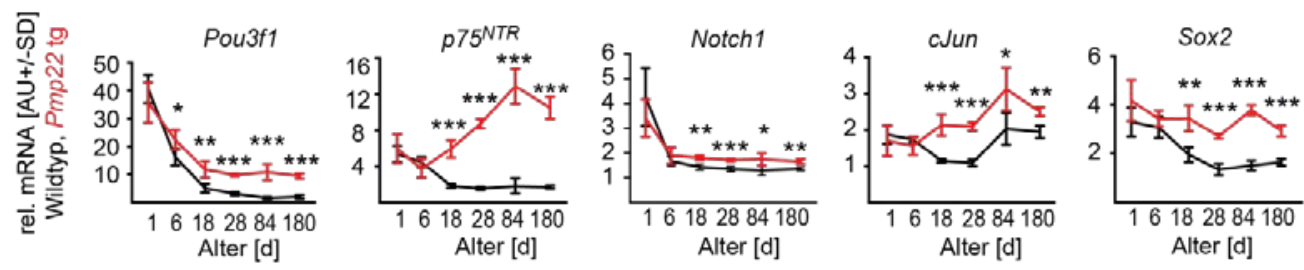

$\mathrm{F}$

$$
\begin{array}{c|c|c|c|c}
\text { P1 } & \text { P6 } & \text { P18 } & \text { P28 } & \text { P84 } \\
\text { w I tg } & \text { wt I tg } & \text { wt I tg } & \text { wt I tg } & \text { wt I tg }
\end{array}
$$
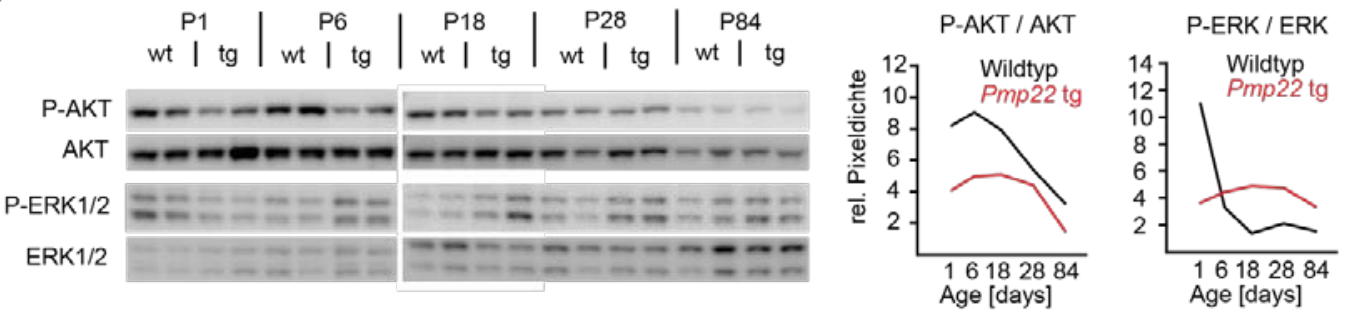

Abbildung 9: Pmp22 Überexpression führt zu eine früh-postnatalen fehlerhaften Differenzierung von Schwannzellen. A Elektronenmikroskopische Aufnahmen von Ischiasnerv-Querschnitten von Wildtyp- und CMT Ratten zeigen bereits zu P6 in CMT Ratten hypermyelinisierte (h) Axone, zu P18 und

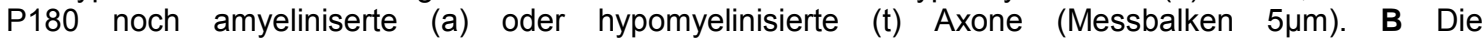
lichtmikroskopische Quantifizierung der Anzahl myelinisierter Axone pro Ischiasnerv zu den Zeitpunkten P6, P18, P28, P84, P180 zeigt dass CMT Ratten stets signifikant weniger Axone haben als WildtypKontrollen ( $n=4-8$ pro Gruppe, T-Test). C Die elektronenmikroskopische Quantifizierung der Myelindicke (g-ratio) von Ischiasnervfasern in Wildtyp- und CMT Ratten zu den Zeitpunkten P6 und P180. Zum Zeitpunkt P6 (oben) zeigen CMT Ratten eine stete Hypermyelinisierung über alle Axonkaliber, während bei P180 (unten) nur noch kleine hypermyelinisierte Fasern, jedoch große hypomyelinisierte Fasern vorliegen (mindestens $n=3$ pro Gruppe und Zeitpunkt mit mindestens 150 vermessenen Fasern pro Tier). D Quantitative Realtime-PCR von Wildtyp- und CMT Ratten mRNA Extrakten aus Ischiasnervgewebe zu den angegebenen Alterszeitpunkten. Die Differenzierungsmarker Hmgcr, Prx und Mpz sind ab P6/P18 in CMT Ratten geringer exprimiert. Pmp22 zeigt in CMT Ratten nur zu den Zeitpunkten P18 und P28 ein geringeres mRNA Level, während eine Überexpression zu den frühen (P1: 2,2-fach; P6: 1,2-fach) und späten ( 1,6-fach) Zeitpunkten sichtbar ist. Die mRNA des Transkriptionsfaktors und Differenzierungsmarkers Egr2 (Krox20) ist weitestgehend unverändert ( $\mathrm{n}=4$ pro Gruppe und Zeitpunkt, TTest). E Quantitative Realtime-PCR von Wildtyp- und CMT Ratten mRNA Extrakten aus Ischiasnervgewebe zu den angegebenen Alterszeitpunkten. Die Dedifferenzierungsmarker (oder Marker unreifer Schwannzellen) Pou3f1, p75 ${ }^{\text {NTR }}$, Notch1, cJun und Sox2 sind in CMT Ratten ab den Zeitpunkten P6/P18 hochreguliert ( $n=4$ pro Gruppe und Zeitpunkt, T-Test). F Western blot Analysen mit Komplettproteinextrakten aus Ischiasnerven von Wildtyp- (wt) und CMT (tg) Ratten zu den angegebenen Zeitpunkten (je zwei biologische Replikate). Die Aktivitäten des PI3K/AKT und des MEK/ERK Signalweges würden gemessen als phosphoryliertes AKT über AKT bzw. phosphoryliertes ERK1/2 über ERK1/2. Densitometrische Quantifizierung der Western blots links in den Diagrammen rechts mit je zwei biologischen Replikaten pro Gruppe und Zeitpunkt. 


\subsection{NEUREGULIN-1 EXPRESSION IN SCHWANNZELLEN BEI NERVENSCHÄDIGUNG}

\subsubsection{NEUREGULIN-1 EXPRESSION IN SCHWANNZELLEN VON MURINEN CMT1A MODELLEN}

In eigenen Vorarbeiten konnte mittels microarray-basierter Genexpressionsprofilanalyse festgestellt werden, dass in mRNA-Extrakten aus Ischiasnerven Pmp22 transgener Ratten neben Dedifferenzierungsmarkern unter anderem ein erhöhtes Level an Nrg1 mRNA vorliegt (Fledrich et al., 2012a). In einer ersten Serie an Experimenten sollte somit zunächst der zelluläre Ursprung, die temporäre Expressionsdynamik sowie der relative Beitrag der unterschiedlichen Nrg1 Isoformen (Typ I, II und III) in Pmp22 transgenen Mäusen und Ratten untersucht werden.

Von Pmp22 transgenen Ratten wurden zu verschieden Alterszeitpunkten Nn. Ischiadci abgesammelt und hinsichtlich einer Nrg1 mRNA Expression analysiert. Es zeigte sich bei diesen Analysen, dass Nrg1 von postnatal Tag 6 an zunehmend in Ischiasnerven Pmp22 transgener Ratten exprimiert wird (Abb. 10A). Wildtypische Ratten verzeichnen einen leichten Anstieg der Nrg1 Expression in Ischiasnerven in Abhängigkeit vom Alter (Abb. 10A). Transgene Mäuse, welche Pmp22 überexprimieren, zeigen ebenfalls eine erhöhte Nrg1 mRNA Expression (Abb. 10B). Innerhalb dieser Analysen wurde ersichtlich, dass spezifisch die solublen Isoformen Nrg1 Typ I und Typ II induziert werden, wohingegen die Nrg1 Typ III Isoform in Ischiasnerven Pmp22 transgener Mäuse signifikant geringer exprimiert wird (Abb. 10B).

A

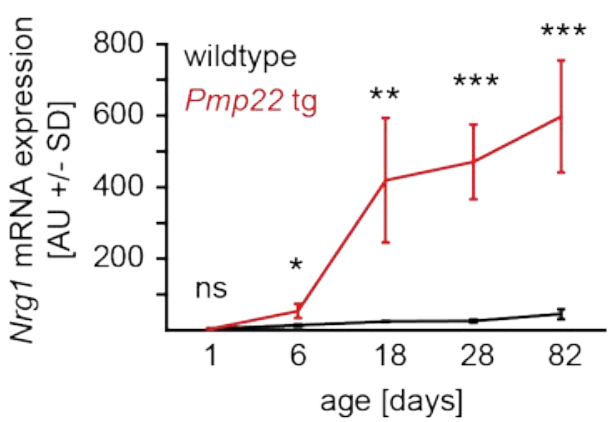

B

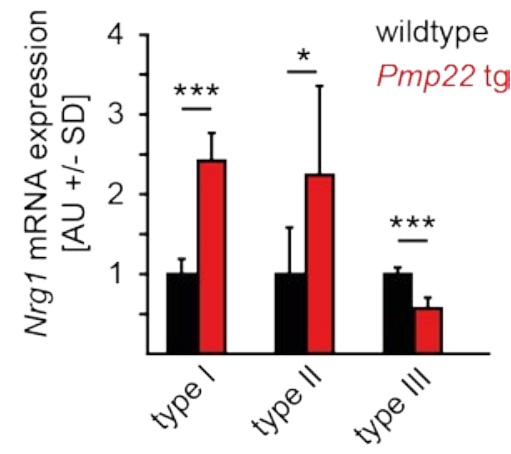

Abbildung 10: Nrg1 mRNA Expression in Ischiasnerven Pmp22 transgener Nager. A: Semiquantitative Real-Time PCR mit mRNA Extrakten aus Ischiasnerven Pmp22 transgener und wildtypischer Ratten zeigt eine progrediente Erhöhung der total Nrg1 mRNA Expression von postnatal Tag 6 an (n=4 pro Genotyp und Zeitpunkt, T-Test). B Isoformspezifische RT-PCRs für Nrg1 Typ I, II und III aus mRNA Extrakten aus Ischiasnerven 6 Monate alter Pmp22 transgener Mäuse zeigt eine spezifische Induktion der Nrg1 Isoformen Typ I und II sowie eine Herunterregulation der Typ III Isoform im Vergleich zu Wildtyp-Kontrollen ( $\mathrm{n}=5$ pro Gruppe, T-Test). 
Wichtige Funktionen für axonal/neuronal exprimiertes Neuregulin-1 als Signal für die Schwannzell-Entwicklung bis hin zur terminalen Myelinisierung wurden bereits beschrieben (Taveggia et al., 2010). Um den zellularen Ursprung (Axon oder Schwannzelle) der erhöhten Nrg1 Expression zu identifizieren wurden deshalb immunhistochemische Färbungen gegen NRG1 in Ischiasnerven Pmp22 transgener Mäuse angefertigt (Abb. 11). Es zeigte sich in Ischiasnervquerschnitten ein NRG1 Signal in myelinisierenden Schwannzellen Pmp22 transgener Mäuse (Abb. 11), sodass tatsächlich von einer glialen und nicht von einer axonalen Lokalisation der erhöhten Nrg1 Expression ausgegangen werden kann. Schwannzellen wildtypischer Mäuse hingegen produzieren kein detektierbares NRG1 Protein (Abb.11).
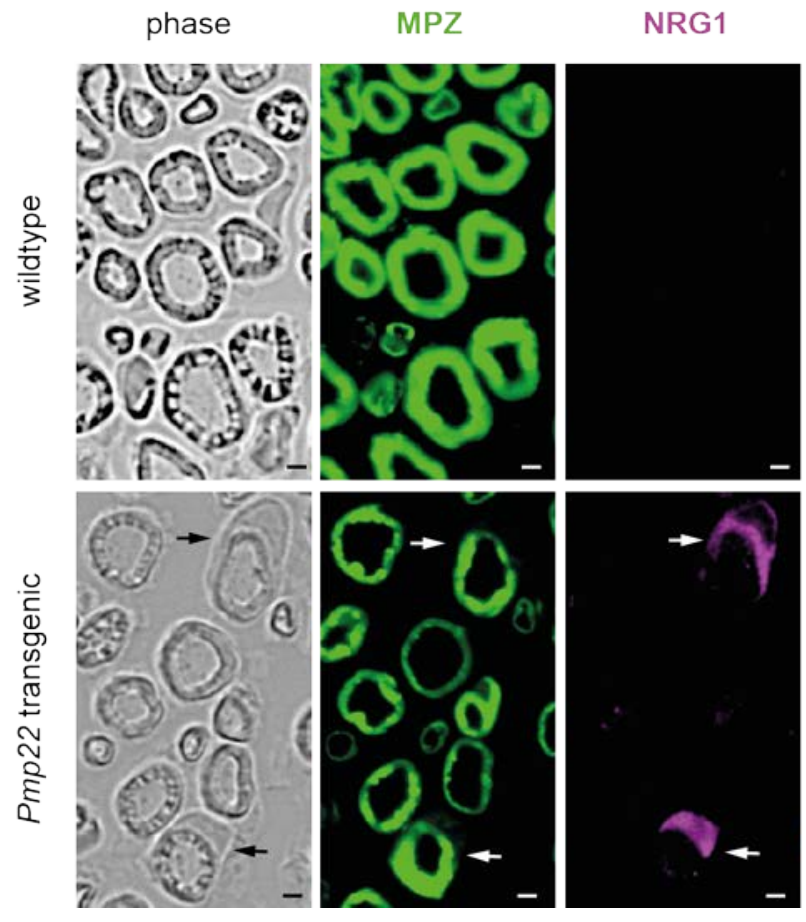

DAPI MPZ NRG1DAPI

Abbildung 11: Neuregulin-1 wird von Pmp22 transgenen Schwannzellen exprimiert. Immunhistochemische Färbung von Ischiasnerv-Querschnitten einer wildtypischen (oben) und Pmp22 transgenen Maus (Alter: 6 Monate). Myelinisierende Schwannzellen (Myelinfärbung gegen MPZ, grün) Pmp22 transgener Mäuse zeigen im Gegensatz zu Wildtyp Mäusen die Expression des NRG1 Proteins (mangenta, indiziert durch Pfeile). Zellkerne sind mit DAPI (blau) gegengefärbt. Phasenkontrastaufnahmen sind zum Vergleich jeweils links abgebildet (Maßstab: $2 \mu \mathrm{m}$ ). 


\subsubsection{NEUREGULIN-1 EXPRESSION IN SCHWANNZELLEN NACH AKUTER NERVENSCHÄDIGUNG}

Ist eine induzierte gliale NRG1-Expression spezifisch für PMP22 überexprimierende Schwannzellen innerhalb der chronischen CMT1A Neuropathie oder eher ein universelles Merkmal erkrankter Schwannzellen? Um diese Frage zu adressieren wurde in der Folge ein akutes Nervenläsionsmodell herangezogen, bei welchem bei Wildtypmäusen der Ischiasnerv experimentell gequetscht wird. Bei unterschiedlichen Zeitpunkten nach der Läsionssetzung wurden die distalen und proximalen Abschnitte des gequetschten Ischiasnerven abgesammelt und hinsichtlich einer Nrg1 Expression untersucht. Hierbei konnte festgestellt werden, dass spezifisch die Nrg1 Typ I Isoform in Schwannzellen nach einer akuten Verletzung transkriptionell hochreguliert wird (Abb. 12). Innerhalb von 24 Stunden erreicht die mRNA Expression von Nrg1 Typ I ein Maximum im distalen Bereich zur Nervenläsion und sinkt nach 4 Wochen wieder auf das Level eines unverletzten Nerven. Auch im proximalen Nervenstumpfen konnte eine Induktion von Nrg1 Typ I gemessen werden, welche jedoch nur etwa halb so hoch ist wie im distalen Bereich (Abb. 12). Auf Proteinebene konnte darüber hinaus mittels Immunhistochemie die NRG1 Expression nach akuter Nervenverletzung in Schwannzellen lokalisiert werden (Stassart und Fledrich et al., 2013).

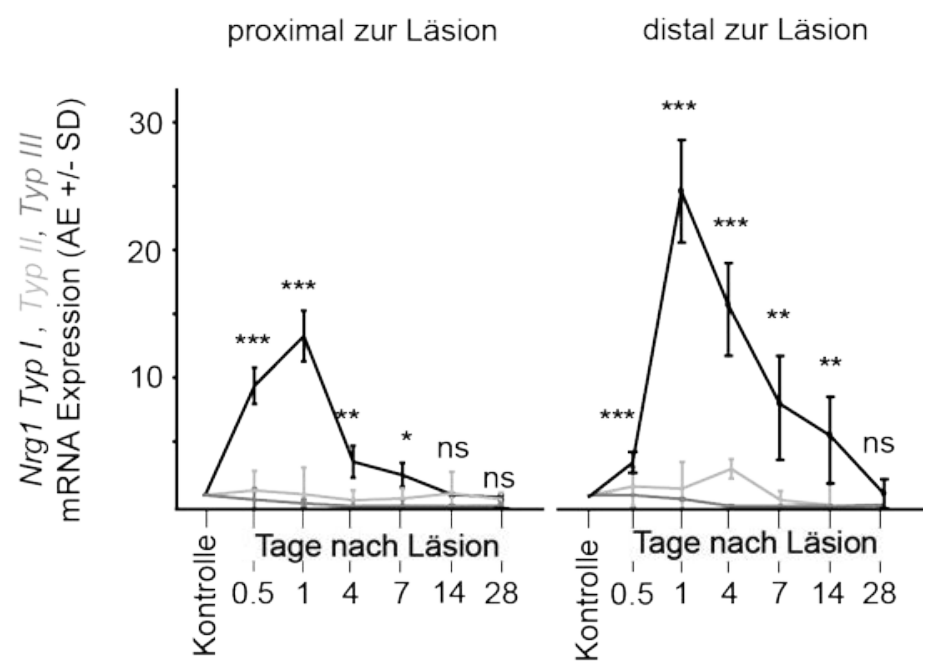

Abbildung 12: Nrg1 mRNA Expression in Ischiasnerven nach akuter Nervenquetschung. Die proximalen und distalen Abschitte des gequetschten Ischiasnerven zeigen ein Maximum einer Nrg1 Typ I mRNA Expression 1 Tag nach Läsion. Das Ausmaß der distalen Induktion von Nrg1 Typ / ist ungefähr doppelt so hoch wie das im proximalen Nervenstumpfen und erreicht nach 28 Tagen wieder ein Normalmaß. Die Isoformen Nrg Typ II und Typ III werden nach einer Nervenquetschung nicht hochreguliert ( $n=4$ pro Zeitpunkt, T-Test). 


\subsection{Die FUnKTIONELLE ReLEVANZ INDUZIERTER NRG1 EXPRESSION IN SCHWANNZELLEN BEI NERVENSCHÄDIGUNGEN}

Eine experimentelle Nervenläsion ist ein nützliches Werkzeug zur Untersuchung von De- und Regenerationsprozessen nach einer Verletzung innerhalb eines definierten Zeitrahmens. Um die funktionelle Relevanz einer NRG1 Expression nach Verletzung in Schwannzellen näher zu untersuchen wurden deshalb Mausmutanten generiert, in denen mit Hilfe des Cre-LoxP Systems das Nrg1 Gen spezifisch in Schwannzellen ablatiert wurde. Hierzu wurde eine Cre-Treiberlinie unter einem Schwannzellspezifischen Promotor (Dhh) benutzt um die mit LoxP-Stellen flankierten Nrg1 Allele einer zweiten Mauslinie zu ablatieren (Stassart und Fledrich et al., 2013). Western blot Analysen mit Proteinextrakten aus Ischiasnerven 4 Tage nach Läsion zeigen eine effiziente Rekombination, da eine NRG1 Bande nur bei Wildtyp-Kontrollen sichtbar wurde (Abb. 13). Innerhalb dieser Analysen wurde auch die Aktivierung der Rezeptortyrosinkinase ErbB2, als Rezeptor für NRG1, untersucht. Im Gegensatz zu Wildtyp-Kontrollen konnte in Mausmutanten ohne Schwannzell-NRG1 keine Phosphorylierung von ErbB2 vier Tage nach Läsion festgestellt werden (Abb. 13). Auch eine erhöhte Aktivität des MEK/ERK Signalweges, dessen Aktivierung bei akuter Nervschädigung bereits bekannt ist (Sheu et al., 2000) konnte in den NRG1 Mausmutanten nicht festgestellt werden (Abb. 13).

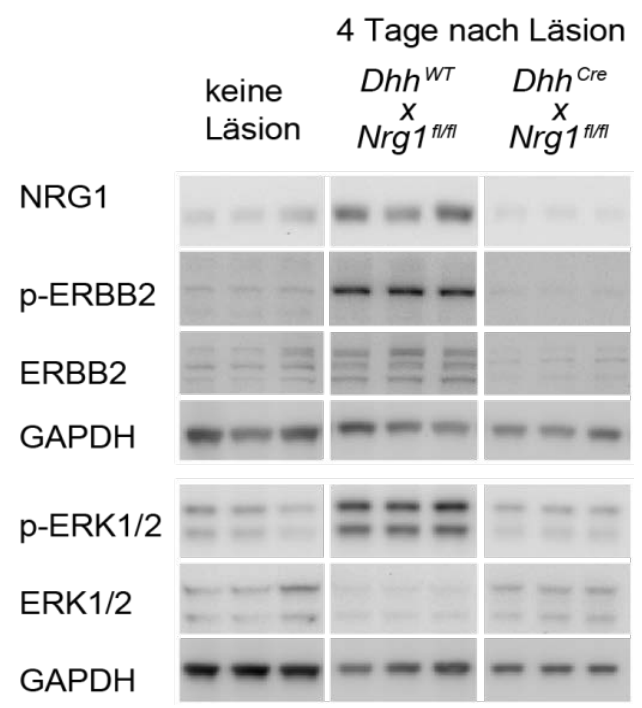

Abbildung 13: Mausmutanten ohne Schwannzell-NRG1 zeigen keine Aktivierung von ErbB2 und ERK1/2 vier Tage nach Nervenquetschung. Western blot Analysen mit Proteinextrakten aus Ischiasnerven von gesunden Wildtyp-Mäusen (keine Läsion, links), von Kontroll-Mäusen (Dhh ${ }^{\mathrm{Cre}} \times \mathrm{Nrg}^{f / f f l}$, Mitte) und Mausmutanten in denen das Nrg1 Gen in Schwannzellen konditional inaktiviert wurde $\left(D h h^{\text {Cre }} x\right.$ $\mathrm{Nrg}^{f / / f I}$, rechts) vier Tage nach Nervenquetschung. Mäuse ohne Schwannzell NRG1 zeigen im Gegensatz zu Kontroll-Mäusen keine erhöhte Phosphorylierung von ErbB2 und ERK1/2. GAPDH dient als Ladekontrolle. 
Morphologisch zeigen Mäuse ohne NRG1 in Schwannzellen nach einer experimentellen Nervenquetschung eine verschlechterte Remyelinisierung, sowie eine weitreichende Beeinträchtigung der funktionellen Regeneration (Stassart und Fledrich et al., 2013).

Zur Untersuchung der funktionellen Relevanz von Schwannzell-NRG1 innerhalb der chronischen Neuropathie CMT1A wurde in Pmp22 transgenen Mäusen, analog zu den Nervenläsionsexperimenten, spezifisch das Nrg1 Gen in Schwannzellen inaktivert. Im Alter von 10 Monaten wurden die Mausmutanten hinsichtlich ihres Phänotyps untersucht und Griffstärkeanalysen sowie Nervenleitgeschwindigkeitsmessungen durchgeführt. Die Griffstärke der Vorderextremitäten ist bei Pmp22 transgenen Mäusen geringer als bei Wildtyp-Kontrollen (Abb. 14A). Pmp22 transgene Mäuse denen das Nrg1 Gen spezifisch in Schwannzellen ablatiert wurde, zeigen im Alter von 10 Monaten eine weitere Beeinträchtigung der Griffstärke (Abb. 14A). Neurographische Messungen ergaben, dass die reduzierte Nervenleitgeschwindigkeit (NLG) bei Pmp22 transgenen Mäusen durch Inaktivierung von Schwannzell-Nrg1 nicht verändert wird (Abb. 14B). Im Gegensatz zeigt eine Quantifizierung der Muskelsummenaktionspotentiale (MSAP), als elektrophysiologisches Korrelat zur Anzahl funktioneller Axone, eine weitere Reduktion durch Nrg1-Ablation in Schwannzellen Pmp22 transgener Mäuse (Abb. 14C-D).

Neuregulin-1 wird sowohl nach akuter Nervenverletzung wie auch bei chronischer Nervenschädigung bei Pmp22 Überexpression in Schwannzellen induziert (Abb. 1013). Die genetische Inaktivierung des Nrg1 Gens in Schwannzellen führt bei beiden Modellen zu einer Verschlechterung des Phänotyps (Stassart und Fledrich et al., 2013 und Abb. 14). 
A

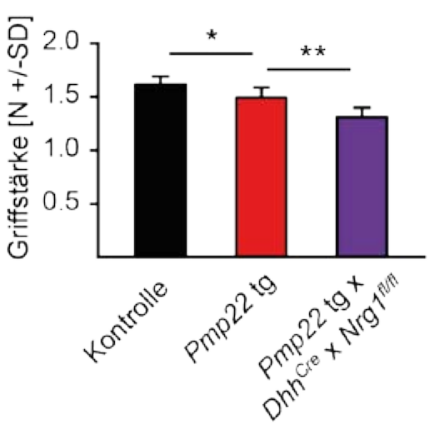

C

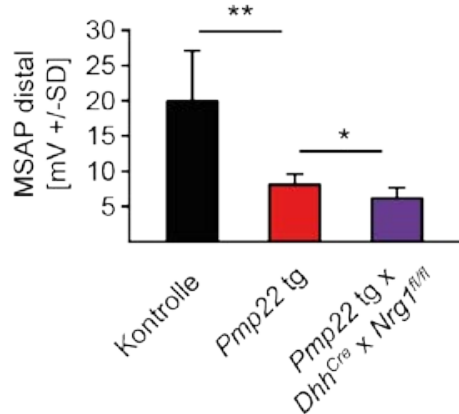

B

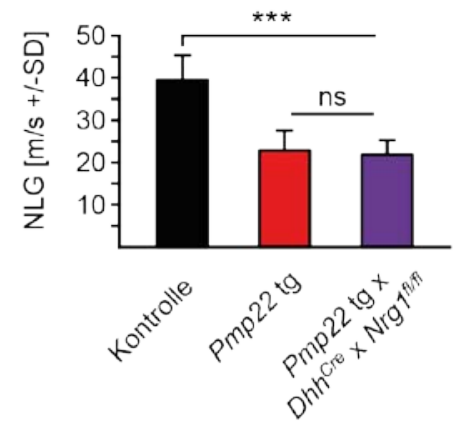

D

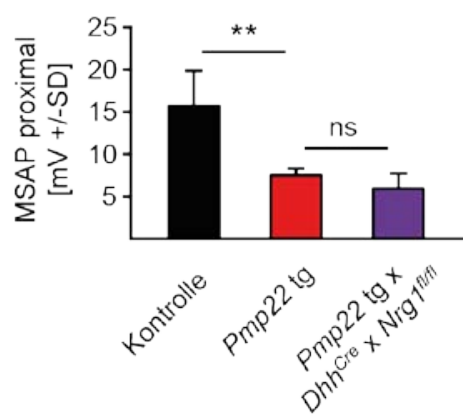

Abbildung 14: Ablation von Schwannzell-Nrg1 verschlechtert den Phänotyp in Pmp22 transgenen Mäusen. A Griffstärkemessung der Vorderextremitäten im Alter von 10 Monaten in Kontroll- $(n=3)$ und Pmp22 transgenen Mäusen mit (Pmp22 tg, $\mathrm{n}=4)$ und ohne Schwannzell-Nrg1 (Pmp22 $\operatorname{tg} \times D^{2} h^{\mathrm{Cre}} \times \mathrm{Nrg}^{\mathrm{fl} / \mathrm{fl}}$, $\mathrm{n}=7$ ) zeigt eine weitere Verschlechterung der Griffstärke in CMT1A Mäusen ohne Schwannzell-NRG1. B Die reduzierte Nervenleitgeschwindigkeit (NLG) bei Pmp22 transgenen Mäusen verändert sich nicht durch NRG1 Ablation in Schwannzellen. C und D Die Muskelsummenaktionspotentiale (MSAP) nach distaler (C) und proximaler Stimulation (D) zeigt eine weitere Amplitudenreduktion in CMT1A Mäusen ohne Schwannzell-NRG1 (signifikant nur in C). (B-D: Kontrolle $\mathrm{n}=5, P m p 22 \operatorname{tg} \mathrm{n}=6, P m p 22 \operatorname{tg} \times \mathrm{Dhh}^{\mathrm{Cre}} \times \mathrm{Nrg}^{\mathrm{flft}}$, $\mathrm{n}=8$, T-test) 
3.4. NeURONALE Expression VON NEUREgUlin-1 BEI AKUTER UND CHRONISCHER NERVENSCHÄDIGUNG

NRG1 Typ I wird von Schwannzellen sowohl nach akuter Nervenschädigung wie auch innerhalb der chronischen CMT1A hochreguliert. Im Gegensatz dazu wird die Typ III Isoform von Nrg1 herunter reguliert. Die Funktion von Neuregulin-1 in Schwannzellen wurde bisher nicht untersucht. Als neuronaler und axonal präsentierter Wachstumsfaktor konnten jedoch insbesondere NRG1 Typ III in der Vergangenheit bedeutende Funktionen bei der Schwannzellreifung bis hin zur Myelinisierung zugeschrieben werden (Taveggia et al., 2010). Im Folgenden sollte deshalb auch die neuronale Expression der beiden Nrg1 Isoformen Typ I und III in den untersuchten Modellen gemessen werden.

Zunächst wurden immunhistochemische Färbungen von NRG1 in Rückenmarkquerschnitten zwei Wochen nach Nervenläsion angefertigt (Abb. 15). Im vierten bis fünften Lumbalsegment befinden sich die Motoneurone, welche in die Ischiasnerven wildtypischer Mäuse projizieren. Auf dieser Höhe konnten zwei Wochen nach Nervenläsion im ipsilateralen Ventralhorn zahlreiche Motoneurone detektiert werden, welche ein deutlich schwächeres NRG1 Signal zeigten als die Motoneurone auf der kontralateralen Seite (Abb. 15).

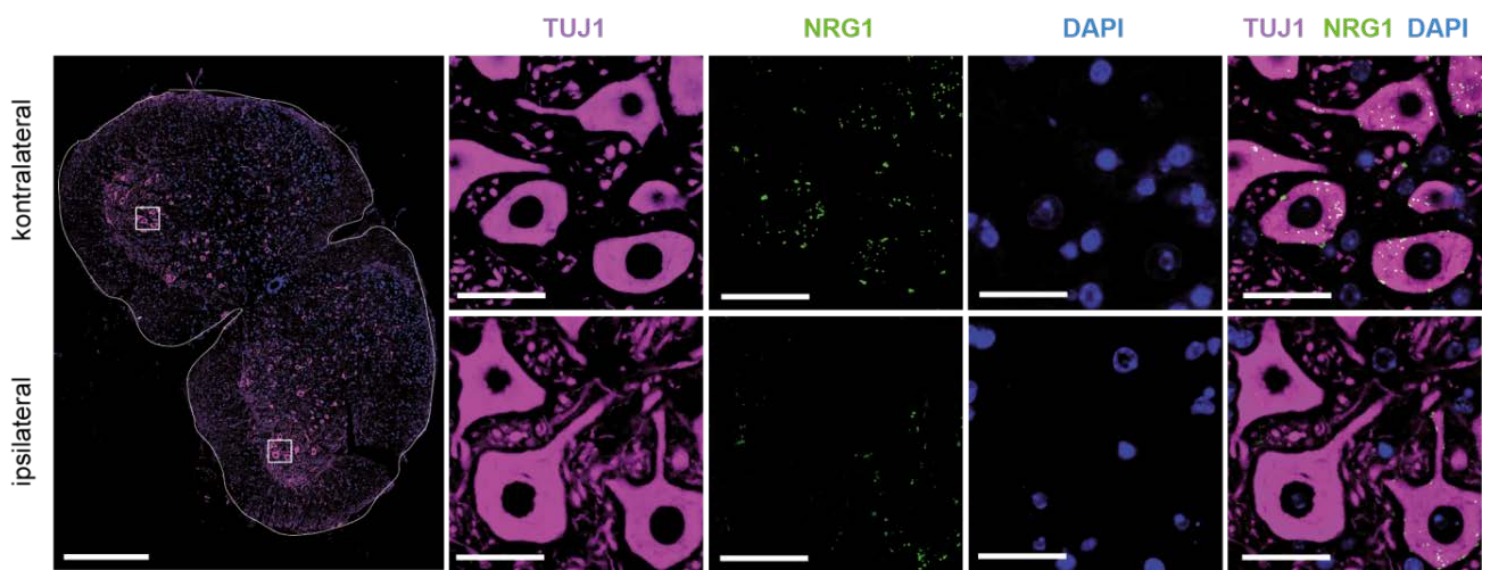

Abbildung 15: Motoneurone zeigen zwei Wochen nach Nervenläsion eine verringerte NRG1 Expression. Immunhistochemische Färbung von NRG1 (grün) im quergeschnittenen Rückenmark (Höhe L5) zwei Wochen nach experimenteller Läsion des Ischiasnerven. Motoneurone (TUJ1=Tubulin, magenta) im ventralen Horn der ipsilateralen Seite zeigen ein deutlich schwächeres NRG1 Signal als vergleichbare Motoneurone auf der kontralateranlen Seite. Zellkerne sind mit DAPI (blau) gegengefärbt. (Messbalken

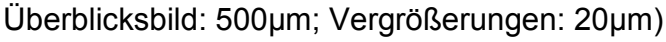

Zur Analyse der mRNA Expression der unterschiedlichen Nrg1 Isoformen wurden Spinalganglien von Wildtypmäusen zwei und vier Wochen nach Nervenläsion herangezogen. Im Vergleich zu Spinalganglien unverletzter Kontrollmäuse ist Nrg1 Typ I zwei Wochen nach Läsion stärker, und Nrg1 Typ III schwächer exprimiert (Abb. 15). 
Vier Wochen nach Nervenläsion ist die mRNA Expression beider Isoformen so hoch wie vor Verletzung (Abb. 15).

Analog wurde auch die mRNA Expression von Nrg1 Typ I und Typ III in Spinalganglien adulter CMT Mäuse untersucht. Es zeigte sich mit einer stärkeren Expression von Nrg1 Typ I und einer schwächeren Expression von Nrg1 Typ III ein ähnliches Bild wie im akuten Nervenläsionsmodell (Abb. 16).

Spinalganglien bestehen nicht nur aus neuronalen Zellen, sondern auch aus sogenannten Satelliten-Schwannzellen (Hyden, 1961). Es ist daher nicht auszuschließen, dass zumindest die induzierte Nrg1 Typ I Expression auf ebendiese Satellitenzellen zurückuführen ist.

A
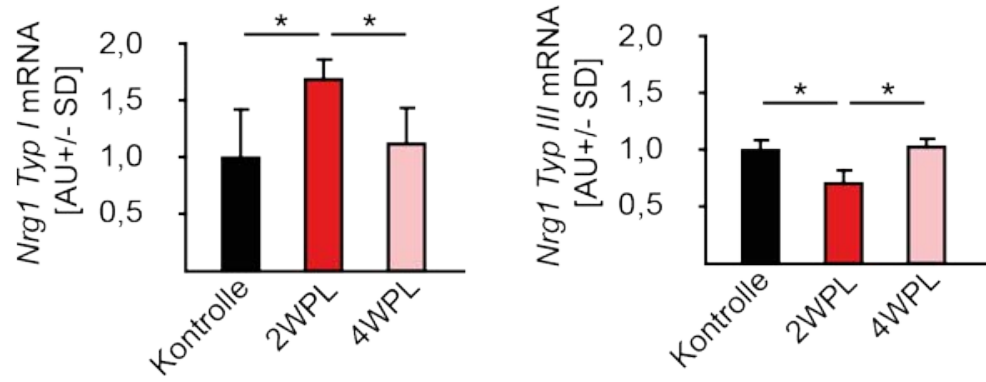

B
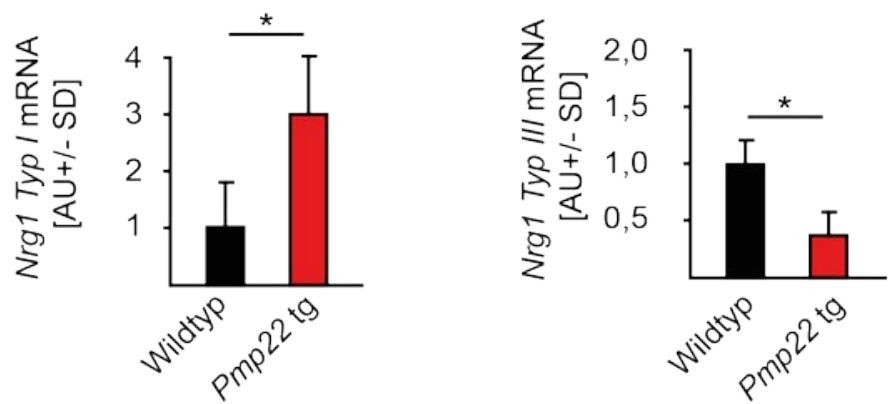

Abbildung 16: In Spinalganglien wird bei Nervenschädigung Nrg1 Typ I mRNA Expression induziert. A Im akuten Nervenläsionsmodell wird in Spinalganglien 2 Wochen post Läsion (2WPL) Nrg1 Typ I (links) hoch- und Nrg Typ III (rechts) herunter reguliert. Nach vier Wochen (4WPL) ist die mRNA Expression beider Isoformen wieder so hoch wie vor der Läsion ( $n=5$ pro Gruppe, T-Test). B Auch in Spinalganglien Pmp22 transgener Mäuse (Alter 6 Monate) ist Nrg1 Typ I (links) im Vergleich zu Wildtypkontrollen stärker exprimiert, während Nrg1 Typ III (rechts) schwächer exprimiert wird ( $\mathrm{n}=5$ pro Gruppe, T-Test). 
3.5. DeR EINFLUSS VON NEURONAL ÜBEREXPRIMIERTEM NRG1 AUf DIE PATHOGENESE VON NERVENSCHÄDIGUNGEN

Die Expression von Neuregulin-1 Typ I wird in Schwannzellen nach akuter und chronischer Nervenschädigung induziert. Im Gegensatz dazu wird Neuregulin-1 Typ III sowohl glial als auch neuronal herunter reguliert. Um die funktionelle Relevanz dieser Beobachtungen näher zu erörtern, sollte in der Folge der Einfluss von neuronal überexprimiertem NRG1 Typ I und Typ III auf die Pathologie in beiden Modellen untersucht werden.

\subsubsection{NEURONALE ÜBEREXPRESSION VON NRG1 TYP I UND TYP III IM NERVENLÄSIONSMODELL}

Nach einer Nervenläsion bleiben remyelinisierte Axone dauerhaft hypomyelinisiert (Schröder, 1972; Sherman and Brophy, 2005). Die neuronale Überexpression der beiden Isoformen NRG1 Typ I und Typ III führte 4 Wochen nach Nervenläsion zu einer vollständigen Wiederherstellung der Myelindicke (Stassart und Fledrich et al., 2013). Elektronenmikroskopische Analysen in quergeschnittenen Ischiasnerven zeigten darüber hinaus, dass Nrg1 Typ I, nicht aber Nrg1 Typ III transgene Tiere 4 Wochen nach Nervenläsion eine erhöhte Anzahl nicht-myelinisierter Axone pro Fläche aufweisen (Abb. 17A). Weitere 4 Wochen später ist dann die Totalanzahl myelinisierter Axone pro Ischiasnerv in Nrg1 Typ I tg Mäusen signifikant höher und in Nrg1 Typ III tg Mäusen signifikant niedriger im Vergleich zu Wildtypkontrollen (Abb. 17B).

Eine elektrophysiologische Untersuchung von Nrg1 Typ I transgenen Mäusen 4 Wochen nach Nervenquetschung zeigte bereits entsprechend eine Verbesserung sowohl der Nervenleitgeschwindigkeit, als auch des Muskelsummenaktionspotentials der Mutanten im Vergleich zu Wildtypkontrollen (Abb. 17C). Als Phänotypanalyse wird im Nervenläsionsmodell der sogenannte Ischiasnerv-Funktionsindex (sciatic nerve functional index, SFI), eine Fußabruckanalyse, herangezogen. In Bezug auf die Parameter Fußabdrucklänge und Zehenspreizung zeigen Nrg1 Typ I Mutanten bereits 2 Wochen nach Nervenläsion eine signifikant bessere Regeneration als Wildtypkontrollen (Abb. 17D). 
A
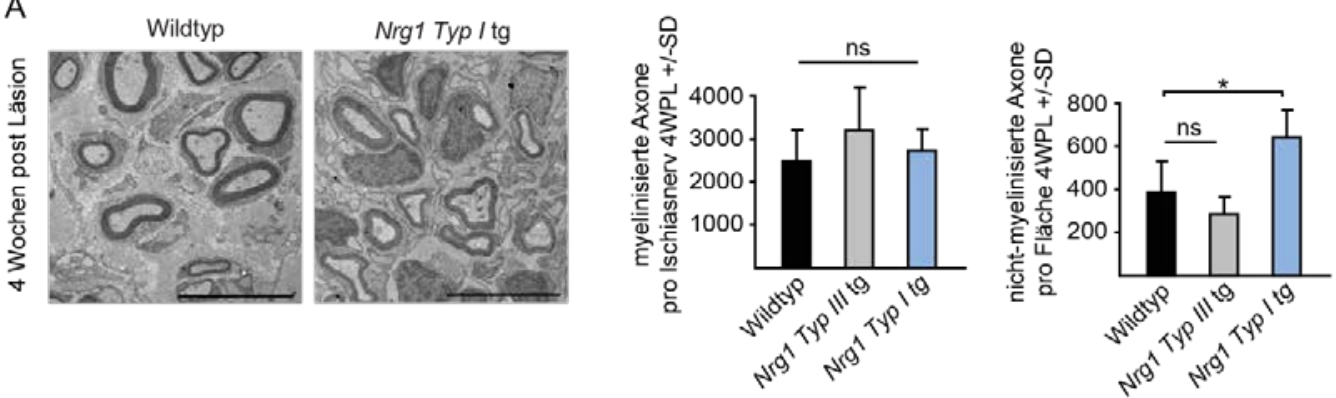

B
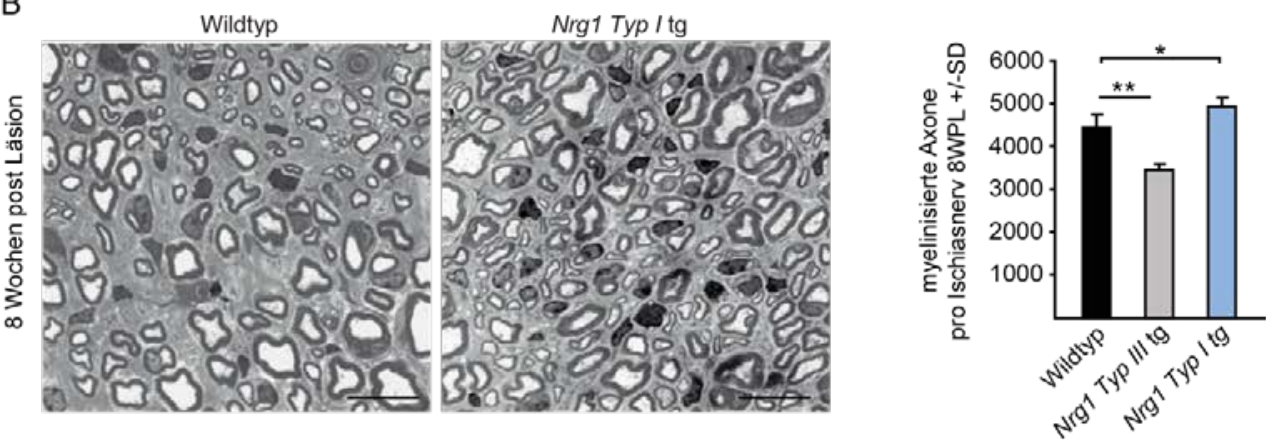

C
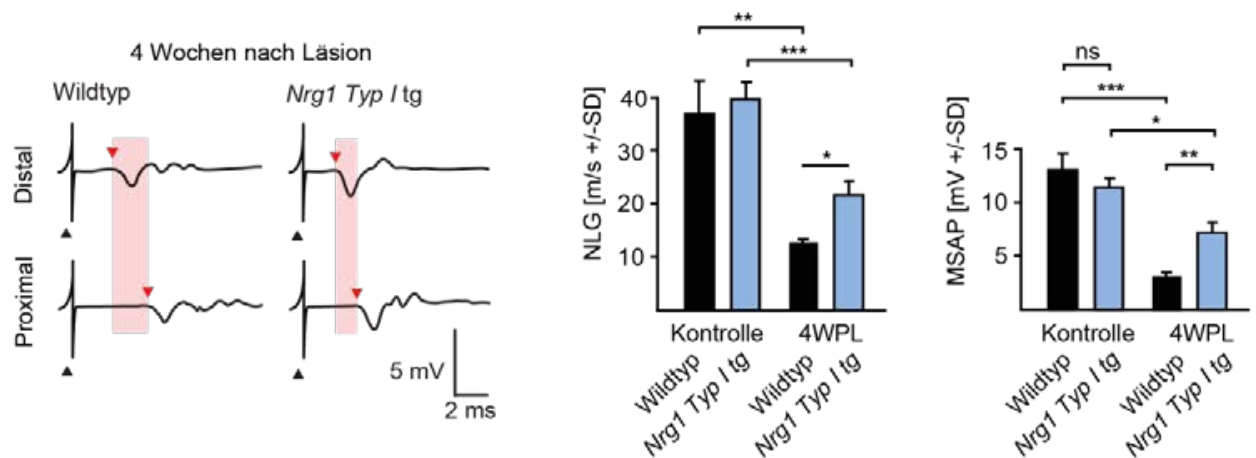

D
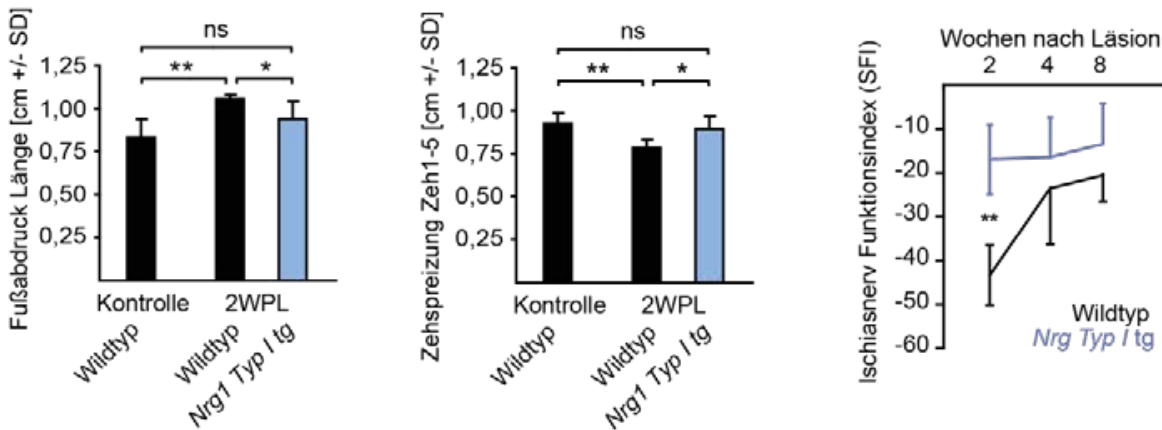

Abbildung 17: Neuronal überexprimiertes NRG1 Typ I, nicht aber Typ III, führt zu einer verbesserten funktionellen Regeneration nach Nervenläsion. A Repräsentative elektronenmikroskopische Aufnahmem quergeschnittener Ischiasnerven von Wildtyp und Nrg1 Typ I transgenen Mäusen zwei Wochen nach

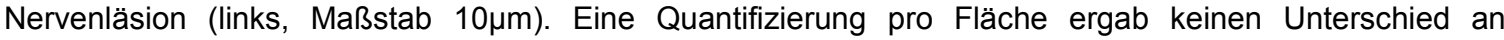
myelinisierten Axonen, jedoch eine erhöhte Anzahl von nicht-myelinisierten Axonen in Nrg1 Typ I transgenen Mäusen (rechts, $n=5$ pro Gruppe, T-Test). B Die lichtmikroskopische Quantifizierung der Totalanzahl myelinisierter Axone pro Ischiasnerv 8 Wochen nach Nervenläsion zeigt eine signifikant höhere Anzahl in Nrg1 Typ I und eine signifikant niedriger Anzahl in Nrg1 Typ III transgenen Mäusen (exemplarische Bilder einer Wildtyp und Nrg1 Typ I tg Maus links, Quantifizierung rechts, $\mathrm{n}=5$ pro Gruppe, T-Test). C Repräsentative Ableitungen einer Wildtyp und Nrg1 Typ I tg Maus 4 Wochen nach Läsion links zeigt eine deutliche Verbesserung der Nervenleitgeschwindigkeit und Amplitude des Muskelsummenaktionspotentials in den Mutanten (pink hervorgehoben, rote Pfeile indizieren Lantenzen, schwarze Pfeile zeigen Reizartefakte, Quantifizierung rechts, $n=5$ pro Gruppe, T-Test). D Fußabdruckanalysen 2 Wochen post Läsion (2WPL) zeigen eine funktionelle Verbesserung des Ischiasnerven in Nrg1 Typ I überexprimierenden Mäusen (links: Fußabdruck-Länge, Mitte: Zehenspreizung, Rechts Ischiasnerv-Funktionsindex 2, 4 und 8 Wochen nach Läsion, n=3-6 pro Gruppe, T-Test). 


\subsubsection{NEURONALE ÜBEREXPRESSION VON NRG1 TYP I UND TYP III IN CMT1A MÄUSEN}

Im Nervenkompressionsmodell führte nur die transgene Überexpression von NRG1 Typ I in Neuronen zu einer verbesserten Remyelinisierung und funktionellen Regeneration im PNS (Typ III: nur verbesserte Remyelinisierung; Stassart und Fledrich et al., 2013). Um zu untersuchen, ob eine solche Überexpression auch in der CMT1A zu einer Verbesserung des Phänotyps führt, wurden in der Folge Pmp22 transgene Mäuse mit Mausmutanten verpaart, die unter der Kontrolle des Thy1 Promotors entweder NRG1 Typ I oder Typ III vorwiegend in Motoneuronen überexprimieren (Michailov et al., 2004). Diese Mäuse wurden im Alter von 6 Monaten histologisch und elektrophysiologisch untersucht (Abb. 18-19).

Eine Quantifizierung der Anzahl myelinisierter Axone pro Ischiasnerv ergab neben einer Reduktion der Axonanzahl bei CMT1A Mäusen im Vergleich zu Wildtyp-Mäusen eine komplette Präservation myelinisierter Axone in Pmp22 x Nrg1 Typ I doppelt transgenen Mäusen (Abb. 18A-B). Hingegen wurde der axonale Verlust bei Pmp22 $\mathrm{x}$ Nrg1 Typ III doppelt transgenen Mäusen nicht aufgehalten (Abb. 18A-B). D.h. nur die neuronale Überexpression von NRG1 Typ I hat einen therapeutischen Effekt bezüglich der Anzahl myelinisierter Axone in CMT1A Mäusen.

Die NRG1 Typ I Überexpression in Neuronen führte im Nervenläsionsmodell zu einer vollständigen Restauration der Myelindicke (Stassart und Fledrich et al., 2013). Eine Quantifizierung des g-ratios als Maß für die Myelindicke ergab jedoch keinen Unterschied zwischen Pmp22 transgenen und Pmp22 x Nrg1 Typ I transgenen Mäusen (Abb. 18C).

Elektrophysiologische Aufnahmen zeigen im Vergleich zu Wildtypkontrollen bei CMT1A Mäusen eine Verringerung der Nervenleitgeschwindigkeit und des Muskelsummenaktionspotentials, sowie eine temporale Dispersion der Ableitungen (Abb. 19A). Die elektrophysiologische Untersuchung dieser Mausmutanten ergab diesbezüglich keinen Einfluss von NRG1 auf die reduzierte Nervenleitgeschwindigkeit in CMT1A Mäusen (Abb. 19B). Entsprechend der verbesserten Axonanzahl in Pmp22 $x$ Nrg1 Typ I transgenen Mäusen ist jedoch das Muskelsummenaktionspotential in diesen Doppelmutanten verbessert (Abb. 19C). Hingegen führt die Überexpression von NRG1 Typ III, wie auch bei der Axonanzahl, zu keiner Verbesserung des Muskelsummenaktionspotentials (Abb. 19C).

Auf histologischer und elektrophysiologischer Ebene zeigte die neuronale Überexpression von NRG1 Typ I einen therapeutischen Effekt auf CMT1A Mäuse. 
A

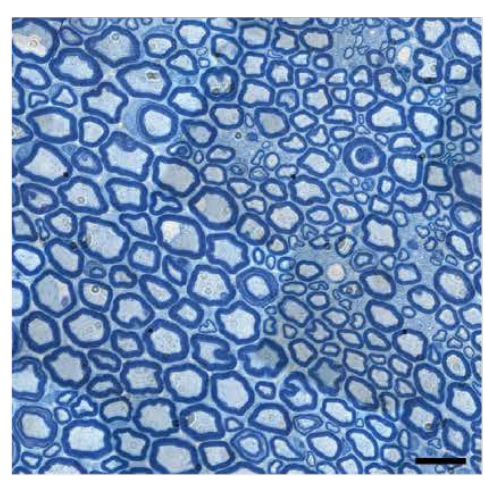

Pmp22 tg $\times$ Nrg1 Typ III tg

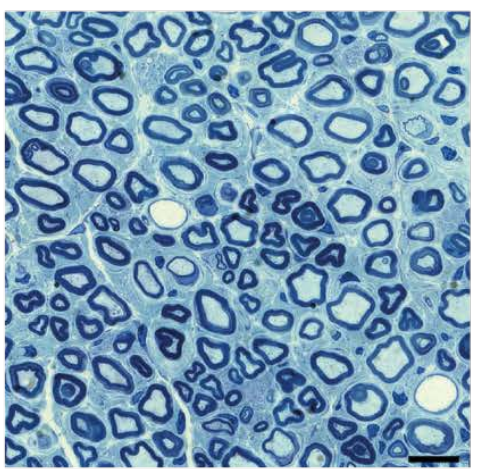

B

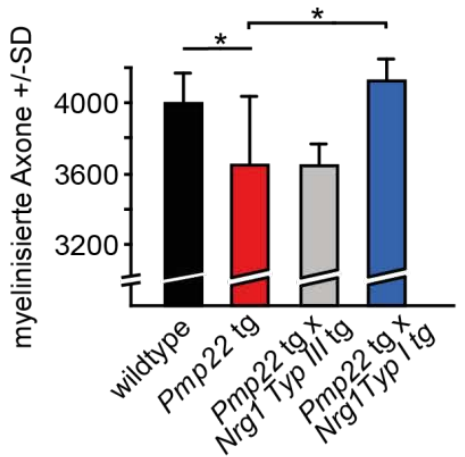

Pmp22 tg

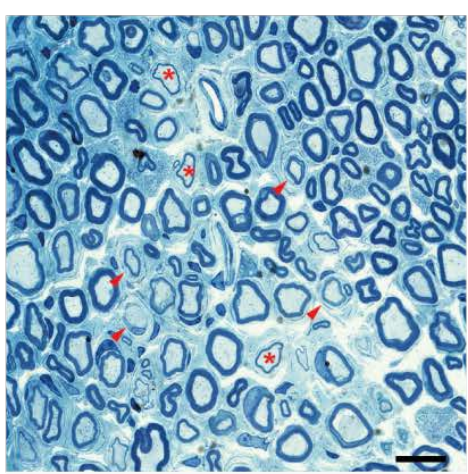

Pmp22 tg $\times$ Nrg1 Typ / tg

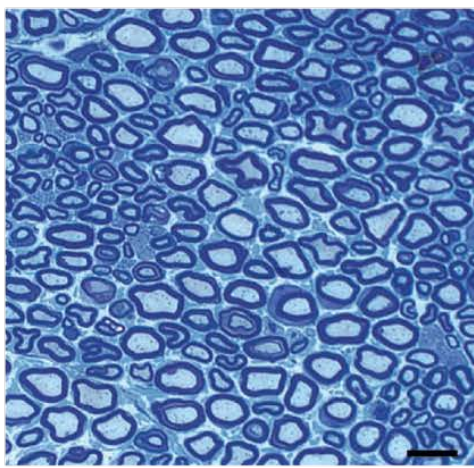

C

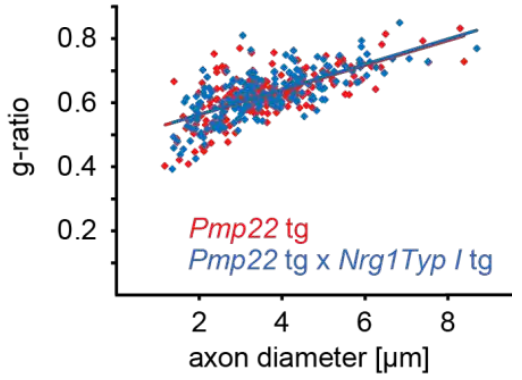

Abbildung 18: Die neuronale Überexpression von NRG1 Typ I führt in CMT1A zu einer axonalen

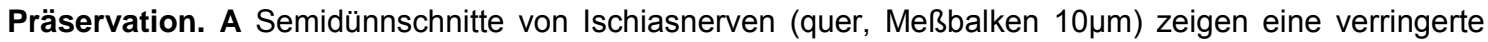
Axondichte bei CMT1A Mäusen (Pmp22 tg) im Vergleich zu Wildtyptieren mit pathologischen Charakteristika wie demyelinisierte Axone (Sternchen) und Zwiebelschalenformationen (Pfeilspitzen). Nur Pmp22 x Nrg1 Typ I, aber nicht Pmp22 x Nrg1 Typ III Mäuse zeigen eine verbesserte Anzahl myelinisierter Axone (Quantifizierung in B, $\mathrm{n}=5-8$ pro Gruppe, T-Test). C Unabhängig von der axonalen Präservation ist die Myelindicke (g-ratio) bei Pmp22 x Nrg1 Typ I Mutanten unverändert im Vergleich zu CMT1A Mäusen ( $\mathrm{n}=3$ pro Gruppe, mindestens 75 Axone pro Tier). 
A

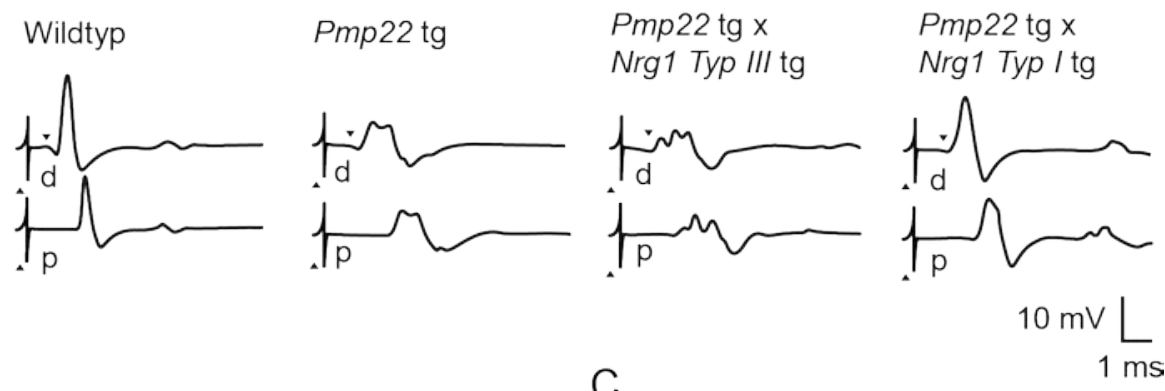

B

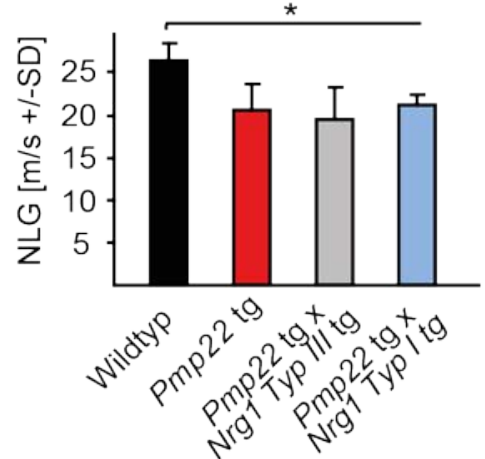

C

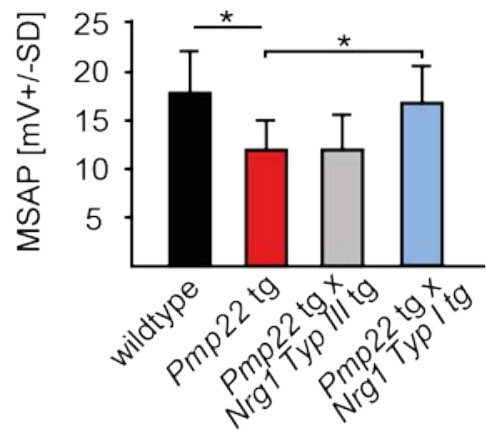

Abbildung 19: Die neuronale Überexpression von NRG1 Typ I verbessert die elektrophysiologische Funktionalität in Ischiasnerven von CMT1A Mäusen. A Exemplarisch dargestellte elektrophysiologische Ableitungen zeigen im Vergleich zum Wildtypen bei CMT1A Mäusen (Pmp22 tg) eine verlängerte Latenz (Pfeilspitze nach unten) und entsprechend eine Nervenleitgeschwindigkeitsverlangsamung. Darüber hinaus zeigen CMT1A Mäuse reduzierte Muskelsummenaktionspotentiale (MSAP) und eine temporale Dispersion der Ableitung. Nur die Überexpression von NRG1 Typ I, nicht aber von Typ III, verbessert das MSAP (Quantifizierung in C) sowie die Dispersion (Pfeilspitze nach oben: Stimulus, d: distale Stimulation, p: proximale Stimulation). B Weder die Überexpression von NRG1 Typ I noch Typ III hat einen Einfluss auf die reduzierte Nervenleitgeschwindigkeit (NLG) in CMT1A Mäusen. ( $n=5-8$ pro Gruppe, T-Test).

In einer weiteren Serie an Experimenten sollten die molekularbiologischen Auswirkungen von NRG1 Typ I auf Pmp22 transgene Mäuse untersucht werden. In Proteinextrakten aus Ischiasnerven von CMT1A Mäusen ist wie auch bei Pmp22 transgenen Ratten eine gestörte Balance der PI3K/AKT und MEK/ERK Signalwege zu messen (Abb. 20A). Diese Dysbalance wird durch die neuronale Überexpression von NRG1 Typ I wieder normalisiert (Abb. 20A). Auch auf mRNA Ebene ist in CMT1A Mäusen eine erhöhte Expression der Dedifferenzierungsmarker cJun, Sox2 und $p 75^{N T R}$ in Ischiasnerven zu verzeichnen, welche durch die Nrg1 Typ I Überexpression wieder normalisiert wurde (Abb. 20C). Die mRNA Expression der Differenzierungsmarker Egr2, Hmgcr sowie Prx ist bis auf Prx hingegen in den Doppelmutanten kaum verändert (Abb. 20B).

Zusammenfassend führt die neuronale Überexpression von NRG1 Typ I, nicht aber von NRG1 Typ III, in CMT1A Mäusen zu einer drastischen Erhöhung der Anzahl myelinisierter Axone pro Ischiasnerv auf Wildtyp-Niveau. Auch die Höhe des 
Muskelsummenaktionspotentials ist in Pmp22 x Nrg Typ I doppelt transgenen Mäusen signifikant verbessert. Auf molekularer Ebene korrelieren diese histologischen und physiologischen Befunde mit einer Normalisierung der Aktivitäten der PI3K/AKT und MEK/ERK Signaltransduktioskaskaden, sowie mit einer Korrektur des Expressionslevels von Dedifferenzierungsmarkern auf mRNA Ebene.

A
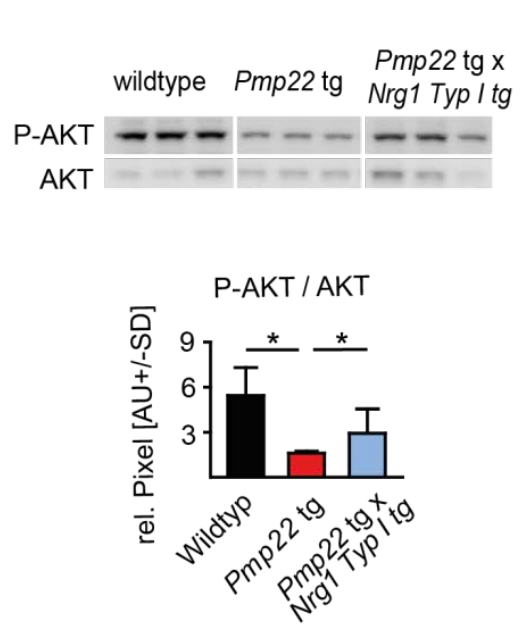
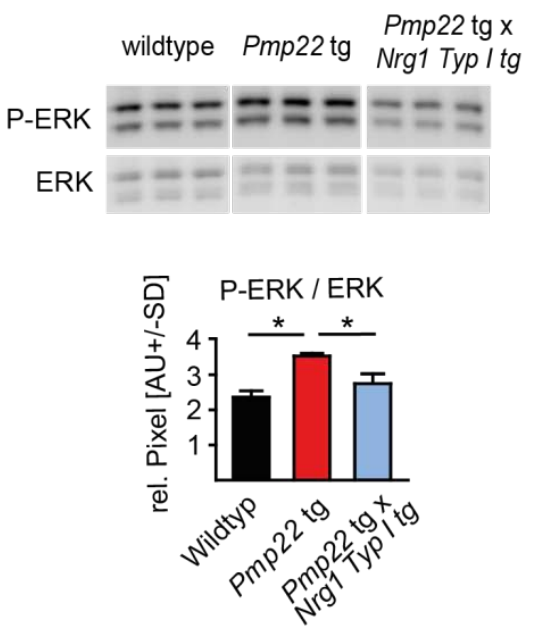

B
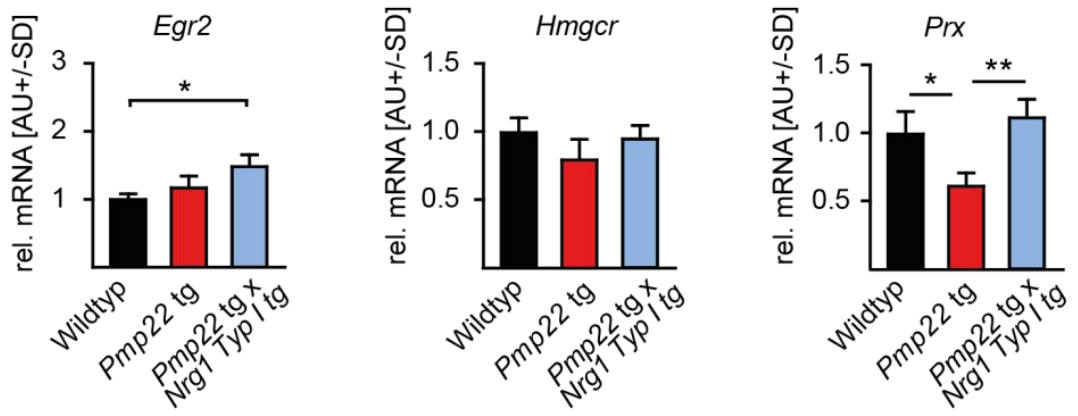

C
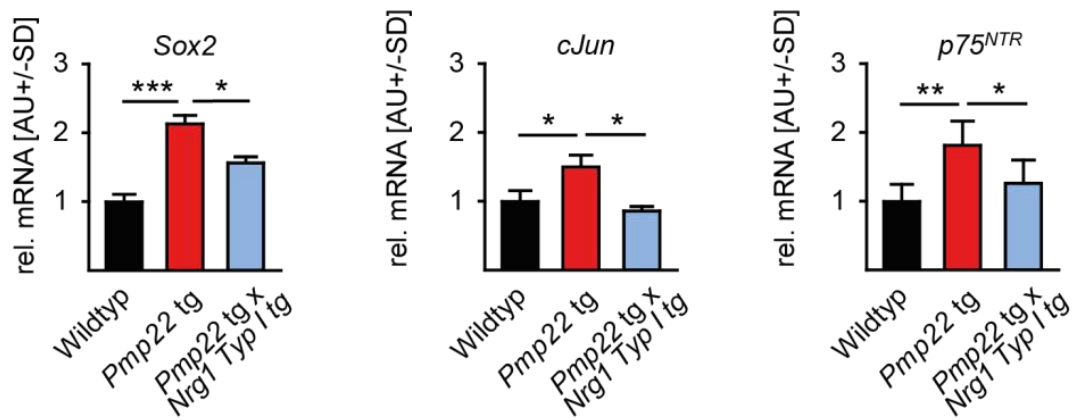

Abbildung 20: NRG1 Typ I normalisiert die molekulare Dedifferenzierungs-Signatur von Schwannzellen in CMT1A Mäusen. A Western Blot Analysen mit Proteinextrakten aus Ischiasnerven von wildtypischen, Pmp22 transgenen und Pmp22 x Nrg1 Typ I doppelt transgenen Mäusen ( $\mathrm{n}=3$ pro Gruppe. CMT1A Mäuse zeigen eine geringere Menge an phosphoryliertem AKT über AKT (links) und eine verstärkte Phosphorylierung von ERK (rechts, densitometrische Quantifizierung jeweils unten, MannWhitney-U-Test). B In Ischiasnerven von CMT1A Mäusen sind die Differenzierungsmarker Hmgcr und Prx transkriptionell herunter reguliert. Das Expressionslevel von Prx wird durch die neuronale Nrg1 Typ I Expression normalisiert. Der Transkriptionfaktor Egr2 ist in CMT1A Mäusen unverändert, wird jedoch durch die Nrg1 Typ I Überexpression hochreguliert. C Die Dedifferenzierungsmarker Sox2, cJun und $p 75^{N T R}$ sind alle in Ischiasnerven von CMT1A Mäusen hochreguliert und werden durch die Nrg1 Typ I Überexpression herunter reguliert (B-C, $\mathrm{n}=5$ pro Gruppe, T-Test). 


\subsection{THERAPIE VON CMT RATTEN MIT REKOMBINANTEM NEUREGULIN-1}

Der genetische Ansatz unter Punkt 3.4.2 zeigte, dass eine überexprimierte soluble NRG1 Isoform einen mildernden Effekt auf die Pathologie von CMT1A Mäusen hatte. In einem nächsten Schritt sollte nun das therapeutische Potential von rekombinantem NRG1 an CMT Ratten erprobt werden.

\subsubsection{FRÜHE KURZZEIT-THERAPIE VON CMT RATTEN MIT NEUREGULIN-1}

Schwannzellen Pmp22 transgener Ratten akquirieren zwischen den postnatal Tagen 6 und 18 einen persistenten Dedifferenzierungsphänotyp. Dieses Zeitfenster wurde entsprechend für eine Kurzzeittherapie ausgewählt um den Effekt verschiedener Dosen von rekombinantem humanem NRG1 zu testen. Als Applikationsform wurde eine intraperitoneale Injektion alle zwei Tage (P6, P8, P10, P12, P14, P16, P18)

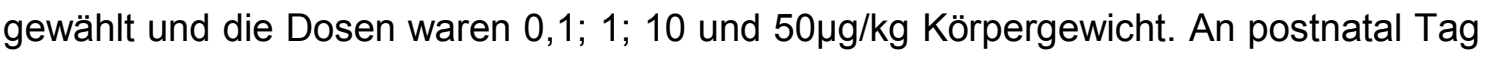
18 wurden die Ratten hinsichtlich ihrer Griffstärke phänotypisiert und das Gewicht gemessen (Abb. 21). Die Griffstärke von 18 Tage alten CMT Ratten ist mit $\sim 0,24 \mathrm{~N}$ nur ungefähr halb so groß wie bei Wildtypkontrollen $(\sim 0,48 \mathrm{~N})$. Es zeigte sich innerhalb der mit NRG1 therapierten CMT Ratten eine signifikante Zunahme der Griffstärke in Abhängigkeit von der NRG1 Dosis mit einem Maximum von $0,55 \mathrm{~N}$ in der $10 \mu \mathrm{g} / \mathrm{kg}$ Gruppe (Abb. 21A). Bei 10 und 50 $\mu \mathrm{g} / \mathrm{kg}$ NRG1 verlierten die CMT Ratten jedoch auch signifikant an Gewicht, sodass hier von ungewünschten systemischen Nebenwirkungen der NRG1 Therapie ausgegangen werden kann (Abb. 21B). Mit der Dosis von $1 \mu \mathrm{g} / \mathrm{kg}$ NRG1 konnte der höchste therapeutische Effekt bezüglich der Griffstärke in CMT Ratten erzielt werden, ohne dass diese an Gewicht verloren (Abb. 21). Die Tiere dieser Behandlungsgruppe wurden in der Folge histologisch und molekularbiologisch weiter untersucht.

An postnatal Tag 18 wurden von den mit $1 \mu \mathrm{g} / \mathrm{kg}$ NRG1 behandelten CMT Ratten Ischiasnerven zur lichtmikroskopischen Quantifizierung der myelinisierten Axone abgesammelt. CMT Ratten haben mit $\sim 6200$ myelinisierten Axonen pro Ischiasnerv zu diesem Alterszeitpunkt etwa 1000 myeliniserte Axone weniger als Wildtypkontrollen (Abb. 22A-B). Die intraperitoneale zweitägliche Behandlung mit $1 \mu \mathrm{g} / \mathrm{kg} N R G 1$ von P6 bis P18 resultierte in CMT Ratten in einer Erhöhung der Anzahl myelinisierter Axone auf Wildtyp-Niveau (Abb. 22A-B). Eine elektronenmikroskopische Analyse der axonalen Kaliber ergab des Weiteren eine signifikante Verbesserung des verminderten mittleren Axondurchmessers bei CMT Ratten nach NRG1 Therapie (Abb. 22C). Auch das $g$-ratio als Maß für die Myelindicke wurde bei Wildtyp-, CMT- und behandelten 
CMT Ratten anhand elektronenmikroskopischer Aufnahmen vermessen, berechnet und gegen den Axondurchmesser aufgetragen (Abb. 22D). Es zeigt sich bei CMT Ratten bei P18 im Vergleich zu Wildtypkontrollen eine bimodale Verteilung der Myelindicke im Bezug zum Axondurchmesser, mit kleinen hypermyeliniserten und großen hypomyelinisierten Axonen (Abb. 22D, links). Eine NRG1 Therapie bei CMT Ratten bewirkte eine leichte Erhöhung (also Normalisierung) des g-ratios der kleinkalibrigen, hypermyelinisierten Axone (Abb. 22D, rechts).

A

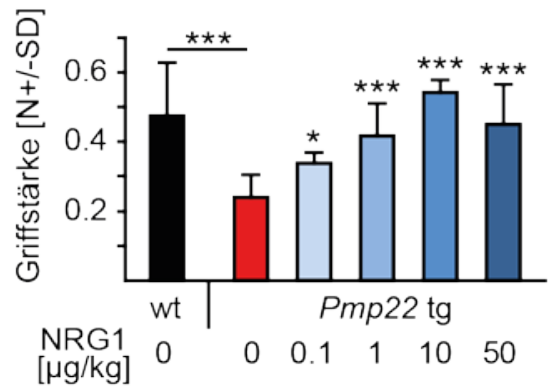

B

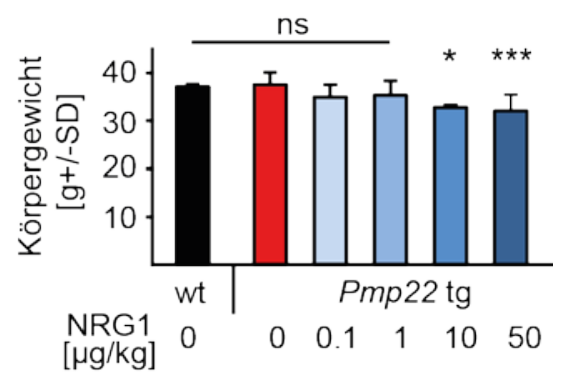

Abbildung 21: Eine Dosis von $1 \mu \mathrm{g} / \mathrm{kg}$ NRG1 verbessert die Griffstärke von CMT Ratten ohne Gewichtsverlust. A CMT Ratten wurden von P6-P18 jeden zweiten Tag mit rekombinantem NRG1 mit den angegebenen Dosen behandelt und bei P18 die Griffstärke der Hinterextremitäten gemessen. Die behandelten CMT Ratten zeigen eine Verbesserung der Griffstärke in Abhängigkeit von der NRG1-Dosis.

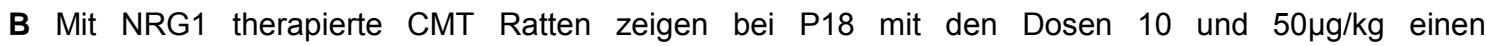
Gewichtsverlust. (wt: n=6; Pmp22 tg: $0 \mu \mathrm{g} / \mathrm{kg}: \mathrm{n}=13,0.1 \mu \mathrm{g} / \mathrm{kg}: \mathrm{n}=4,1 \mu \mathrm{g} / \mathrm{kg}: \mathrm{n}=11,10 \mu \mathrm{g} / \mathrm{kg}: \mathrm{n}=3,50 \mu \mathrm{g} / \mathrm{kg}$ : $\mathrm{n}=6$; One-way ANOVA und Dunnetts Post-Test) 
A

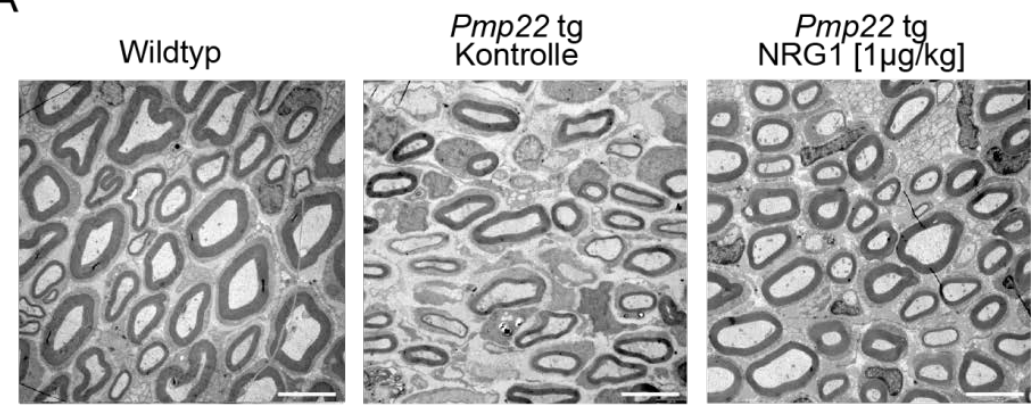

B

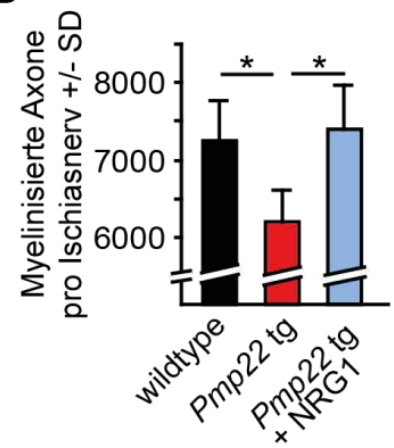

C

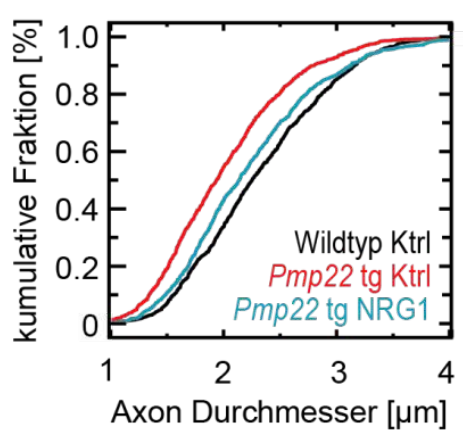

D
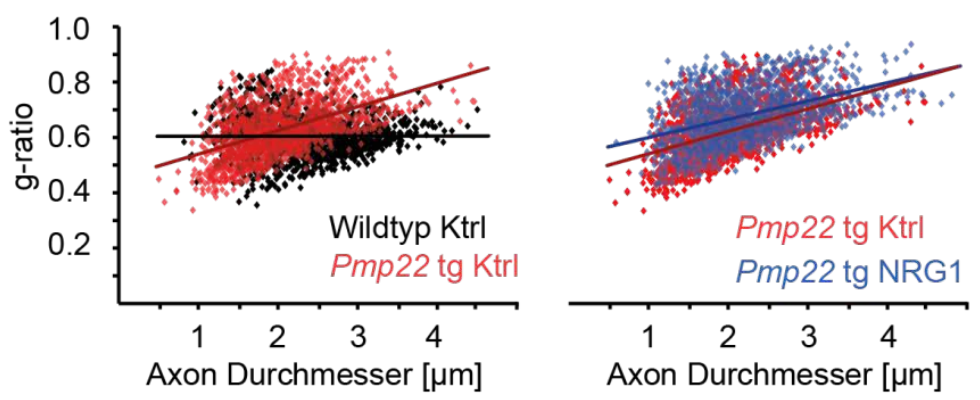

Abbildung 22: Die frühe Therapie von CMT Ratten mit 1 $\mu \mathrm{g} / \mathrm{kg}$ NRG1 normalisiert die Anzahl myelinisierter Axone bei P18. A Elektronenmikroskopische Aufnahmen von Ischiasnerv-Querschnitten zum Alter von P18 von einer Wildtypkontrolle (links), einer CMT Ratten-Kontrolle (mitte) und einer mit $1 \mu \mathrm{g} / \mathrm{kg}$ NRG1 behandelten CMT Ratte. Die verminderte Anzahl myelinisierter Axone bei CMT Ratten wird durch die NRG1 Therapie normalisiert. B Lichtmikroskopische Quantifizierung von A (Wildtyp: $\mathrm{n}=4$, Pmp22 tg: $\mathrm{n}=3$, Pmp22 tg + NRG1: $\mathrm{n}=5, \mathrm{~T}$-Test). C Eine kumulative Auftragung des elektronenmikroskopisch ermittelten Axondurchmesser zeigt, dass CMT Ratten im Alter von 18 Tagen ein vermindertes mittleres Faserkaliber haben als Widltypkontrollen ( $\operatorname{mmax}=0,21, P<0.001$ ), welches durch die NRG1 Therapie signifikant verbessert wurde $(\mathrm{Dmax}=0.14, \mathrm{P}<0.001$, im Vergleich zu Pmp22 tg Kontrollen; $\mathrm{n}=3$ pro Gruppe, mindestens 300 Axone pro Tier wurden vermessen, Kolmogorov Smirnov test). D Die Auftragung der Myelindicke ( $g$-ratio) auf den Axon Durchmesser zeigt bei P18 bei CMT Ratten eine bimodale Verteilung im Vergleich zu Wildtypkontrollen, mit kleinen hypermyelinisierten und großen hypomyelinisierten Axonen (links). Durch die Therapie mit $1 \mu \mathrm{g} / \mathrm{kg}$ NRG1 wurde die Myelindicke bei CMT Ratten nur marginal beeinflusst mit einer leicht Verbesserung der Myelindicke kleinkalibriger Axone Richtung Wildtyp ( $n=6$ pro Gruppe, mindestens 200 Axone pro Tier). 
Die intraperitoneale Therapie von CMT Ratten mit rekombinantem NRG1 von P6 bis P18 alle zwei Tage bewirkte eine deutliche Verbesserung der Griffstärke bei P18 (Abb. 21). Darüber hinaus konnte durch dieses Therapie-Paradigma eine Normalisierung der Anzahl myelinisierter Axon pro Ischiasnerv bei P18 und eine Verbesserung des verringerten Axondurchmessers erreicht werden (Abb. 22A-C). Die NRG1 Therapie beeinflusste hierbei jedoch weitestgehend nicht die bei CMT Ratten fehlerhafte Myelinisierung an sich (Abb. 22D).

Um zu untersuchen, wie sich dieser therapeutische Effekt auf molekularer Ebene wiederspiegelt, wurden Protein und mRNA Extrakte aus Ischiasnerven weiter untersucht. Wie auch adulte CMT1A Mäuse zeigen CMT Ratten im Alter von 18 Tagen eine schwächere Aktivität des PI3K/AKT Signalweges (gemessen als phosphoryliertes AKT über konstitutivem AKT) und eine erhöhte Aktivität der MEK/ERK Kaskade (gemessen als phosphoryliertes ERK1/2 über konstitutivem ERK1/2) in Ischiasnerven (Abb. 23A). Diese Dysbalance zwischen beiden Signalwegen wurde durch die Behandlung mit $1 \mu \mathrm{g} / \mathrm{kg} \mathrm{NRG1}$ ausgeglichen und jeweils in Richtung Wildtyp-Niveau verschoben (Abb. 23A). Auf mRNA Ebene führte die Therapie mit NRG1 bei CMT Ratten zu einer erhöhten Expression des grundsätzlich in CMT Ratten unveränderten Transkriptionsfaktors und Differenzierungsmarkers Egr2 (Krox20) (Abb. 23B). Die in Ischiasnerven von CMT Ratten bei P18 geringer exprimierten Differenzierungsmarker Hmgcr und Prx blieben von der NRG1 Therapie unbeeinflusst (Abb. 23B). Im Gegensatz dazu konnte durch die NRG1 Therapie die erhöhte mRNA Expression der Dedifferenzierungsmarker cJun, Sox2 und $p 75^{N T R}$ signifikant gesenkt werden (Abb. 23C). Durch die immunhistochemische Quantifizierung von Zellkernen, welche eine Expression der Transkriptionsfaktoren cJUN und SOX2 zeigen, konnten die mRNA Befunde (Abb. 23C) auch auf Proteinebene bestätigt werden (Abb. 23D).

Zwischen den postnatal Tagen P6 und P18 akquirieren Pmp22 überexprimierende Schwannzellen von CMT Ratten einen persistenten Dedifferenzierungsphänotyp mit einer verstärkten mRNA Expression von Dedifferenzierungs-Markern und einer Dysbalance zwischen den PI3K/AKT und MEK/ERK Signaltransduktionskaskaden (Abb. 23). Diese molekulare Signatur korreliert histopathologisch mit einer reduzierten Anzahl myelinisierter Fasern pro peripherem Nerv (Abb. 22), sowie phänotypisch mit einer geringeren Griffstärke (Abb. 21). Die intraperitoneale Applikation von $1 \mu \mathrm{g} / \mathrm{kg}$ rekombinantem, humanem NRG1 alle zwei Tage zwischen P6 und P18 führte zu einer massiven Verbesserung des CMT1A Phänotyps auf molekularer, histologischer und phänotypischer Ebene (Abb. 21-23). 
A

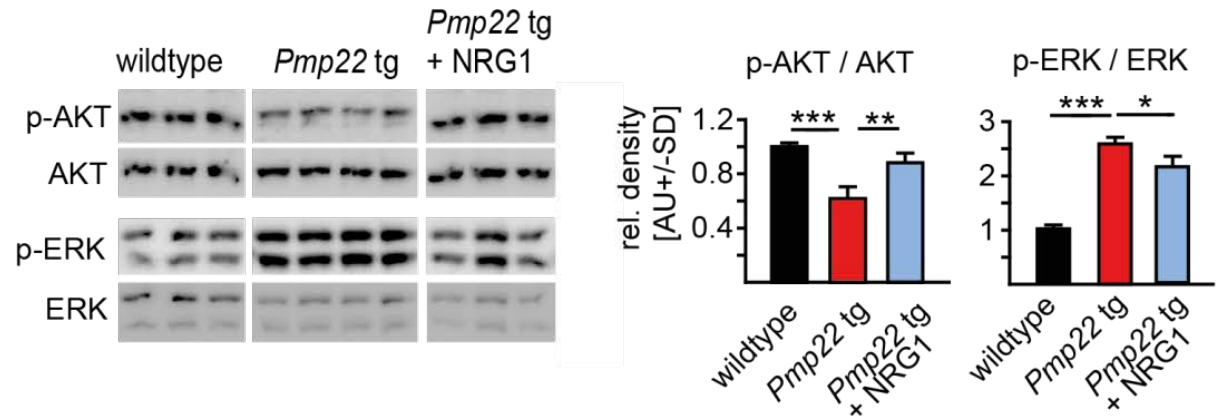

B
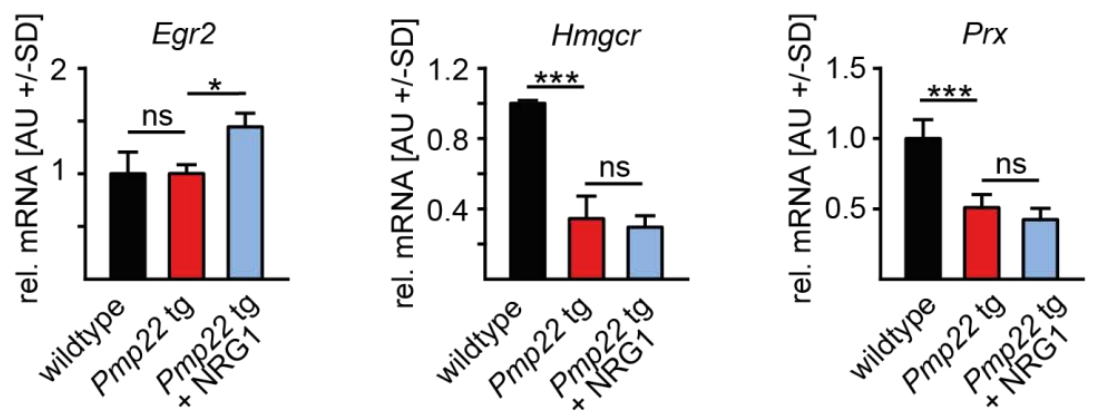

C
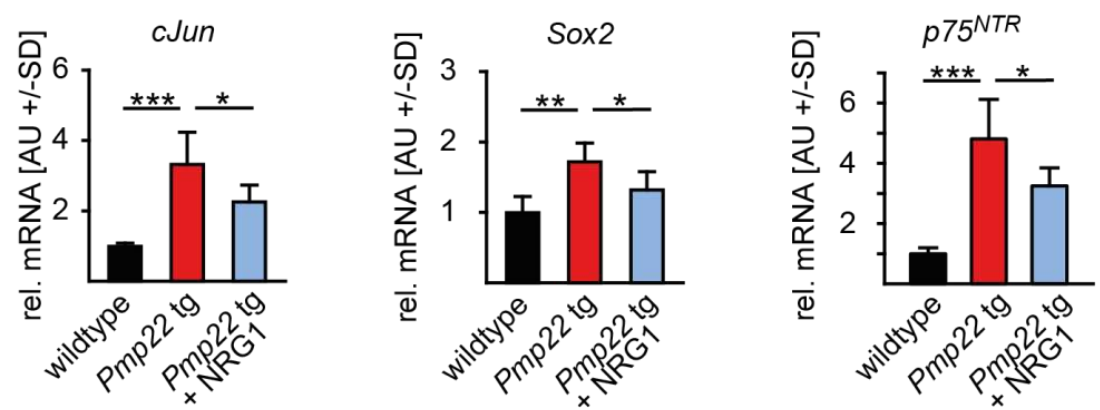

D
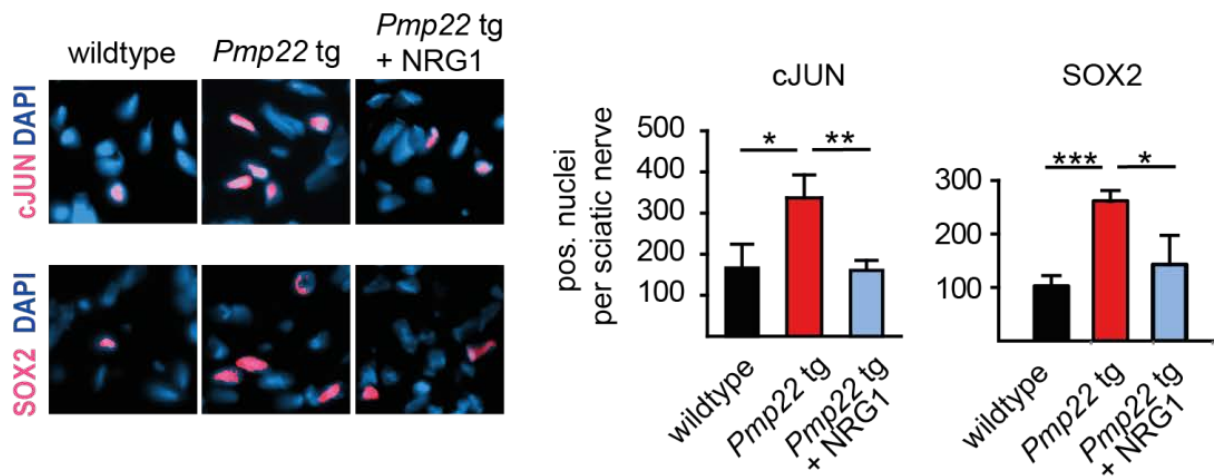

Abbildung 23: Die frühe NRG1 Therapie normalisiert den molekularen Dedifferenzierungsphänotyp Pmp22 überexprimierender Schwannzellen in CMT Ratten bei P18. A Western blot Analysen mit Proteinextrakten aus Ischiasnerven von 18 Tage alten Wildtypkontrollen $(n=3)$, Placebo behandelten CMT Ratten (Pmp22, $\mathrm{n}=4)$ und mit $1 \mu \mathrm{g} / \mathrm{kg}$ NRG1 behandelten CMT Ratten $(\mathrm{n}=3)$ zeigen eine Normalisierung der verringerten Phosphorylierung von AKT bei CMT Ratten nach NRG1 Therapie. Im Gegensatz dazu ist die erhöhte Phosphorylierung von ERK1/2 in CMT Ratten durch NRG1 etwas gesenkt worden (rechts: densitometrische Quantifizierung der Western Blots links, Mann-Whitney-U Test). B Die mRNA Expression der Differenzierungsmarker Hmgcr und Prx ist in Ischiasnerven von CMT Ratten bei P18 geringer und wird durch die NRG1 Therapie nicht verändert. Lediglich der Transkriptionsfaktor Egr2 wird durch NRG1 in CMT Ratten induziert ( $\mathrm{n}=5$ pro Gruppe, T-Test). C Die bei P18 in Ischiasnerven von CMT Ratten hochregulierten Dedifferenzierungsmarker cJun, Sox2 und $p 75^{N T R}$ werden durch die NRG1 Therapie in Richtung Wildtyp-Niveau korrigiert. D Immunhistochemische Analyse der SOX2 bzW. cJUN positiven Zellkerne pro Ischiasnerv-Querschnitt zeigt eine Normalisierung der erhöhten Anzahl SOX2 und cJUN positiver Kerne in CMT Ratten nach NRG1 Therapie ( $n=3$ pro Gruppe, T-Test) 


\subsubsection{SPÄTE LANGZEIT THERAPIE VON CMT RATTEN MIT NEUREGULIN-1}

Die frühe Kurzzeit Therapie mit NRG1 zeigte einen massiven therapeutischen Effekt auf die frühe Pathogenese von CMT Ratten. Im Folgenden sollte nun untersucht werden, ob auch ein klinischeres Behandlungsparadigma mit NRG1, d.h. eine späte Langzeittherapie, positive Effekte auf die progrediente Erkrankung von CMT Ratten aufzeigt. Hierzu wurden Pmp22 transgene Ratten von P18 bis P90 jeden zweiten Tag mit $1 \mu \mathrm{g} / \mathrm{kg}$ NRG1 behandelt und bei P90 zunächst phänotypisch, elektrophysiologisch und histologisch untersucht. Die Analyse der Griffstärke dieser spät mit NRG1 behandelten CMT Ratten zeigte im Alter von 90 Tagen eine leichte aber signifikante Verbesserung im Vergleich zu Placebo-behandelten CMT Ratten (Abb. 24A). Die anschließende lichtmikroskopische Quantifizierung der Anzahl myelinisierter Axone pro Ischiasnerv zeigte jedoch keine signifikante Verbesserung nach NRG1 Therapie (Abb. 24B). Diese Daten werden auch durch elektrophysiologische Untersuchungen gestützt, welche keinen Einfluss der NRG1 Therapie auf die reduzierte NLG und des reduzierten MSAPs zeigen (Abb. 24C).

A

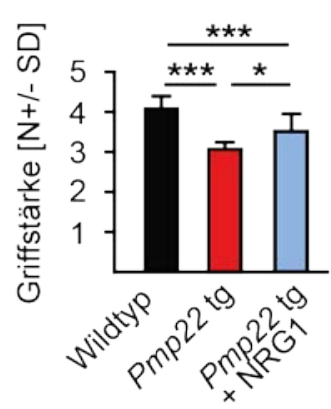

C

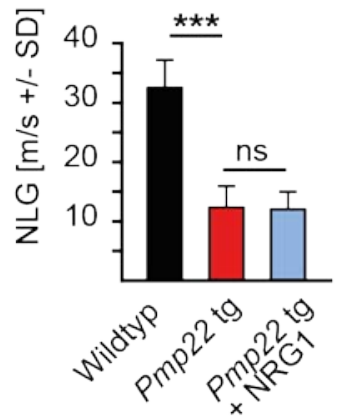

B
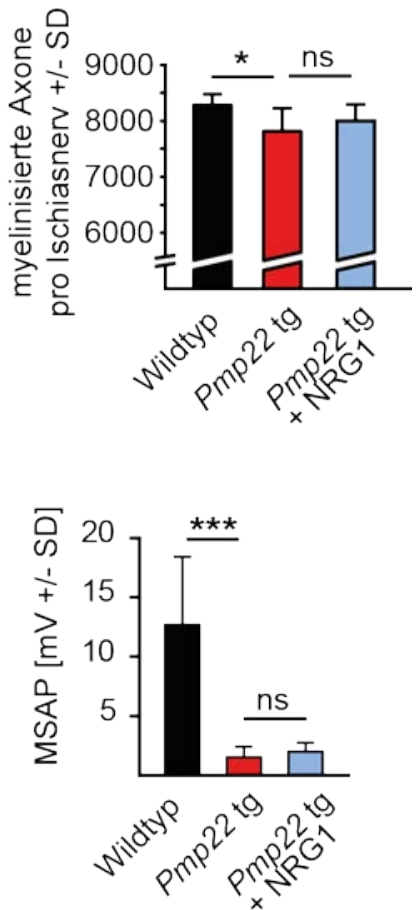

Abbildung 24: Eine späte Behandlung von CMT Ratten mit NRG1 hat nur einen geringen therapeutischen Effekt. A Die Griffstärke der Vorderextremitäten zeigte nach einer $1 \mu \mathrm{g} / \mathrm{kg} \mathrm{NRG1}$ Behandlung von P18-P90 eine signifikante Kraftzunahme in CMT Ratten ( $n=10-15$ pro Gruppe, T-Test). B Im Gegensatz dazu zeigte die lichtmikroskopische Quantifizierung der myelinisierten Axone pro Ischiasnerv keine signifikante Verbesserung in der Behandlungsgruppe ( $\mathrm{n}=5$ pro Gruppe, T-Test). C Auch elektrophysiologische Ableitungen zeigten keinen therapeutischen Effekt der späten NRG1 Behandlung in CMT Ratten hinsichtlich der Nervenleitgeschwindigkeit (links) und des Muskelsummenaktionspotentials (rechts, $n=10-15$ pro Gruppe, T-Test). 
Eine späte Langzeittherapie mit NRG1 von P18 bis P90 bewirkt somit in CMT Ratten lediglich eine leichte Verbesserung der Griffstärke mit P90. Die Anzahl myelinisierter Axone, sowie die elektrophysiologischen Parameter NLG und MSAP bleiben durch die NRG1 Therapie unter diesem Paradigma jedoch unbeeinflusst (Abb. 24).

\subsubsection{THERAPEUTISCHER LANGZEITEFFEKT EINER FRÜHEN KURZZEITBEHANDLUNG VON CMT RATTEN MIT NRG1}

Eine NRG1 Therapie beginnend bei P18 bis P90 hat bei CMT Ratten nur marginale Effekte auf den Phänotyp (Abb. 24). Eine frühe Kurzzeittherapie von P6 bis P18 hingegen bewirkte eine phänotypische, histologische und molekularbiologische Korrektur der untersuchten krankheitsspezifischen Parameter in CMT Ratten. Im genetischen Ansatz (siehe 3.2.2) führte die neuronale Überexpression von Nrg1 Typ I bei CMT1A Mäusen zu einer langfristigen Verbesserung des Phänotyps bis ins fortgeschrittene Erwachsenenalter (6 Monate). Im Folgenden sollte deshalb die Nachhaltigkeit des frühen Therapieerfolges bei CMT Ratten untersucht werden. CMT Ratten wurden also erneut von P6 bis P18 alle zwei Tage mit $1 \mu \mathrm{g} / \mathrm{kg}$ NRG1 behandelt und deren Phänotyp im Alter von 90 Tagen untersucht (Abb. 25). Die Griffstärke Messung ergab, dass die früh mit NRG1 behandelten Tiere bei P90 noch immer einen deutlich verbesserten, von Wildtypkontrollen nicht unterscheidbaren Phänotyp zeigen (Abb. 25A). Auch auf histologischer Ebene zeigte sich bei P90, wie bei der Auswertung der frühen Kurzzeittherapie bei P18 (Abb. 22B), die gleiche Anzahl myelinisierter Axone pro Ischiasnerv in NRG1 behandelten CMT Ratten im Vergleich zu Wildtyp-Kontrollen (Abb. 25B). Entsprechend zeigen früh mit NRG1 behandelte CMT Ratten im Alter ein höheres Muskelsummenaktionspotential als Pmp22 transgene Kontrollratten (Abb. 25C-D). Die Nervenleitgeschwindigkeit hingegen blieb durch die NRG1 Behandlung in der CMT Ratte unbeeinflusst (Abb. 25D). 
A

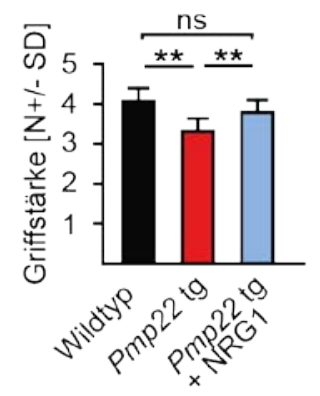

B

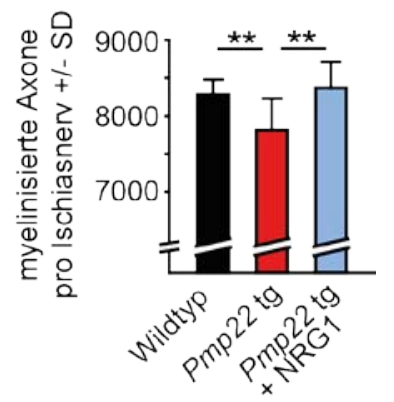

C

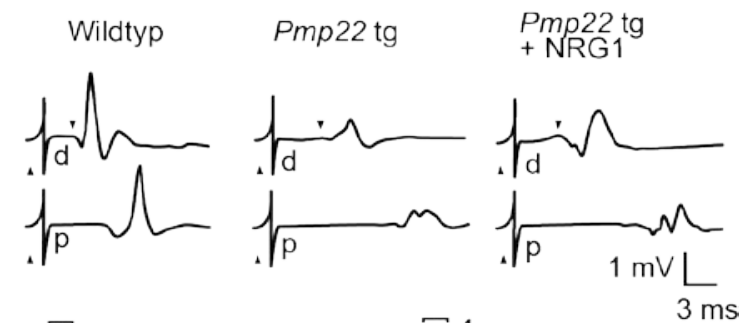

$\mathrm{D}$
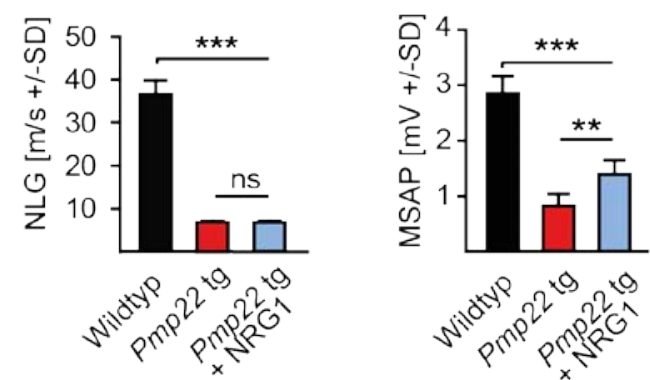

Abbildung 25: Früh mit NRG1 behandelte CMT Ratten zeigen im Alter einen verbesserten Phänotyp. A Messung der Griffstärke der Hinterextremitäten im Alter von 90 Tagen bei Wildtyp- $(n=4)$, Kontroll-CMT Ratten (Pmp22 tg, $\mathrm{n}=8$ ) und bei P6 bis P18 mit NRG1 behandelten CMT Ratten (Pmp22 tg + NRG1, n=6). Behandelte CMT Ratten zeigen eine persistente Verbesserung der Griffstärke (T-Test). B Auch die lichtmikroskopische Quantifizierung der Anzahl myelinisierter Axone pro Ischiasnerv zeigte die Nachhaltigkeit einer frühen NRG1 Behandlung bei CMT Ratten mit einer von Wildtypen nicht unterscheidbaren Axonanzahl (Wildtyp: $n=5 ;$ Pmp22 tg: $n=12 ;$ Pmp22 tg + NRG1: $n=6$; T-Test). C Repräsentative elektrophysiologische Ableitungen zeigen eine Verbesserung der verringerten Amplitude bei CMT Ratten, die früh mit NRG1 behandelt wurden. D Quantifizierung von $\mathbf{C}$ zeigt keinen Einfluss einer frühen NRG1 Therapie auf die NLG, jedoch auf das MSAP im Alter von 90 Tagen (Wildtyp: n=4, Pmp22 tg: $\mathrm{n}=7 ;$ Pmp22 tg + NRG1: $\mathrm{n}=5 ;$ T-Test). 
4. DISKUSSION

\subsection{Die Plastizität VON SCHWANNZELLEN EMÖGLICHT REgenerative PROZESSE NACH NERVENSCHÄDIGUNGEN}

Verletzungen des peripheren Nervensystems sind die Folge von traumatischen Ereignissen, Entzündungen, Tumoren, Stoffwechselerkrankungen sowie von genetischen Defekten. Nach solchen Verletzungen weist das PNS eine außerordentliche Plastizität und Regenerationsfähigkeit auf (Jessen und Mirsky 2008). Nach einer akuten Nervenverletzung degenerieren die Axone distal der Schädigung im Rahmen der Wallerischen Degeneration und Schwannzellen unterlaufen einen Prozess der Dedifferenzierung. Das erneute Auswachsen von Axonen erfolgt erst nach einigen Tagen und erfordert, dass sich dedifferenzierte Schwannzellen zu Büngner-Bändern angeordnet haben.

Dedifferenzierte Schwannzellen exprimieren nach akuten Nervenschädigungen Gene, deren Proteine in weiten Teilen auch während der entwicklungsbiologischen Myelinisierung gebildet werden, allen voran den Transkriptionsfaktor c-JUN (Jessen und Mirsky, 2008). Jedoch werden auch einzelne Faktoren ausschließlich nach einer Nervenverletzung gebildet, oder die funktionelle Relevanz von Genen unterscheidet sich zwischen Entwicklung und nach Nervenverletzung. So induzieren Schwannzellen nach einer akuten Nervenverletzung die Expression des Wachstumsfaktors Nrg1 Typ I (Abb. 12). Während Mausmutanten mit einer spezifischen Ablation des Nrg1 Gens in Schwannzellen eine normale Entwicklung ohne Beeinträchtigung der Myelinisierung im PNS aufweisen, führte die Inaktivierung von Nrg1 nach einer akuten Nervenverletzung hingegen $z u$ einer drastischen Verschlechterung der Remyelinisierung sowie der funktionellen Regeneration (Stassart und Fledrich et al., 2013). Schwannzell-NRG1 (spezifisch die Typ I Isoform) kann somit als ein endogener Reparaturfaktor angesehen werden, dessen Expression bei Verletzungen des PNS eine wichtige Rolle spielt (Stassart und Fledrich et al., 2013).

Eine Veränderung des Schwannzellphänotyps ist jedoch nicht spezifisch für akute Nervenverletzungen des PNS, sondern lässt sich auch bei demyelinisierenden peripheren Neuropathien beobachten. So lassen sich hypermyelinisierende, demyelinisierende, remyelinisierende und stark proliferierende Schwannzellen in neuropathischen Nerven finden, die sich zuweilen in multiplen konzentrischen Lagen um Axone zu sogenannten Zwiebelschalen formieren (Dyck et al., 2005). Darüber hinaus lassen sich bei chronisch und akut geschädigten Nerven ähnliche Genexpressionsprofile in Schwannzellen feststellen. PMP22 überexprimierende 
Schwannzellen von CMT1A Patienten und Tiermodellen zeigen gleichermaßen eine erhöhte Expression von c-JUN (Hutton et al., 2011; Martini et al., 2013) und in der vorliegenden Arbeit konnte gezeigt werden, dass Schwannzellen von CMT Ratten auf transkriptioneller Ebene bereits früh postnatal einen persistenten Dedifferenzierungsphänotyp entwickeln. Auch wird in Tiermodellen für die CMT1A die Expression von Nrg1 Typ I in Schwannzellen selbst induziert, und die Ablation von Schwannzell-NRG1 verschlechterte den motorischen und elektrophysiologischen Phänotyp von Pmp22 transgenen Mäusen signifikant (Abb. 14). Die neuronale Überexpression von NRG1 Typ I (nicht aber von Typ III) bewirkte eine verbesserte funktionelle Regeneration nach experimenteller Nervenläsion sowie eine signifikante Verbesserung der neuropathische Charakteristika in CMT1A Mäusen (Abb. 17 - 20). Die bisherigen Daten zeigen also, dass NRG1 Typ I zwar als Reparaturfaktor von Schwannzellen selbst gebildet wird, dass das therapeutische Potential dieser autokrinen Stimulation aber experimentell weiter ausgeschöpft werden kann.

Im Gegensatz zur akuten Nervenschädigung, bei welcher zunächst die Axone degenerieren und die denervierten Schwannzellen erst in der Folge transient dedifferenzieren, geht bei demyelinisierenden Neuropathien ein primärer und dauerhafter Schwannzell-Defekt einem sekundären axonalen Verlust voraus (Martini et al., 2013). Die klinische Beeinträchtigung ist jedoch in beiden Fällen durch die axonale Degeneration begründet. Über die sekundäre axonale Degeneration bei demyelinisierenden Neuropathien ist im Vergleich zur Wallerischen Degeneration nach akuter Nervenverletzung verhältnismäßig wenig bekannt (Martini et al., 2013). Eine natürlich vorkommende Mutation bei Mäusen auf Chromosom 4 verlangsamt den Prozess der Wallerischen Degeneration nach akuter Nervenschädigung und wird deshalb Wallerian degeneration slow (Wld ${ }^{S}$ ) genannt (Lunn et al., 1989; Lyon et al., 1993). Die Fähigkeit von Axonen in $W^{S}{ }^{S}$ Mäusen auch noch Wochen nach der Degeneration des neuronalen Zellkörpers während des physiologisch programmierten Zelltodes vieler Neuronen während der Entwicklung zu überleben, beweist die Existenz von unabhängigen Mechanismen zwischen Axon- und Neuron-degeneration (Deckwerth and Johnson, 1994; Wang et al., 2012). Das Einbringen des Wld ${ }^{\text {S }}$ Locus in CMT Nagetiermodellen bremste den axonalen Verlust signifikant und resultierte in einer ausgeprägten Linderung des neuropathischen Phänotyps (Samsam et al., 2003; Meyer zu Hörste et al., 2011).

Diese Beobachtungen legen nahe, dass ähnliche finale molekulare Mechanismen einer axonalen Degeneration bei akuten und chronischen Nervenschädigungen zu Grunde liegen könnten (Wang et al., 2012). Die genannten Gemeinsamkeiten in der Pathologie zwischen akuten und chronischen Nervenschädigungen deuten trotz 
unterschiedlicher Ätiologie auf eine funktionell gleichartige terminale Axondegeneration hin (final common pathway; Nave, 2010; Martini et al., 2013). Das genauere Verständnis dieser degenerativen Mechanismen und der Bedeutung des Schwannzelldifferenzierungsstatus könnten in der Folge die Entwicklung universeller therapeutischer Ansätze erlauben, und darüber hinaus eine Extrapolation von Erkenntnissen aus dem verhältnismäßig einfachen Nervenläsionsmodell auf die ungleich komplexeren Neuropathien ermöglichen.

\subsection{AUSMAß UND ZEITPUNKT DER AKTIVITÄT VON SIGNALTRANSDUKTIONSKASKADEN REGULIEREN DEN DIFFERENZIERUNGSSTATUS VON SCHWANNZELLEN}

Die embryonale Entwicklung von Schwannzellen im peripheren Nervensystem bis hin zur postnatalen Myelinisierung wird maßgeblich durch den neuronalen Wachstumsfaktor Neuregulin-1 Typ III gesteuert (Nave and Salzer, 2006). Die Menge des axonal präsentierten NRG1 Typ III dient der Schwannzelle dabei als Surrogatmarker für das Axonkaliber und determiniert die Dicke der Myelinscheide (Michailov et al., 2004). Axonales NRG1 Typ III vermittelt seine Wirkung über gliale ErbB Rezeptortyrosinkinasen, die wiederum verschiedene Signaltransduktionskaskaden aktivieren (Stassart et al., 2012). Zwei für die Myelinisierung essentielle, durch NRG1 beeinflusste Signalwege sind der PI3K/AKT und der MEK/ERK Signalweg (Taveggia et al., 2010). PI3K phosphoryliert das Membranlipid PIP2 (Phosphatidylinositol 4,5-bisphosphate) zu PIP3 (Phosphatidylinositol $(3,4,5)$-trisphosphate), einen bedeutenden sekundären Botenstoff der unter anderem AKT aktivert (Stassart et al., 2012). Die NRG1 induzierte PI3K Aktivität vermittelt die Myelinisierung im PNS in Abhängigkeit von AKT und bewirkt die Transkription von $M p z$ und Srebp (sterol responsive element binding protein), ein Schlüsseltranskriptionsfaktor für die Cholesterolbiosynthese (Porstmann et al., 2005; Wakatsuki et al., 2009). Eine zentrale Rolle kommt hierbei der Kinase mTOR zu, welche wiederum als sekundärer Botenstoff (second messenger) der PI3K/AKT Kaskade das Wachstum der Myelinscheide reguliert (Sherman et al., 2012). Im Gegensatz zum ZNS führt ein konstitutiv aktives AKT im PNS jedoch nicht zu einer Hypermyelinisierung (Flores et al., 2008). Allerdings triggert die Erhöhung des intrazellulären PIP3 Spiegels durch eine konditionale Ablation der Phosphatase PTEN (phosphatase and tensin homolog) in Schwannzellen die Genese einer tomakulösen Neuropathie mit fokalen Myelinausfaltungen (Göbbels et al., 2012). Durch eigene Vorarbeiten konnte gezeigt werden, dass Pmp22 haploinsuffiziente Mäuse (ein Tiermodell für die humane hereditäre Neuropathie mit Neigung zu Druckläsionen, 
HNPP) in Ischiasnerven eine erhöhte PI3K/AKT Aktivität aufzeigen. HNPP ist in der Tat eine tomakulöse Neuropathie und eine verstärkte Wirkung der PI3K/AKT Kaskade könnte hierfür kausal sein.

Die konstitutive Aktivierung des MEK/ERK Weges führt im PNS zu einer Hypermyelinisierung während der Entwicklung (Ishii et al., 2013). Mäuse in denen in Schwannzellen spezifisch ERK1/2 ablatiert wurde, zeigen hingegen eine starke Beeinträchtigung der PNS Entwicklung mit einer betonten Hypomyelinisierung (Newbern et al., 2011). Die artifizielle Aktivierung der MEK/ERK Kaskade in Schwannzellen adulter Mäuse induziert hingegen eine Dedifferenzierung von Schwannzellen unabhängig von einer Nervenschädigung (Napoli et al., 2012). Es wird also deutlich, dass die vermittelte Wirkung der erwähnten Signalwege in Schwannzellen nicht nur von dem Ausmaß der Aktivierung, sondern auch stark von der temporalen Dynamik ebendieser abhängig ist.

In der vorliegenden Arbeit wurden die Aktivitäten der PI3K/AKT und MEK/ERK Signalwege in Ischiasnerv-Proteinextrakten von CMT- und Wildtyp-Ratten zu unterschiedlichen Zeitpunkten gemessen. Es zeigte sich eine niedrigere Aktivität der PI3K/AKT Kaskade in CMT Ratten vom postnatal Tag 1 an über das ganze Leben hinweg. Dieser geringeren Wirkung der PI3K/AKT Kaskade in CMT Ratten steht ab postnatal Tag 6 ein persistent erhöhtes Level an phosphoryliertem ERK gegenüber. Die beiden Signalwege befinden sich also in Schwannzellen von CMT Ratten in einem prominenten Ungleichgewicht zueinander. Diese Dysbalance korreliert auf transkriptioneller Ebene mit einer verstärkten mRNA Expression von Dedifferenzierungsmarkern. Ist der Differenzierungsdefekt durch das Ungleichgewicht der PI3K/AKT und MEK/ERK Kaskaden kausal begründet? Aus anderen Zelltypen ist bekannt, dass der PI3K-Signalweg einen kreuzinhibierenden Effekt auf den MEK/ERK Signalweg hat (Mendoza et al., 2011). Dieser Befund konnte in eigenen in vitro Vorexperimenten bestätigt werden und es zeigte sich, dass die pharmakologische PI3K Aktivierung auch in primären Schwannzellen zu einer Inhibition der MEK/ERK Kaskade führt (MSc Arbeit von Axel Klink). NRG1 ist ein potenter Aktivator der PI3K-Kaskade und die neuronale Überexpression von NRG1 Typ I erhöht in der Tat die reduzierte PI3K/AKT Aktivität in Schwannzellen Pmp22 transgener Mäuse (Abb. 20). Hingegen wird die aberrante Aktivität von MEK/ERK in CMT1A Mäusen durch das Einbringen eines neuronalen Nrg1 Typ I Transgens normalisiert (Abb. 20). Diese korrigierte Balance beider Signalwege korrelierte auf mRNA Ebene mit der Normalisierung des Expressionslevels verschiedener Dedifferenzierungsmarker (Abb. 20). Nicht nur der histologische und elektrophysiologische Phänotyp von CMT1A Mäusen, sondern auch die molekulare Signatur Pmp22 transgener Schwannzellen wurde durch die 
Überexpression von NRG1 Typ I normalisiert. Dieser genetische Ansatz zeigt also, dass eine Korrektur der Balance zwischen PI3K/AKT und MEK/ERK Signalweg durch NRG1 Typ I einen umfassenden therapeutischen Effekt auf die Pathologie Pmp22 transgener Mäuse vermittelt (Hypothetisches Modell: Abb. 26). Hingegen führte die neuronale Überexpression des doppelt in der Membran verankerten NRG1 Typ III in CMT Mäusen zu keiner Verbesserung des Phänotyps. Analog zeigen NRG1 Typ III transgene Mäuse auch im Nervenläsionsmodell im Gegensatz zu NRG1 Typ I transgenen Mäusen keine verbesserte axonale Regeneration. Es ist also allein die soluble NRG1 Typ I Isoform, die bei neuronaler Überexpression einen therapeutischen Effekt bei akuter und chronischer Nervenschädigung vermitteln kann.

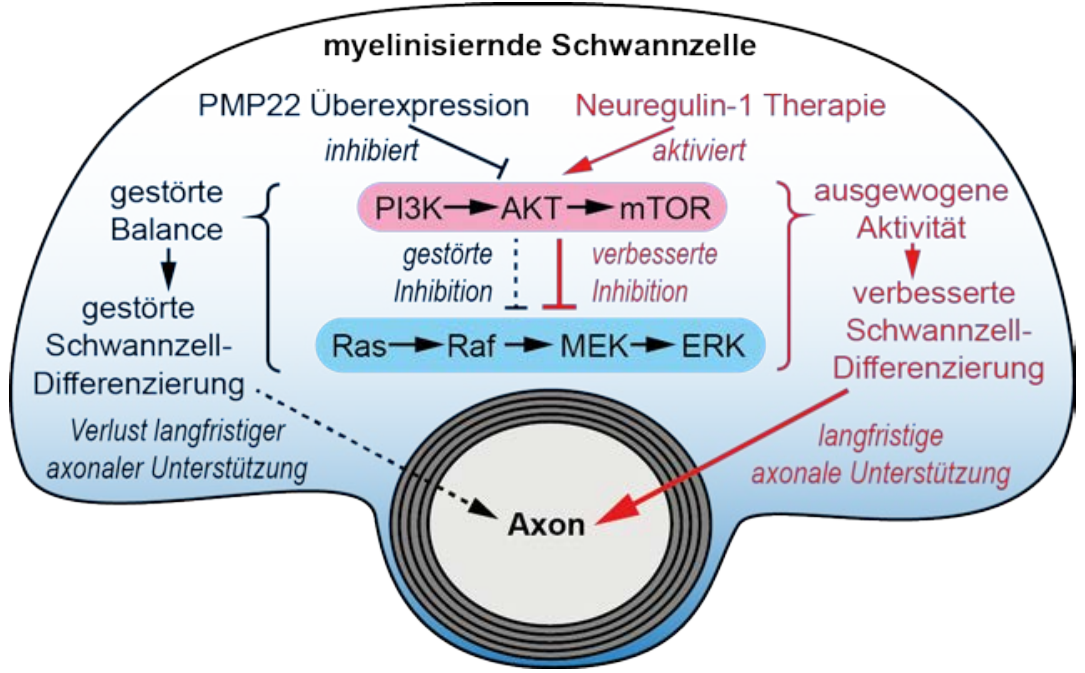

Abbildung 26: Hypothetisches Modell zur Pathologie und NRG1 Therapie in PMP22 überexprimierenden Schwannzellen. PMP22 Überexpression inhibiert den PI3K/AKT Signalweg was eine schwächere Rückkopplungsinhibition zum MEK/ERK Signalweg zur Folge hat. Die gestörte Balance beider Signalwege beeinträchtigt die adäquate Differenzierung der Schwannzellen und somit auch die langfristige Unterstützung von Axonen (links). Eine NRG1 Behandlung stellt die Balance zwischen PI3K/AKT und MEK/ERK wieder her und gewährleistet dabei eine verbesserte Differenzierung von Pmp22 überexprimierenden Schwannzellen, sowie eine langfristige Nervenfunktion.

\subsection{EINE FRÜHE KURZZEITTHERAPIE MIT REKOMBINANTEM NRG1 VERHINDERT DiE FEHLERHAFTE DIFFERENZIERUNG VON SCHWANNZELLEN}

Können diese grundlegenden Erkenntnisse zur Nervenregeneration und -preservation durch NRG1 Typ I auch therapeutisch nutzbar gemacht werden? NRG1 wurde in der Vergangenheit bereits erfolgreich in klinischen Phase II Studien bei kardiovaskulären Erkrankungen getestet und zeigte keine nennenswerten Nebenwirkungen (MendesFerreira et al., 2013). Bei systemischer Verabreichung vermittelt rekombinantes humanes NRG1 (rhNRG1, die EGF-ähnliche Domäne) ErbB2 anhängige Effekte und bei klinischen Studien wurden Dosen von 0,3 - 2,4 $\mu \mathrm{g} / \mathrm{kg}$ rhNRG1 verwendet (Bersell 
et al., 2009; Kato et al., 2011; Mendes-Ferreira et al., 2013). Die verwendeten Dosen bei präklinischen Studien in Nagetiermodellen reichten von $1,25 \mathrm{ng} / \mathrm{kg}$ bis $1 \mathrm{mg} / \mathrm{kg}$ (ter Laak et al., 2000; Mendes-Ferreira et al., 2013; Solomon et al., 2014). In einem pharmakologisch-therapeutischen Ansatz für die CMT1A sollten nun Pmp22 transgene Ratten mit rhNRG1 behandelt werden. Als therapeutischer Zeitrahmen wurde zunächst jene Phase gewählt, in der Pmp22 überexprimierende Schwannzellen den gestörten Differenzierungsphänotyp entwickeln, zwischen P6 und P18. CMT Ratten wurden mit unterschiedlichen Dosen an NRG1 $(0,1-50 \mu \mathrm{g} / \mathrm{kg})$ behandelt und die Griffstärke bei P18 gemessen. Es zeigte sich ein dosisabhängiger Therapieerfolg im Bezug zur Griffstärke und die Dosisgruppe, welche die maximale Griffstärke in CMT Ratten bei unverändertem Körpergewicht zeigte $(1 \mu \mathrm{g} / \mathrm{kg})$, wurde weiter auf histologischer und molekularer Ebene untersucht. Wie im genetischen Ansatz mit neuronal überexprimiertem NRG1 Typ I zeigte sich bei der pharmakologischen Behandlung mit rekombinantem NRG1 eine Erhöhung der Anzahl myelinisierter Axone auf Wildtypniveau ohne die gestörte Myelindicke zu beeinflussen (Abb. 22). Neben einer Korrektur der Balance zwischen den PI3K/AKT und MEK/ERK Signalwegen bewirkte die NRG1 Therapie auch eine Verringerung der mRNA- und Protein-Expression verschiedener Dedifferenzierungsmarker (Abb. 23). Die Behandlung von CMT Ratten mit rhNRG1 von P6 bis P18 verhinderte also eine fehlerhafte Differenzierung von Schwannzellen auf molekularer Ebene, präservierte histologisch die Anzahl myelinisierter Axone pro peripherem Nerv und bewirkte phänotypisch eine Verbesserung der Griffstärke auf Wildtypniveau. Da dieses Behandlungsparadigma während der Entwicklung die krankheitsspezifischen Charakteristika von CMT Ratten nahezu revidiert, stellte sich die Frage ob auch eine später einsetzende Therapie noch erfolgreich sein würde. Die zweitägliche Behandlungstrategie mit $1 \mu \mathrm{g} / \mathrm{kg}$ rhNRG1 von P18 bis P90 bewirkte bei CMT Ratten eine signifikante Verbesserung der Griffstärke, konnte jedoch auf elektrophysiologischer und histologischer Ebene keine messbaren therapeutischen Effekte erzielen. Eine frühe Behandlung mit rhNRG1 ist also erforderlich, um die Anzahl myelinisierter Axone in CMT Ratten zu erhöhen. Im genetischen Ansatz bewirkte die neuronale NRG1 Typ I Überexpression bei CMT Mäusen jedoch auch eine weitreichende Verbesserung des Phänotyps auch noch im hohen Alter von 6 Monaten. Daraus kann die Hypothese abgeleitet werden, dass eine frühe Kurzzeitbehandlung auch noch zu therapeutischen Effekten im Alter führen kann. Um diese Hypothese zu untersuchen, wurden in einer weiteren Therapiestudie erneut CMT Ratten von P6 bis P18 mit $1 \mu \mathrm{g} / \mathrm{kg}$ rhNRG1 behandelt und im Alter von 9 Wochen analysiert. In der Tat waren die behandelten CMT Ratten im Alter von 9 Wochen noch signifikant stärker als Placebo behandelte Tiere und auch die Anzahl myelinisierter 
Axone befand sich auf Wildtyp-niveau. Solubles NRG1 hat also ein erstaunliches therapeutisches Potential um den Differenzierungsdefekt Pmp22 überexprimierender Schwannzellen zu beheben und die CMT1A Erkrankung in Tiermodellen zu lindern (Abb. 26Pmp22 transgene Ratten sprechen am besten innerhalb eines zweiwöchigen Zeitfensters während der frühen postnatalen Entwicklung auf eine Therapie mit rhNRG1 an. Eine später einsetzende Behandlung ist nicht annähernd so erfolgreich. Warum ist das korrekte Zeitfenster einer NRG1 Therapie unabdingbar, um eine Verbesserung der Nervenfunktion innerhalb der CMT1A Erkrankung zu erzielen? Eine frühe NRG1 Behandlung korrigiert die gestörte Balance der PI3K/AKT und MEK/ERK Signaltransduktionskaskaden, was Pmp22 transgenen Schwannzellen ermöglicht, besser zu differenzieren. NRG1 erhöht dabei drastisch die Kompetenz von Schwannzellen die Axone zu myelinisieren ohne die fehlerhafte Myelinisierung an sich (z.B. Hypermyelinisierung) zu beeinflussen. Diese Wiederherstellung des Myelinisierunspotentials Pmp22 überexprimierender Schwannzellen protegiert zeitgleich die axonale Funktion und lindert den Fortschritt der Krankheit im Tiermodell bis ins Erwachsenenalter. Zukünftige Experimente könnten klären, ob NRG1 auch axoprotektive Funktionen in Schwannzellen unabhängig von der Myelinisierung stimuliert.

Die CMT1A Erkrankung wird oftmals als demyelinisierende Neuropathie mit einem Krankheitsbeginn in der zweiten Lebensdekade angesehen (Dyck and Thomas, 2005). In der vorgelegten Arbeit wird ein Konzept vorgeschlagen, in dem ein PMP22 induzierter Zelldefekt während der frühen postnatalen Entwicklung die Schwannzelldifferenzierung chronisch beeinträchtigt und im Laufe der Zeit zu sekundärer Demyelinisierung, Zwiebelschalenformation und schließlich Axondegeneration führt (Abb. 26). Eine transiente Schwannzell-Dedifferenzierung ist Teil eines wirkungsvollen Reparaturprozesses nach akuter Nervenverletzung (Jessen und Mirsky, 2008). Ein steter Differenzierungsdefekt scheint hingegen die Langzeitfunktion von Axonen und deren Integrität zu beeinträchtigen. Eine gestörte Schwannzelldifferenzierung wurde auch für andere Neuropathien berichtet (Patzkó et al., 2012; D'Antonio et al., 2013). NRG1 sollte deshalb als Therapeutikum für Erkrankungen des peripheren Nervensystems in Erwägung gezogen werden, in welchen die Schwannzelldifferenzierung beeinträchtigt ist. 


\section{ZUSAMMENFASSUNG}

Eine Duplikation des Genes für das periphere Myelinprotein 22kDa (PMP22) begründet die häufigste erbliche Neuropathie, die unheilbare Charcot-Marie-Tooth Erkrankung $1 \mathrm{~A}$ (CMT1A). Obwohl die Demyelinisierung peripherer Nervenfasern ein krankheitsspezifisches Charakteristikum darstellt, ist die klinische Erkrankungsschwere von CMT1A Patienten durch das Ausmaß des axonalen Verlustes determiniert. Betroffene Menschen leiden unter progressiver, distal betonter Muskelatrophie und unter sensorischen Defiziten.

In der vorliegenden Promotionsschrift konnte unter Zuhilfenahme Pmp22 transgener Nagetiermodelle für die CMT1A gezeigt werden, dass Pmp22 überexprimierende Schwannzellen bereits während der frühen postnatalen Entwicklung einen molekularen Phänotyp entwickeln, der dem dedifferenzierter Schwannzellen nach akuter Nervenläsion ähnelt. Im Unterschied zum Läsionsmodell wird der Dedifferenzierungsphänotyp Pmp22 überexprimierender Schwannzellen jedoch durch ein unausgewogenes Verhältnis der Aktivitäten der PI3K/AKT und MEK/ERK Signaltransduktionskaskaden verursacht. Beiden Modellen gemeinsam ist hingegen die Induktion des Wachstumsfaktors Neuregulin-1 (NRG1) Typ I in Schwannzellen. Anhand konditionaler Nrg1 Ablation in Schwannzellen konnte in der Folge belegt werden, dass die Synthese von NRG1 Typ I für die Nervenregeneration nach akuter Schädigung in Wildtypmäusen essentiell ist. Auch CMT1A Mäuse ohne NRG1 in Schwannzellen entwickeln einen schwereren Krankheitsverlauf. Im Gegensatz dazu führte die experimentelle Verstärkung der NRG1 Signalwirkung durch axonale Überexpression von NRG1 Typ I in CMT1A Mäusen zu einer Verbesserung vieler krankheitsspezifischer Charakteristika. Insbesondere resultierte die gesteigerte Aktivität der beeinträchtigten PI3K/AKT Signaltransduktionskaskade zu einer verbesserten Differenzierung von Schwannzellen. In der Folge konnte somit die langfristige axonale Integrität im PNS erkrankter CMT1A Mäuse gewährleistet werden. In einer präklinischen experimentellen Therapie eines CMT1A Rattenmodelles mit rekombinantem humanem NRG1 wurde eine nahezu komplette Kompensation des Entwicklungsdefizits peripherer Nerven erreicht. Die pharmakologische Verabreichung von NRG1 innerhalb eines zweiwöchigen Zeitfensters während der postnatalen Entwicklung genügte, um eine verbesserte Nervenfunktion bis ins Erwachsenenalter zu gewährleisten. Anhand der vorgelegten Daten kann geschlussfolgert werden, dass die Schwannzell-Differenzierung innerhalb eines kurzen postnatalen Zeitfensters essentiell für die langfristige gliale Unterstützung der axonalen Funktion ist. 


\section{ABBILDUNGSVERZEICHNIS}

Abbildung 1: Myelinproteine des PNS.

Abbildung 2: Entwicklungsstadien von Schwannzellen im peripheren Nervensystem.

Abbildung 3: Die Struktur der Neuregulin-1 Isoformen Typ I - III.

Abbildung 4: Klinische Charakteristika der CMT

Abbildung 5: Querschnitte durch Nervi suralis

Abbildung 6: Schematische Darstellung des Rekombinations - hot spots auf Chromosom 17

Abbildung 7: Das Periphere Myelin Protein 22kDa (PMP22).

Abbildung 8: $\quad$ Pmp22 transgene Ratten sind ein Tiermodell für die humane CMT1A Erkrankung.

Abbildung 9: Pmp22 Überexpression führt zu eine früh-postnatalen fehlerhaften Differenzierung von Schwannzellen.

Abbildung 10: Nrg1 mRNA Expression in Ischiasnerven Pmp22 transgener Nager

Abbildung 11: Neuregulin-1 wird von Pmp22 transgenen Schwannzellen exprimiert.

Abbildung 12: Nrg1 mRNA Expression in Ischiasnerven nach akuter Nervenquetschung.

Abbildung 13: Mausmutanten ohne Schwannzell-NRG1 zeigen keine Aktivierung von ErbB2 und ERK1/2 vier Tage nach Nervenquetschung.

Abbildung 14: Ablation von Schwannzell-Nrg1 verschlechtert den Phänotyp in Pmp22 transgenen Mäusen.

Abbildung 15: Motoneurone zeigen zwei Wochen nach Nervenläsion eine verringerte NRG1 Expression.

Abbildung 16: In Spinalganglien wird bei Nervenschädigung Nrg1 Typ I mRNA Expression induziert.

Abbildung 17: Neuronal überexprimiertes NRG1 Typ I, nicht aber Typ III, führt zu einer verbesserten funktionellen Regeneration nach Nervenläsion.

Abbildung 18: Die neuronale Überexpression von NRG1 Typ I führt in CMT1A zu einer axonalen Präservation. 
Abbildung 19: Die neuronale Überexpression von NRG1 Typ I verbessert die elektrophysiologische Funktionalität in Ischiasnerven von CMT1A Mäusen.

Abbildung 20: NRG1 Typ I normalisiert die molekulare DedifferenzierungsSignatur von Schwannzellen in CMT1A Mäusen.

Abbildung 21: Eine Dosis von 1 $\mu \mathrm{g} / \mathrm{kg}$ NRG1 verbessert die Griffstärke von CMT Ratten ohne Gewichtsverlust.

Abbildung 22: Die frühe Therapie von CMT Ratten mit $1 \mu \mathrm{g} / \mathrm{kg} \mathrm{NRG1}$ normalisiert die Anzahl myelinisierter Axone bei P18.

Abbildung 23: Die frühe NRG1 Therapie normalisiert den molekularen Dedifferenzierungsphänotyp Pmp22 überexprimierender Schwannzellen in CMT Ratten bei P18.

Abbildung 24: Eine späte Behandlung von CMT Ratten mit NRG1 hat nur einen geringen therapeutischen Effekt.

Abbildung 25: Früh mit NRG1 behandelte CMT Ratten zeigen im Alter einen verbesserten Phänotyp.

Abbildung 26: Hypothetisches Modell zur Pathologie und NRG1 Therapie in PMP22 überexprimierenden Schwannzellen.

Tabelle 1: Klassifikation peripherer hereditärer Neuropathien mit identifizierter genetischer Ursache. 


\section{LITERATURVERZEICHNIS}

Adlkofer K, Martini R, Aguzzi A, Zielasek J, Toyka K V, Suter U (1995)

Hypermyelination and demyelinating peripheral neuropathy in Pmp22-deficient mice.

Nature genetics 11:274-280.

Arthur-Farraj PJ, Latouche M, Wilton DK, Quintes S, Chabrol E, Banerjee A, Woodhoo A, Jenkins B, Rahman M, Turmaine M, Wicher GK, Mitter R, Greensmith L, Behrens A, Raivich G, Mirsky R, Jessen KR (2012) c-Jun reprograms Schwann cells of injured nerves to generate a repair cell essential for regeneration. Neuron 75:633-647.

Bähr M, Frotscher M (2009) Neurologisch-topische Diagnostik. Thieme, Stuttgart; Auflage: 9., überarbeitete Auflage.

Berciano J, García A, Calleja J, Combarros O (2000) Clinico-electrophysiological correlation of extensor digitorum brevis muscle atrophy in children with charcot-marietooth disease 1A duplication. Neuromuscular disorders : NMD 10:419-424.

Bersell K, Arab S, Haring B, Kühn B (2009) Neuregulin1/ErbB4 signaling induces cardiomyocyte proliferation and repair of heart injury. Cell 138:257-270.

Birchmeier C, Nave K-A (2008) Neuregulin-1, a key axonal signal that drives Schwann cell growth and differentiation. Glia 56:1491-1497.

Birouk N, Gouider R, Le Guern E, Gugenheim M, Tardieu S, Maisonobe T, Le Forestier N, Agid Y, Brice a, Bouche P (1997) Charcot-Marie-Tooth disease type 1A with $17 p 11.2$ duplication. Clinical and electrophysiological phenotype study and factors influencing disease severity in 119 cases. Brain: A journal of neurology 120 ( Pt 5:813823.

Boerkoel CF, Inoue K, Reiter LT, Warner LE, Lupski JR (1999) Molecular mechanisms for CMT1A duplication and HNPP deletion. Annals Of The New York Academy Of Sciences 883:22-35.

Bort S, Sevilla T, Vílchez JJ, Prieto F, Palau F (1995) [The diagnosis and prevalence of locus CMT1A duplication in Charcot-Marie-Tooth disease type 1]. Medicina clínica 104:648-652.

Bosse F (2012) Extrinsic cellular and molecular mediators of peripheral axonal regeneration. Cell and tissue research 349:5-14.

Bouché P, Gherardi R, Cathala HP, Lhermitte F, Castaigne P (1983) Peroneal muscular atrophy. Part 1. Clinical and electrophysiological study. Journal of the neurological sciences 61:389-399.

Brancolini C, Edomi P, Marzinotto S, Schneider C (2000) Exposure at the cell surface is required for gas3/PMP22 To regulate both cell death and cell spreading: implication for the Charcot-Marie-Tooth type 1A and Dejerine-Sottas diseases. Molecular biology of the cell 11:2901-2914. 
Brancolini C, Marzinotto S, Edomi P, Agostoni E, Fiorentini C, Müller HW, Schneider C (1999) Rho-dependent regulation of cell spreading by the tetraspan membrane protein Gas3/PMP22. Molecular biology of the cell 10:2441-2459.

Brockes JP, Fields KL, Raff MC (1979) Studies on cultured rat Schwann cells. I. Establishment of purified populations from cultures of peripheral nerve. Brain research 165:105-118.

Brownlees J, Ackerley S, Grierson AJ, Jacobsen NJO, Shea K, Anderton BH, Leigh PN, Shaw CE, Miller CCJ (2002) Charcot-Marie-Tooth disease neurofilament mutations disrupt neurofilament assembly and axonal transport. Human molecular genetics $11: 2837-2844$.

Burns J, Ouvrier R (2006) Pes cavus pathogenesis in Charcot-Marie-Tooth disease type 1A. Brain : a journal of neurology 129:E50; author reply E51.

Campbell NA, Reece JB (2009) Biologie - Der neue Campbell [Gebundene Ausgabe]. Pearson; Auflage: 8., aktualisierte Auflage.

Carenini S, Neuberg D, Schachner M, Suter U, Martini R (1999) Localization and functional roles of PMP22 in peripheral nerves of P0-deficient mice. Glia 28:256-264.

Carroll SL, Miller ML, Frohnert PW, Kim SS, Corbett JA (1997) Expression of neuregulins and their putative receptors, ErbB2 and ErbB3, is induced during Wallerian degeneration. The Journal of neuroscience : the official journal of the Society for Neuroscience 17:1642-1659.

Charcot JM, Marie P (1886) Sur un forme particulière d'atrophie musculaire progressive, souvent familiaale débutant par les pieds et les jambes et atteignant plus tards les mains. Revue Medical:97-138.

Chen Z-L, Yu W-M, Strickland S (2007) Peripheral regeneration. Annual review of neuroscience 30:209-233.

Chies R, Nobbio L, Edomi P, Schenone A, Schneider C, Brancolini C (2003) Alterations in the Arf6-regulated plasma membrane endosomal recycling pathway in cells overexpressing the tetraspan protein Gas3/PMP22. Journal of Cell Science 116:987999.

Cronk JC, Kipnis J (2013) Microglia - the brain's busy bees. F1000prime reports 5:53.

D'Antonio M, Musner N, Scapin C, Ungaro D, Del Carro U, Ron D, Feltri ML, Wrabetz L (2013) Resetting translational homeostasis restores myelination in Charcot-MarieTooth disease type 1B mice. The Journal of experimental medicine 210:821-838.

D'Urso D, Ehrhardt P, Müller HW (1999) Peripheral myelin protein 22 and protein zero: a novel association in peripheral nervous system myelin. The Journal of neuroscience: the official journal of the Society for Neuroscience 19:3396-3403.

De Waegh SM, Lee VM, Brady ST (1992) Local modulation of neurofilament phosphorylation, axonal caliber, and slow axonal transport by myelinating Schwann cells. Cell 68:451-463. 
Deckwerth TL, Johnson EM (1994) Neurites can remain viable after destruction of the neuronal soma by programmed cell death (apoptosis). Developmental biology 165:6372.

Dyck PJ, Lambert EH (1968) Lower motor and primary sensory neuron diseases with peroneal muscular atrophy. II. Neurologic, genetic, and electrophysiologic findings in various neuronal degenerations. Archives of neurology 18:619-625.

Dyck PJ, Thomas PK (2005) Peripheral Neuropathy, 4th Edition | P. K. Thomas, Peter Dyck | ISBN 9780721694917. Book Available at: http://store.elsevier.com/PeripheralNeuropathy/P_-K_-Thomas/isbn-9780721694917/ [Accessed September 16, 2013].

Eckert R, Randall D, Burggren W, French K (2002) Tierphysiologie. Thieme, Stuttgart.

Ellis D, Malcolm S (1994) Proteolipid protein gene dosage effect in PelizaeusMerzbacher disease. Nature genetics 6:333-334.

Emery AE (1991) Population frequencies of inherited neuromuscular diseases--a world survey. Neuromuscular disorders : NMD 1:19-29.

Fabbretti E, Edomi P, Brancolini C, Schneider C (1995) Apoptotic phenotype induced by overexpression of wild-type gas3/PMP22: its relation to the demyelinating peripheral neuropathy CMT1A. Genes \& development 9:1846-1856.

Falls DL (2003) Neuregulins: functions, forms, and signaling strategies. Experimental cell research 284:14-30.

Fleck D, van Bebber F, Colombo A, Galante C, Schwenk BM, Rabe L, Hampel H, Novak B, Kremmer E, Tahirovic S, Edbauer D, Lichtenthaler SF, Schmid B, Willem M, Haass C (2013) Dual cleavage of neuregulin 1 type III by BACE1 and ADAM17 liberates its EGF-like domain and allows paracrine signaling. The Journal of neuroscience : the official journal of the Society for Neuroscience 33:7856-7869.

Fledrich R, Schlotter-Weigel B, Schnizer TJ, Wichert SP, Stassart RM, Zu Hörste GM, Klink A, Weiss BG, Haag U, Walter MC, Rautenstrauss B, Paulus W, Rossner MJ, Sereda MW (2012a) A rat model of Charcot-Marie-Tooth disease 1 A recapitulates disease variability and supplies biomarkers of axonal loss in patients. Brain: A journal of neurology 135:72-87.

Fledrich R, Stassart RM, Sereda MW (2012b) Murine therapeutic models for CharcotMarie-Tooth (CMT) disease. British medical bulletin 102:89-113.

Flores Al, Narayanan SP, Morse EN, Shick HE, Yin X, Kidd G, Avila RL, Kirschner DA, Macklin WB (2008) Constitutively active Akt induces enhanced myelination in the CNS. The Journal of neuroscience : the official journal of the Society for Neuroscience 28:7174-7183.

Friede RL, Bischhausen R (1982) How are sheath dimensions affected by axon caliber and internode length? Brain research 235:335-350.

Frostick SP, Yin Q, Kemp GJ (1998) Schwann cells, neurotrophic factors, and peripheral nerve regeneration. Microsurgery 18:397-405. 
García A, Combarros O, Calleja J, Berciano J (1998) Charcot-Marie-Tooth disease type $1 \mathrm{~A}$ with $17 \mathrm{p}$ duplication in infancy and early childhood: a longitudinal clinical and electrophysiologic study. Neurology 50:1061-1067.

Garcia CA, Malamut RE, England JD, Parry GS, Liu P, Lupski JR (1995) Clinical variability in two pairs of identical twins with the Charcot-Marie-Tooth disease type $1 \mathrm{~A}$ duplication. Neurology 45:2090-2093.

Giese KP, Martini R, Lemke G, Soriano P, Schachner M (1992) Mouse P0 gene disruption leads to hypomyelination, abnormal expression of recognition molecules, and degeneration of myelin and axons. Cell 71:565-576.

Grandis M, Leandri M, Vigo T, Cilli M, Sereda MW, Gherardi G, Benedetti L, Mancardi G, Abbruzzese M, Nave K-A, Nobbio L, Schenone A (2004) Early abnormalities in sciatic nerve function and structure in a rat model of Charcot-Marie-Tooth type $1 \mathrm{~A}$ disease. Experimental Neurology 191:213-223.

Guénard V, Montag D, Schachner M, Martini R (1996) Onion bulb cells in mice deficient for myelin genes share molecular properties with immature, differentiated nonmyelinating, and denervated Schwann cells. Glia 18:27-38.

Hanemann CO, Stoll G, D'Urso D, Fricke W, Martin JJ, Van Broeckhoven C, Mancardi GL, Bartke I, Müller HW (1994) Peripheral myelin protein-22 expression in CharcotMarie-Tooth disease type 1a sural nerve biopsies. Journal of neuroscience research $37: 654-659$.

Haney C, Snipes GJ, Shooter EM, Suter U, Garcia C, Griffin JW, Trapp BD (1996) Ultrastructural distribution of PMP22 in Charcot-Marie-Tooth disease type 1A. Journal of neuropathology and experimental neurology 55:290-299.

Harding A, Thomas $P(1980)$ The clinical features of hereditary motor and sensory neuropathy types I and II. Brain: a journal of neurology 17:259-280.

Hellemans J, Mortier G, De Paepe A, Speleman F, Vandesompele J (2007) qBase relative quantification framework and software for management and automated analysis of real-time quantitative PCR data. Genome biology 8:R19.

Houlden H, Reilly M (2006) Molecular genetics of autosomal-dominant demyelinating Charcot-Marie-Tooth disease. Genetics 8:43-62.

Hutton EJ, Carty L, Laurá M, Houlden H, Lunn MPT, Brandner S, Mirsky R, Jessen K, Reilly MM (2011) c-Jun expression in human neuropathies: a pilot study. Journal of the peripheral nervous system: JPNS 16:295-303.

Huxley C, Passage E, Manson a, Putzu G, Figarella-Branger D, Pellissier JF, Fontés M (1996) Construction of a mouse model of Charcot-Marie-Tooth disease type $1 \mathrm{~A}$ by pronuclear injection of human YAC DNA. Human Molecular Genetics 5:563-569.

Huxley C, Passage E, Robertson a M, Youl B, Huston S, Manson a, Sabéran-Djoniedi D, Figarella-Branger D, Pellissier JF, Thomas PK, Fontés M (1998) Correlation between varying levels of PMP22 expression and the degree of demyelination and reduction in nerve conduction velocity in transgenic mice. Human Molecular Genetics 7:449-458. 
Hyden H (1961) Satellite cells in the nervous system. Scientific American 205:62-70.

Inouye H, Kirschner DA (1994) Membrane topology of PLP in CNS myelin: evaluation of models. Neurochemical research 19:975-981.

Ionasescu V V (1995) Charcot-Marie-Tooth neuropathies: from clinical description to molecular genetics. Muscle \& nerve 18:267-275.

Jessen KR, Mirsky R (2005) The origin and development of glial cells in peripheral nerves. Nature Reviews Neuroscience 6:671-682.

Jessen KR, Mirsky R (2008) Negative regulation of myelination: relevance for development, injury, and demyelinating disease. Glia 56:1552-1565.

Kaku D, Parry G, Malamut R, Lupski J, Garcia C (1993) Uniform slowing of conduction velocities in Charcot-Marie-Tooth polyneuropathy type 1. Neurology.

Karlsson U, Schultz RL (1965) Fixation of the central nervous system from electron microscopy by aldehyde perfusion. Journal of ultrastructure research 12:160-186.

Kato T, Abe Y, Sotoyama H, Kakita A, Kominami R, Hirokawa S, Ozaki M, Takahashi $\mathrm{H}$, Nawa $\mathrm{H}$ (2011) Transient exposure of neonatal mice to neuregulin-1 results in hyperdopaminergic states in adulthood: implication in neurodevelopmental hypothesis for schizophrenia. Molecular psychiatry 16:307-320.

Killian JM, Tiwari PS, Jacobson S, Jackson RD, Lupski JR (1996) Longitudinal studies of the duplication form of Charcot-Marie-Tooth polyneuropathy. Muscle nerve 19:7478.

Kitamura K, Suzuki M, Uyemura K (1976) Purification and partial characterization of two glycoproteins in bovine peripheral nerve myelin membrane. Biochimica et biophysica acta 455:806-816.

Krajewski KM, Lewis R a, Fuerst DR, Turansky C, Hinderer SR, Garbern J, Kamholz J, Shy ME (2000) Neurological dysfunction and axonal degeneration in Charcot-MarieTooth disease type 1A. Brain: A journal of neurology 123 ( Pt 7:1516-1527.

Kuhlenbäumer G, Young P, Hünermund G, Ringelstein B, Stögbauer F (2002) Clinical features and molecular genetics of hereditary peripheral neuropathies. Journal of Neurology 249:1629-1650.

Kurihara S, Adachi Y, Wada K, Awaki E, Harada H, Nakashima K (2002) An epidemiological genetic study of Charcot-Marie-Tooth disease in Western Japan. Neuroepidemiology 21:246-250.

Laemmli UK (1970) Cleavage of structural proteins during the assembly of the head of bacteriophage T4. Nature 227:680-685.

Luft JH (1961) Improvements in epoxy resin embedding methods. The Journal of biophysical and biochemical cytology 9:409-414.

Lunn ER, Perry VH, Brown MC, Rosen H, Gordon S (1989) Absence of Wallerian Degeneration does not Hinder Regeneration in Peripheral Nerve. The European journal of neuroscience 1:27-33. 
Lupski JR, De Oca-Luna RM, Slaugenhaupt S, Pentao L, Guzzetta V, Trask BJ, Saucedo-Cardenas O, Barker DF, Killian JM, Garcia C a, Chakravarti a, Patel PI (1991) DNA duplication associated with Charcot-Marie-Tooth disease type 1A. Cell 66:219-232.

Lyon MF, Ogunkolade BW, Brown MC, Atherton DJ, Perry VH (1993) A gene affecting Wallerian nerve degeneration maps distally on mouse chromosome 4. Proceedings of the National Academy of Sciences of the United States of America 90:9717-9720.

Magyar JP, Martini R, Ruelicke T, Aguzzi a, Adlkofer K, Dembic Z, Zielasek J, Toyka K $V$, Suter U (1996) Impaired differentiation of Schwann cells in transgenic mice with increased PMP22 gene dosage. Journal of Neuroscience 16:5351-5360.

Manfioletti G, Ruaro ME, Del Sal G, Philipson L, Schneider C (1990) A growth arrestspecific (gas) gene codes for a membrane protein. Molecular and cellular biology 10:2924-2930.

Martini R (2000) Animal models for inherited peripheral neuropathies: chances to find treatment strategies? Journal of neuroscience research 61:244-250.

Martini R, Klein D, Groh J (2013) Similarities between inherited demyelinating neuropathies and Wallerian degeneration: an old repair program may cause myelin and axon perturbation under nonlesion conditions. The American journal of pathology 183:655-660.

Martini R, Zielasek J, Toyka K V, Giese KP, Schachner M (1995) Protein zero (P0)deficient mice show myelin degeneration in peripheral nerves characteristic of inherited human neuropathies. Nature genetics 11:281-286.

Matsunami N, Smith B, Ballard L, Lensch MW, Robertson M, Albertsen H, Hanemann CO, Müller HW, Bird TD, White R (1992) Peripheral myelin protein-22 gene maps in the duplication in chromosome 17p11.2 associated with Charcot-Marie-Tooth 1A. Nature genetics 1:176-179.

Mendes-Ferreira P, De Keulenaer GW, Leite-Moreira AF, Brás-Silva C (2013) Therapeutic potential of neuregulin-1 in cardiovascular disease. Drug discovery today 18:836-842.

Mendoza MC, Er EE, Blenis J (2011) The Ras-ERK and PI3K-mTOR pathways: crosstalk and compensation. Trends in biochemical sciences 36:320-328.

Meyer zu Hörste G, Miesbach TA, Muller JI, Fledrich R, Stassart RM, Kieseier BC, Coleman MP, Sereda MW (2011) The Wlds transgene reduces axon loss in a CharcotMarie-Tooth disease $1 \mathrm{~A}$ rat model and nicotinamide delays post-traumatic axonal degeneration. Neurobiology of Disease 42:1-8.

Meyer zu Hörste G, Prukop T, Nave K-A, Sereda MW (2006) Myelin disorders: Causes and perspectives of Charcot-Marie-Tooth neuropathy. Journal of molecular neuroscience : MN 28:77-88.

Michailov G V, Sereda MW, Brinkmann BG, Fischer TM, Haug B, Birchmeier C, Role L, Lai C, Schwab MH, Nave K-A (2004) Axonal neuregulin-1 regulates myelin sheath thickness. Science 304:700-703. 
Mirsky R, Woodhoo A, Parkinson DB, Arthur-Farraj P, Bhaskaran A, Jessen KR (2008) Novel signals controlling embryonic Schwann cell development, myelination and dedifferentiation. Journal of the peripheral nervous system : JPNS 13:122-135.

Morocutti C, Colazza GB, Soldati G, D'Alessio C, Damiano M, Casali C, Pierelli F (2002) Charcot-Marie-Tooth disease in Molise, a central-southern region of Italy: an epidemiological study. Neuroepidemiology 21:241-245.

Mullis K, Faloona F, Scharf S, Saiki R, Horn G, Erlich H (1986) Specific enzymatic amplification of DNA in vitro: the polymerase chain reaction. Cold Spring Harbor symposia on quantitative biology $51 \mathrm{Pt}$ 1:263-273.

Naef R, Suter U (1999) Impaired intracellular trafficking is a common disease mechanism of PMP22 point mutations in peripheral neuropathies. Neurobiology of Disease 6:1-14.

Napoli I, Noon L, Ribeiro S, Kerai A, Parrinello S, Rosenberg L, Collins M, Harrisingh M, White I, Woodhoo a, Lloyd A (2012) A central role for the ERK-signaling pathway in controlling Schwann cell plasticity and peripheral nerve regeneration in vivo. Neuron 73:729-742.

Nave K-A (2010) Myelination and support of axonal integrity by glia. Nature 468:244252.

Nave K-A, Salzer JL (2006) Axonal regulation of myelination by neuregulin 1. Current opinion in neurobiology 16:492-500.

Nelis E et al. (1996) Estimation of the mutation frequencies in Charcot-Marie-Tooth disease type 1 and hereditary neuropathy with liability to pressure palsies: a European collaborative study. European journal of human genetics: EJHG 4:25-33.

Neuberg DH, Sancho S, Suter U (1999) Altered molecular architecture of peripheral nerves in mice lacking the peripheral myelin protein 22 or connexin32. Journal of neuroscience research 58:612-623.

Newbern J, Birchmeier C (2010) Nrg1/ErbB signaling networks in Schwann cell development and myelination. Seminars in cell \& developmental biology 21:922-928.

Newbern JM, Li X, Shoemaker SE, Zhou J, Zhong J, Wu Y, Bonder D, Hollenback S, Coppola G, Geschwind DH, Landreth GE, Snider WD (2011) Specific functions for ERK/MAPK signaling during PNS development. Neuron 69:91-105.

Nicholson GA (1991) Penetrance of the hereditary motor and sensory neuropathy la mutation: assessment by nerve conduction studies. Neurology 41:547-552.

Nicholson GA, Kennerson ML, Keats BJ, Mesterovic N, Churcher W, Barker D, Ross DA (1992) Charcot-Marie-Tooth neuropathy type 1A mutation: apparent crossovers with D17S122 are due to a duplication. American journal of medical genetics 44:455460.

Niemann A, Berger P, Suter U (2006) Pathomechanisms of mutant proteins in CharcotMarie-Tooth disease. NeuroMolecular Medicine 8:217-242. 
Nishimura T, Yoshikawa H, Fujimura H, Sakoda S, Yanagihara T (1996) Accumulation of peripheral myelin protein 22 in onion bulbs and Schwann cells of biopsied nerves from patients with Charcot-Marie-Tooth disease type 1A. Acta neuropathologica 92:454-460.

Notterpek L, Roux KJ, Amici SA, Yazdanpour A, Rahner C, Fletcher BS (2001) Peripheral myelin protein 22 is a constituent of intercellular junctions in epithelia. Proceedings of the National Academy of Sciences of the United States of America 98:14404-14409.

Notterpek L, Ryan MC, Tobler a R, Shooter EM (1999) PMP22 accumulation in aggresomes: implications for CMT1A pathology. Neurobiology of Disease 6:450-460.

Palau F, Löfgren a, De Jonghe P, Bort S, Nelis E, Sevilla T, Martin JJ, Vilchez J, Prieto F, Van Broeckhoven C (1993) Origin of the de novo duplication in Charcot-Marie-Tooth disease type 1A: unequal nonsister chromatid exchange during spermatogenesis. Human Molecular Genetics 2:2031-2035.

Pareek S, Suter U, Snipes GJ, Welcher AA, Shooter EM, Murphy RA (1993) Detection and processing of peripheral myelin protein PMP22 in cultured Schwann cells. The Journal of biological chemistry 268:10372-10379.

Pareyson D, Marchesi C (2009) Diagnosis, natural history, and management of Charcot-Marie-Tooth disease. The Lancet 8:654-667.

Patzkó A, Bai Y, Saporta MA, Katona I, Wu X, Vizzuso D, Feltri ML, Wang S, Dillon LM, Kamholz J, Kirschner D, Sarkar FH, Wrabetz L, Shy ME (2012) Curcumin derivatives promote Schwann cell differentiation and improve neuropathy in R98C CMT1B mice. Brain : a journal of neurology 135:3551-3566.

Pentao L, Wise C a, Chinault a C, Patel PI, Lupski JR (1992) Charcot-Marie-Tooth type $1 \mathrm{~A}$ duplication appears to arise from recombination at repeat sequences flanking the 1.5 Mb monomer unit. Nature Genetics 2:292-300.

Pérez-Ollé R, López-Toledano MA, Goryunov D, Cabrera-Poch N, Stefanis L, Brown K, Liem RKH (2005) Mutations in the neurofilament light gene linked to Charcot-MarieTooth disease cause defects in transport. Journal of neurochemistry 93:861-874.

Peters A, Palay SL, Webster H deF. (1991) Fine Structure of the Nervous System: Neurons and Their Supporting Cells. Oxford University Press, USA.

Popot JL, Pham Dinh D, Dautigny A (1991) Major myelin proteolipid: the 4-alpha-helix topology. The Journal of membrane biology 123:278.

Porstmann T, Griffiths B, Chung Y-L, Delpuech O, Griffiths JR, Downward J, Schulze A (2005) PKB/Akt induces transcription of enzymes involved in cholesterol and fatty acid biosynthesis via activation of SREBP. Oncogene 24:6465-6481.

Quarles RH, Macklin WB, Morell P (2006) Myelin formation, structure, and biochemistry. In: Basic Neurochemistry, 7th Editio. (Siegel GJ et al., ed), pp 51-71.

Raeymaekers P, Timmerman V, Nelis E, De Jonghe P, Hoogendijk JE, Baas F, Barker DF, Martin JJ, De Visser M, Bolhuis PA (1991) Duplication in chromosome 17p11.2 in 
Charcot-Marie-Tooth neuropathy type 1a (CMT 1a). The HMSN Collaborative Research Group. Neuromuscular disorders: NMD 1:93-97.

Reilly MM, Shy ME (2009) Diagnosis and new treatments in genetic neuropathies. Journal of neurology, neurosurgery, and psychiatry 80:1304-1314.

Reynolds ES (1963) The use of lead citrate at high pH as an electron-opaque stain in electron microscopy. The Journal of cell biology 17:208-212.

Richardson KC, Jarett L, Finke EH (1960) Embedding in epoxy resins for ultrathin sectioning in electron microscopy. Stain technology 35:313-323.

Roa BB, Dyck PJ, Marks HG, Chance PF, Lupski JR (1993) Dejerine-Sottas syndrome associated with point mutation in the peripheral myelin protein 22 (PMP22) gene.

Nature genetics 5:269-273.

Robertson AM, Perea J, McGuigan A, King RHM, Muddle JR, Gabreëls-Festen AA, Thomas PK, Huxley C (2002) Comparison of a new pmp22 transgenic mouse line with other mouse models and human patients with CMT1A. Journal of anatomy 200:377390.

Roux KJ, Amici SA, Fletcher BS, Notterpek L (2005) Modulation of epithelial morphology, monolayer permeability, and cell migration by growth arrest specific 3/peripheral myelin protein 22. Molecular biology of the cell 16:1142-1151.

Roux KJ, Amici SA, Notterpek L (2004) The temporospatial expression of peripheral myelin protein 22 at the developing blood-nerve and blood-brain barriers. The Journal of comparative neurology 474:578-588.

Sahenk Z, Chen L, Mendell JR (1999) Effects of PMP22 duplication and deletions on the axonal cytoskeleton. Annals of Neurology 45:16-24.

Samsam M, Mi W, Wessig C, Zielasek J, Toyka K V, Coleman MP, Martini R (2003) The Wlds mutation delays robust loss of motor and sensory axons in a genetic model for myelin-related axonopathy. The Journal of neuroscience : the official journal of the Society for Neuroscience 23:2833-2839.

Sancho S, Young P, Suter U (2001) Regulation of Schwann cell proliferation and apoptosis in PMP22-deficient mice and mouse models of Charcot-Marie-Tooth disease type 1A. Brain : a journal of neurology 124:2177-2187.

Sandrock AW, Dryer SE, Rosen KM, Gozani SN, Kramer R, Theill LE, Fischbach GD (1997) Maintenance of acetylcholine receptor number by neuregulins at the neuromuscular junction in vivo. Science (New York, NY) 276:599-603.

Sasaki T, Gotow T, Shiozaki M, Sakaue F, Saito T, Julien J-P, Uchiyama Y, Hisanaga S-I (2006) Aggregate formation and phosphorylation of neurofilament-L Pro22 CharcotMarie-Tooth disease mutants. Human molecular genetics 15:943-952.

Schröder JM (1972) Altered ratio between axon diameter and myelin sheath thickness in regenerated nerve fibers. Brain research 45:49-65. 
Sereda M, Griffiths I, Pühlhofer a, Stewart H, Rossner MJ, Zimmerman F, Magyar JP, Schneider a, Hund E, Meinck HM, Suter U, Nave K a (1996) A transgenic rat model of Charcot-Marie-Tooth disease. Neuron 16:1049-1060.

Sereda MW (1999) Altered protein synthesis in sciatic nerve by transgenic overexpression of PMP22 in the CMT rat. Annals of the New York Academy of Sciences 883:530-532.

Sereda MW, Meyer Zu Hörste G, Suter U, Uzma N, Nave K-A (2003) Therapeutic administration of progesterone antagonist in a model of Charcot-Marie-Tooth disease (CMT-1A). Nature Medicine 9:1533-1537.

Sherman DL, Brophy PJ (2005) Mechanisms of axon ensheathment and myelin growth. Nature reviews Neuroscience 6:683-690.

Sherman DL, Krols M, Wu L-MN, Grove M, Nave K-A, Gangloff Y-G, Brophy PJ (2012) Arrest of myelination and reduced axon growth when Schwann cells lack mTOR. The Journal of neuroscience : the official journal of the Society for Neuroscience 32:18171825.

Sheu JY, Kulhanek DJ, Eckenstein FP (2000) Differential patterns of ERK and STAT3 phosphorylation after sciatic nerve transection in the rat. Experimental neurology 166:392-402.

Simons M, Trotter J (2007) Wrapping it up: the cell biology of myelination. Current opinion in neurobiology 17:533-540.

Skre H (1974) Genetic and clinical aspects of Charcot-Marie-Tooth's disease. Clinical genetics 6:98-118.

Snaidero N, Möbius W, Czopka T, Hekking LHP, Mathisen C, Verkleij D, Goebbels S, Edgar J, Merkler D, Lyons DA, Nave K-A, Simons M (2014) Myelin Membrane Wrapping of CNS Axons by $\mathrm{PI}(3,4,5) \mathrm{P} 3-$ Dependent Polarized Growth at the Inner Tongue. Cell 156:277-290.

Snipes GJ, Suter U (1995) Molecular anatomy and genetics of myelin proteins in the peripheral nervous system. Journal of anatomy 186 ( Pt 3:483-494.

Snipes GJ, Suter U, Shooter EM (1993) The genetics of myelin. Current opinion in neurobiology 3:694-702.

Snipes GJ, Suter U, Welcher a a, Shooter EM (1992) Characterization of a novel peripheral nervous system myelin protein (PMP-22/SR13). The Journal of Cell Biology 117:225-238.

Solomon W, Wilson NO, Anderson L, Pitts S, Patrickson J, Liu M, Ford BD, Stiles JK (2014) Neuregulin-1 attenuates mortality associated with experimental cerebral malaria. Journal of neuroinflammation 11:9.

Spreyer P, Kuhn G, Hanemann CO, Gillen C, Schaal H, Kuhn R, Lemke G, Müller HW (1991) Axon-regulated expression of a Schwann cell transcript that is homologous to a "growth arrest-specific" gene. the The European Molecular Biology Organization Journal 10:3661-3668. 
Stassart RM, Fledrich R, Velanac V, Brinkmann BG, Schwab MH, Meijer D, Sereda MW, Nave K-A (2013) A role for Schwann cell-derived neuregulin-1 in remyelination. Nature neuroscience 16:48-54.

Stassart RM, Goebbels S, Nave K-A (2012) Factors controlling myelin formation. In: Neuroglia, 3rd Editio. (Kettenmann H, Ransom BR, eds), pp 555-572. Oxford University Press.

Stoll G, Müller HW (1999) Nerve injury, axonal degeneration and neural regeneration: basic insights. Brain pathology (Zurich, Switzerland) 9:313-325.

Suter U, Scherer SS (2003) Disease mechanisms in inherited neuropathies. Nature Reviews Neuroscience 4:714-726.

Suter U, Snipes GJ, Schoener-Scott R, Welcher AA, Pareek S, Lupski JR, Murphy RA, Shooter EM, Patel PI (1994) Regulation of tissue-specific expression of alternative peripheral myelin protein-22 (PMP22) gene transcripts by two promoters. The Journal of biological chemistry 269:25795-25808.

Suter U, Welcher AA, Snipes GJ (1993) Progress in the molecular understanding of hereditary peripheral neuropathies reveals new insights into the biology of the peripheral nervous system. Trends in neurosciences 16:50-56.

Taveggia C, Feltri ML, Wrabetz L (2010) Signals to promote myelin formation and repair. Nature reviews Neurology 6:276-287.

Taveggia C, Zanazzi G, Petrylak A, Yano H, Rosenbluth J, Einheber S, Xu X, Esper RM, Loeb JA, Shrager P, Chao M V, Falls DL, Role L, Salzer JL (2005) Neuregulin-1 type III determines the ensheathment fate of axons. Neuron 47:681-694.

Ter Laak MP, Hamers FP, Kirk CJ, Gispen WH (2000) rhGGF2 protects against cisplatin-induced neuropathy in the rat. Journal of neuroscience research 60:237-244.

Timmerman V, Nelis E, Van Hul W, Nieuwenhuijsen BW, Chen KL, Wang S, Ben Othman K, Cullen B, Leach RJ, Hanemann CO (1992) The peripheral myelin protein gene PMP-22 is contained within the Charcot-Marie-Tooth disease type 1A duplication. Nature genetics 1:171-175.

Tobler AR, Liu N, Mueller L, Shooter EM (2002) Differential aggregation of the Trembler and Trembler $\mathrm{J}$ mutants of peripheral myelin protein 22. Proceedings of the National Academy of Sciences of the United States of America 99:483-488.

Tooth $\mathrm{HH}$ (1886) The peroneal type of progressive muscular atrophy.

Vallat JM, Sindou P, Preux PM, Tabaraud F, Milor AM, Couratier P, LeGuern E, Brice A (1996) Ultrastructural PMP22 expression in inherited demyelinating neuropathies. Annals of neurology 39:813-817.

Van de Wetering RA, Gabreëls-Festen AA, Kremer H, Kalscheuer VM, Gabreëls FJ, Mariman EC (1999) Regulation and expression of the murine PMP22 gene.

Mammalian genome : official journal of the International Mammalian Genome Society 10:419-422. 
Vandesompele J, Preter K De, Poppe B, Roy N Van, Paepe A De (2002) Accurate normalization of real-time quantitative RT -PCR data by geometric averaging of multiple internal control genes. :1-12.

Wakatsuki S, Yumoto N, Komatsu K, Araki T, Sehara-Fujisawa A (2009) Roles of meltrin-beta/ADAM19 in progression of Schwann cell differentiation and myelination during sciatic nerve regeneration. The Journal of biological chemistry 284:2957-2966.

Wang JT, Medress ZA, Barres BA (2012) Axon degeneration: molecular mechanisms of a self-destruction pathway. The Journal of cell biology 196:7-18.

Welcher AA, De Leon M, Suter U, Snipes GJ, Meakin SO, Shooter EM (1992) Isolation of transcriptionally regulated sequences associated with neuronal and non-neuronal cell interactions. Progress in brain research 94:163-176.

Wise CA, Garcia CA, Davis SN, Heju Z, Pentao L, Patel PI, Lupski JR (1993) Molecular analyses of unrelated Charcot-Marie-Tooth (CMT) disease patients suggest a high frequency of the CMTIA duplication. American journal of human genetics 53:853-863.

Wolpowitz D, Mason TB, Dietrich P, Mendelsohn M, Talmage DA, Role LW (2000) Cysteine-rich domain isoforms of the neuregulin-1 gene are required for maintenance of peripheral synapses. Neuron 25:79-91.

Yin X, Kidd GJ, Wrabetz L, Feltri ML, Messing A, Trapp BD (2000) Schwann cell myelination requires timely and precise targeting of $P(0)$ protein. The Journal of cell biology 148:1009-1020.

Yiu EM, Burns J, Ryan MM, Ouvrier RA (2008) Neurophysiologic abnormalities in children with Charcot-Marie-Tooth disease type 1A. Journal of the peripheral nervous system : JPNS 13:236-241.

Yoshikawa H, Nishimura T, Nakatsuji Y, Fujimura H, Himoro M, Hayasaka K, Sakoda S, Yanagihara T (1994) Elevated expression of messenger RNA for peripheral myelin protein 22 in biopsied peripheral nerves of patients with Charcot-Marie-Tooth disease type 1A. Annals of neurology 35:445-450.

Zhao C, Takita J, Tanaka Y, Setou M, Nakagawa T, Takeda S, Yang HW, Terada S, Nakata T, Takei Y, Saito M, Tsuji S, Hayashi Y, Hirokawa N (2001) Charcot-MarieTooth disease type $2 \mathrm{~A}$ caused by mutation in a microtubule motor KIF1Bbeta. Cell 105:587-597.

Züchner S et al. (2004) Mutations in the mitochondrial GTPase mitofusin 2 cause Charcot-Marie-Tooth neuropathy type 2A. Nature genetics 36:449-451. 


\section{PuBliKATIONSVERZEICHNIS}

Fledrich $\mathbf{R}^{*}$, Stassart RM*, Klink A, Rasch LM, Prukop T, Abdelaal TAM, Haag L, Czesnik D, Kungl T, Keric N, Stadelmann C, Brück W, Nave KA, Sereda MW (2014) Soluble Neuregulin-1 promotes Schwann cell differentiation in Charcot Marie Tooth disease 1A. Nature medicine (in press)

Stassart RM*, Fledrich $\mathbf{R}^{*}$, Velanac V, Brinkmann BG, Schwab MH, Meijer D, Sereda MW, Nave K-A (2013) A role for Schwann cell-derived neuregulin-1 in remyelination. Nature neuroscience 16:48-54.

Fledrich R, Schlotter-Weigel B, Schnizer TJ, Wichert SP, Stassart RM, Zu Hörste GM, Klink A, Weiss BG, Haag U, Walter MC, Rautenstrauss B, Paulus W, Rossner MJ, Sereda MW (2012a) A rat model of Charcot-Marie-Tooth disease 1A recapitulates disease variability and supplies biomarkers of axonal loss in patients.

Brain: A journal of neurology 135:72-87.

Fledrich R, Stassart RM, Sereda MW (2012b) Murine therapeutic models for CharcotMarie-Tooth (CMT) disease. British medical bulletin 102:89-113.

Makoukji J, Belle M, Meffre D, Stassart R, Grenier J, Shackleford G, Fledrich R, Fonte C, Branchu J, Goulard M, De Waele C, Charbonnier F, Sereda MW, Baulieu E-E, Schumacher M, Bernard S, Massaad C (2012) Lithium enhances remyelination of peripheral nerves. Proceedings of the National Academy of Sciences of the United States of America 109:2-7.

Gess B, Röhr D, Fledrich R, Sereda MW, Kleffner I, Humberg A, Nowitzki J, Strecker J-K, Halfter H, Young P (2011) Sodium-dependent vitamin C transporter 2 deficiency causes hypomyelination and extracellular matrix defects in the peripheral nervous system. Journal of Neuroscience 31:17180-17192.

Meyer zu Hörste G, Miesbach T a, Muller JI, Fledrich R, Stassart RM, Kieseier BC, Coleman MP, Sereda MW (2011) The Wlds transgene reduces axon loss in a CharcotMarie-Tooth disease $1 \mathrm{~A}$ rat model and nicotinamide delays post-traumatic axonal degeneration. Neurobiology of Disease 42:1-8. 
VORTRÄGE AUF WISSENSCHAFTLICHEN FACHTAGUNGEN

Eingeladen zu: Gordon Research Conference on Myelin, Ventura, USA, 2014:

Schwann Cell Neuregulin-1 is an Endogenous Factor for Myelin Repair.

Eingeladen zu: Gordon Research Seminar on Myelin, Ventura, USA, 2014

Soluble Neuregulin-1 treatment targets Schwann cell dys-differentiation in rodent models of Charcot Marie Tooth disease $1 \mathrm{~A}$.

CMT Meeting, Antwerpen, Belgien, 2013

Soluble neuregulin-1 treatment rescues axonal loss in rodent models for Charcot Marie Tooth disease $1 \mathrm{~A}$.

Tagung Deutsche Gesellschaft für Neurologie, Düsseldorf, Deutschland, 2009 Validierung von Erkrankungsmarkern bei der Charcot-Marie-Tooth Erkrankung $1 \mathrm{~A}$ (CMT1A).

\section{POSTERPRÄSENTATIONEN AUF WISSENSCHAFTLICHEN FACHTAGUNGEN}

Fledrich R., Stassart R.M., Klink A., Rasch L.M., Nave K.-A., Sereda M.-W.

Soluble Neuregulin-1 treatment targets Schwann cell dys-differentiation in rodent models of Charcot Marie Tooth disease 1A.

GLIA Meeting, Berlin, Deutschland, 2013

Fledrich R., Stassart R.M., Rasch L.M., Haag L, Czesnik D., Nave K.-A., Sereda M.W. Neuregulin-1 type I enhances functional recovery after acute peripheral nerve injury and rescues axonal loss in a mouse model for Charcot Marie Tooth disease $1 \mathrm{~A}$ (CMT1A).

Myelin Meeting, Kassel, Deutschland, 2013

Fledrich R., Schlotter-Weigel B., Schnizer T.J., Stassart R. M., Wichert S.P., Meyer zu Horste G., Weiss B.G., Haag U., Walter M.C., Rautenstrauss B., Paulus W., Nave K.A., Rossner M.J., Sereda M.W. Identification and Validation of disease marker in CharcotMarie-Tooth disease 1A (CMT1A).

PNS Meeting, Potomac Washington D.C., USA, 2011

Fledrich R., Schlotter-Weigel B., Schnizer T.J., Stassart R. M., Wichert S.P., Meyer zu Horste G., Weiss B.G., Haag U., Walter M.C., Rautenstrauss B., Paulus W., Nave K.A., Rossner M.J., Sereda M.W. Identification and Validation of disease marker in CharcotMarie-Tooth disease 1A (CMT1A).

CMT Meeting, Potomac Washington D.C., USA, 2011

Fledrich R., Schlotter-Weigel B., Schnizer T.J., Stassart R. M., Wichert S.P., Meyer zu Horste G., Weiss B.G., Haag U., Walter M.C., Rautenstrauss B., Paulus W., Nave K.A., Rossner M.J., Sereda M.W. Identification and Validation of disease marker in CharcotMarie-Tooth disease 1A (CMT1A).

Myelin Meeting, Kassel, Deutschland, 2011

Fledrich R., Schnizer T.J., Stassart R. M., Wichert S.P., Meyer zu Horste G., Paulus W., Nave K.A., Rossner M.J., Sereda M.W. Prognostic and Diagnostic Markers of CMT1A in a transgenic rat model.

CMT Meeting, Antwerpen, Belgien, 2009 
LEBENSLAUF

Name:

Fledrich

Vorname:

Robert

Geboren:

am 01.04.1983 in Erlabrunn

Nationalität:

Deutsch

Berufsadresse:

Max Planck Institut für Experimentelle Medizin

Abteilung für Neurogenetik

Hermann-Rein-Str. 3

37075 Göttingen

Email:

fledrich@em.mpg.de

Werdegang:

seit 2011

Doktorand am Max Planck Institut für Experimentelle Medizin, AG Molekulare und Translationale Neurologie. Titel: „Die Rolle von Neuregulin-1 in Erkrankungen des peripheren Nervensystems“"

$2009-2011$

Wissenschaftlicher Mitarbeiter am MPI für Experimentelle Medizin, AG Molekulare und Translationale Neurologie Diplom in Biologie (Neurophysiologie, Biochemie, organische

$2003-2009$ Chemie) der Georg August Universität Göttingen

$2002-2003$ Studium der Biologie an Universität Göttingen

2002 Studium der Bioinformatik an der Universität Leipzig

2001 Zivildienst am Helios Klinikum Aue

Allgemeine Hochschulreife in Aue

Sprachen:

Deutsch (Muttersprache)

Englisch (fließend)

Russisch (Grundkenntnisse) 
WISSENSCHAFTLICHE TÄTIGKEITEN

seit 2011

$2009-2011$

$2006-2009$

LEHRTÄTIGKEITEN

$2013 / 2014$

Seit 01/2014

$6 / 2013-1 / 2014$

$05 / 2013-07 / 2013$

$01 / 2013-04 / 2013$

$07 / 2013-09 / 2013$
Doktorand am Max Planck Institut für Experimentelle Medizin, AG Molekulare und Translationale Neurologie („Die Rolle von Neuregulin-1 in Erkrankungen des peripheren Nervensystems") Wissenschaftlicher Mitarbeiter am Max Planck Institut für Experimentelle Medizin, AG Molekulare und Translationale Neurologie

Diplomarbeit am Max Planck Institut für Experimentelle Medizin, AG Molekulare und Translationale Neurologie („Prognostische und Diagnostische Marker der Charcot-Marie-Tooth-Erkrankung im Tiermodell")

Wissenschaftliche Hilfskraft am Max Planck Institut für Experimentelle Medizin, Abteilung für Neurogenetik

Seminarleitung zur Vorlesung Neuropharmacology im MSc/PhD/MD-PhD Programm der International Max Planck Research School

Betreung Msc-Arbeit von Tamer A.M. Abdelaal mit dem Thema: „The therapeutic impact of phosphatidylcholine on Charcot Marie Tooth disease $1 \mathrm{~A}$ in vitro“

Betreuung MSc-Arbeit von Axel Klink mit dem Thema: "The role of Neuregulin-1 (NRG1) during peripheral nerve development and in acute and chronic diseases of the peripheral nervous system".

Betreuung des MSc Studenten Tamer A.M. Abdelaal während einer Laborrotation im Rahmen der International Max Planck Research School

Betreuung BSc-Arbeit von Maximillian Hoffmann („Der Einfluss von GDNF auf die Pathogenese PMP22-transgener Mäuse einem Tiermodell der Charcot-Marie-Tooth-Erkrankung 1A“) Betreuung BSc-Arbeit von Peter Veselcic („Beschreibung der phänotypischen und morphologischen Auswirkungen von Neuregulin-1 Typ I auf PMP22 transgene Mäuse“) 
01/2012 - 04/2012 Betreung BSc-Arbeit von Maren Rudolph („Experimentelle Therapie eines Pmp22-transgenen Tiermodells der CharcotMarie-Tooth Erkrankung mit einem GABAB-Agonisten")

01/2011 - 04/2011 Betreuung BSc-Arbeit von Axel Klink („Morphologische Charakterisierung der CMT-Ratte in Bezug auf die Hypermyelinisierung kleinkalibriger Axone“)

seit 2008 Betreuung zahlreicher Laborpraktika in der AG Molekulare und Translationale Neurologie am MPI für Exp Med 2005/2006/2007 Seminarleitung beim Praktikum Biologie für Mediziner (Themen: Genetik I+II und Entwicklungsbiologie) 